\author{
UNIVERSIDADE DE SÃO PAULO \\ FACULDADE DE CIÊNCIAS FARMACÊUTICAS \\ Programa de Pós-Graduação em Ciência dos Alimentos \\ Área de Bromatologia
}

\title{
Avaliação do estresse oxidativo em humanos e em animais suplementados com ácidos graxos polinsaturados Omega-3
}

\section{Vânia Claudia Barros Monteiro}

Dissertação para obtenção do grau de MESTRE

Orientadora:

Profa. Dra. Inar Alves de Castro 


\author{
UNIVERSIDADE DE SÃO PAULO \\ FACULDADE DE CIÊNCIAS FARMACÊUTICAS \\ Programa de Pós-Graduação em Ciência dos Alimentos \\ Área de Bromatologia
}

Avaliação do estresse oxidativo em humanos e em animais suplementados com ácidos graxos polinsaturados Omega-3

Vânia Claudia Barros Monteiro

Dissertação para obtenção do grau de MESTRE

Orientadora:

Profa. Dra. Inar Alves de Castro 
Ficha Catalográfica

Elaborada pela Divisão de Biblioteca e

Documentação do Conjunto das Químicas da USP.

Monteiro, Vânia Claudia Barros

M775a Avaliação do estresse oxidativo em humanos e em animais suplementados com ácidos graxos polinsaturados omega - 3 / Vânia Claudia Barros Monteiro . -- São Paulo, 2006.

$98 \mathrm{p}$.

Dissertação (mestrado) - Faculdade de Ciências Farmacêuticas da Universidade de São Paulo. Departamento de Alimentos e Nutrição Experimental.

Orientador: Castro, Inar Alves de

1. Bromatologia 2. Lipídios : Metabolismo I. T. II. Castro, Inar Alves de, orientador. 


\title{
Vânia Claudia Barros Monteiro
}

\section{Avaliação do estresse oxidativo em humanos e em animais suplementados com ácidos graxos polinsaturados Omega-3}

\author{
Comissão Julgadora \\ da \\ Dissertação para obtenção do grau de Mestre
}

Profa. Dra. Inar Alves de Castro

Orientadora/Presidente

\begin{tabular}{c}
\hline $1^{\circ}$. examinador \\
\hline $2^{\circ}$. examinador
\end{tabular}

São Paulo, de de 


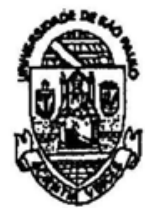

\section{UNIVERSIDADE DE SÃO PAULO}

\section{Relatório de Defesa}

Relatório de defesa pública de Dissertaçăo do(a) Senhor(a) Vania Claudia Barros Monteiro no Programa: Ciência dos Alimentos, do(a) Faculdade de Ciências Farmacêuticas da Universidade de Săo Paulo.

Aos 24 dias do més de abril de 2007, no(a) Bloco 13A - FCF / USP realizou-se a Defesa da Dissertaçăo do(a) Senhor(a) Vania Claudia Barros Monteiro, apresentada para a obtençăo do título de Mestre em Ciếncia dos Alimentos - Area: Bromatologia, intitulada:

"Avaliaçăo do estresse oxidativo em humanos e em animais suplementados com ácidos graxos polinsaturados omega-3"

Após declarada aberta a sessăo, o(a) $\mathrm{Sr}$ (a) Presidente passa a palavra aos examinadores para as devidas argúiçőes que se desenvolvem nos termos regimentais. Em seguida, a Comissão Julgadora proclama o resultado:

\begin{tabular}{|c|c|c|c|c|}
\hline Nome dos Participantes da Banca & & Vínculo do Docente & Sigla da Unidade & Resultado \\
\hline Inar Alves de Castro & & Presidente & FCF - USP & ADROUADA \\
\hline Deborah Helena Markowicz Bastos & & Titular & FSP - USP & aprovates \\
\hline Silvia Berlanga de Moraes Barros & & Titular & FCF - USP & apeovado \\
\hline \multicolumn{5}{|l|}{ Resultado Final: } \\
\hline & Parecer da Coml & Issăo Julgadora * & & \\
\hline
\end{tabular}

\section{Comentários da Defesa (opcional)}

Edilson Feitosa dos Santos

Técnico Acadêmico, lavrei a presente ata, que assino juntamente com os(as) Senhorgs asy Săo Paulo, aos 24 dias do més de abril de 2007. $y+r$

Debolah Helena Markowicz Bastos
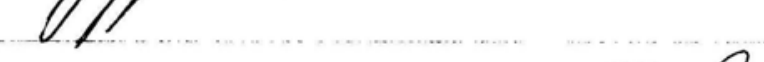

rees

Silyia Berlanqa de Moraes Barros

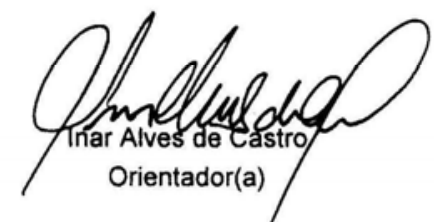

- Obs: Se o candidato for reprovado por algum dos membros, o preenchimento do parecer é obrigatóri Nos termos do artigo 110, do RG-USP, encaminhe-se o presente relatorio à CPG, para homologaçăo.

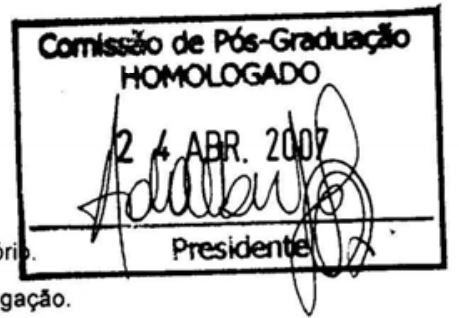

Impresso em: 24/04/2007 
"Aqueles que têm um grande autocontrole, ou que estão totalmente absortos no trabalho, falam pouco. Palavra e ação juntas não andam bem. Repare na natureza: trabalha continuamente, mas em silêncio."

Mahatma Gandhi 
À minha família, em especial Eduardo, Juliana, Rhaíssa e Víctor Hugo pelo incentivo, apoio e compreensão pelo pouco tempo que thes foi dedicado durante este projeto. 


\section{Agradecimentos}

À Profa. Dra. Inar Alves de Castro pela orientação, incentivo e incessante colaboração.

Ao Departamento de Alimentos e Nutrição Experimental da Faculdade de Ciências Farmacêuticas - USP e a Comissão de Pós-Graduação pela oportunidade de realizar este curso.

À Fundação de Amparo à Pesquisa do Estado de São Paulo (FAPESP) pelo suporte financeiro para a realização da pesquisa.

Ao Conselho Nacional de Desenvolvimento Científico e Tecnológico (CNPq) pela concessão de bolsa de estudo.

À Tânia, Cleonice, Mônica e Edílson da Secretaria do Bloco 14 por todo o auxílio dispensado.

À Elaine, Jorge e Majô da Secretaria de Pós-Graduação pela atenção disponibilizada.

Aos voluntários pela valiosa contribuição no desenvolvimento da pesquisa.

Ao Marcelo e José Donato pela relevante colaboração na realização do projeto e elaboração dos artigos.

À Rosângela do Laboratório de Lípides pela análise do perfil de ácidos graxos.

À Renata do Laboratório de Análises Clínicas responsável pelas análises de lipoproteínas. 
À Illana do Laboratório de Análise de Alimentos e a Maria Luiza do Laboratório de Química, Bioquímica e Biologia Molecular de Alimentos pelas quantificações realizadas.

Às técnicas Luciene e Ivanir pelo auxílio na realização de análises.

À Flávia, Wagner e Renata do Biotério de Criação e Experimentação da FCF/IQ pela ajuda e cuidado com os animais de estudo.

Ao Ângelo, Adriana e Leila da Biblioteca do Conjunto das Químicas pela solicitude às Referências Bibliográficas e a Base de Dados.

À Movere - Núcleo de Atividades Esportistas Ltda. por acolher os voluntários que participaram da pesquisa durante $\mathrm{o}$ atendimento.

À Elaine do Carmo Carmone de Brito da Coleta Domiciliar de Exames Laboratoriais (CDEL) pelo profissionalismo no atendimento aos voluntários.

À Guiomar dos Santos Vieira pela produção do suplemento na CRIALIMENTOS Ind. Com. Ltda.

Aos amigos do Laboratório, Roberto, Caroline e Marliz.

Aos estagiários de Iniciação Científica, Kelen, Mariana, Arthur e Ana Carolina, pela intensa colaboração, companheirismo e amizade.

À Joana e a Lourdinha pela atenção, carinho e pelos cafezinhos.

A todos que direta ou indiretamente colaboraram para a realização deste trabalho. 


\section{SUMÁRIO}

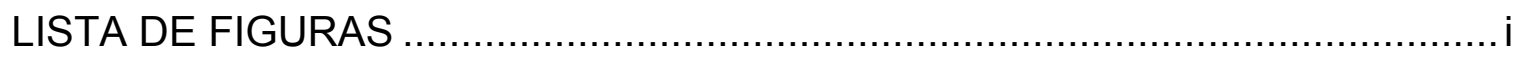

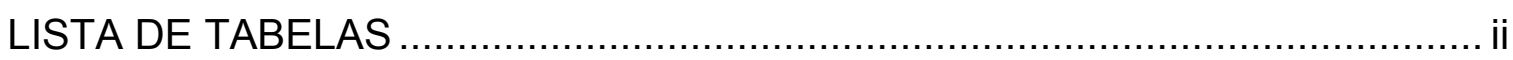

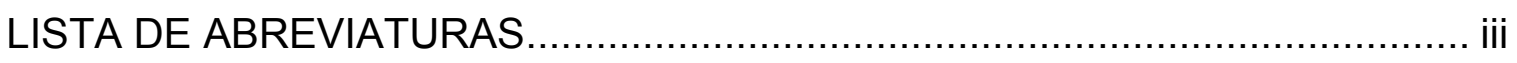

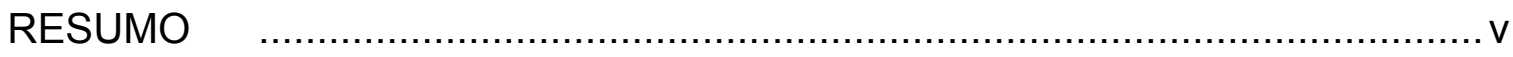

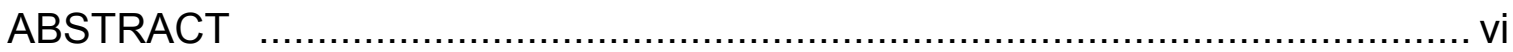

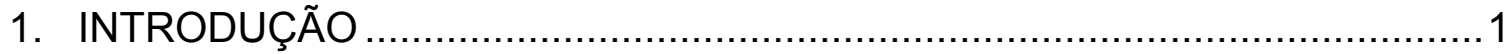

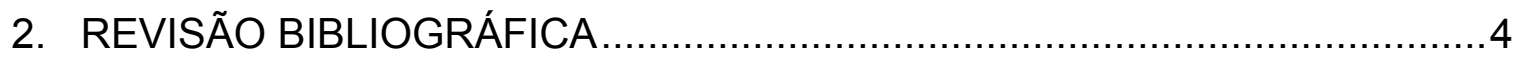

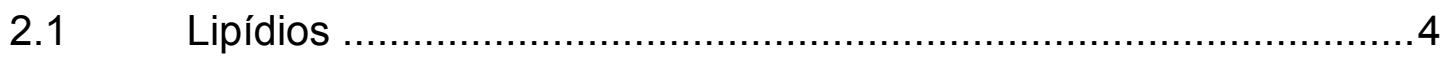

2.1.1 Classificação e estrutura química ..........................................4

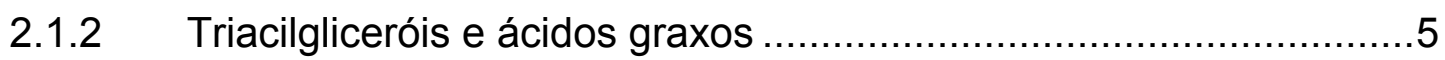

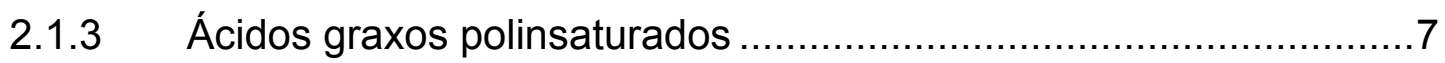

2.1.4 Recomendação de ingestão de ácidos graxos polinsaturados ......10

2.1.5 Biossíntese dos eicosanóides ..............................................11

2.2 Doenças arteriais coronarianas .......................................... 13

2.2.1 Doenças cardiovasculares .............................................. 13

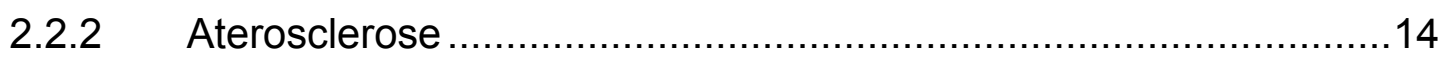

2.2.3 LDL modificada e aterosclerose........................................... 16

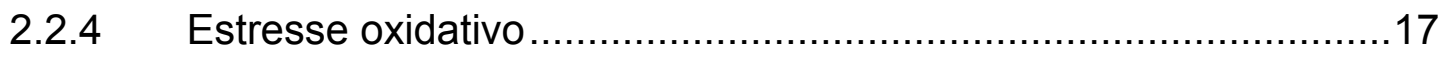

2.3 Métodos para avaliação do estresse oxidativo in vivo ...................24

$2.4 \quad$ Alimentos funcionais ............................................................ 26

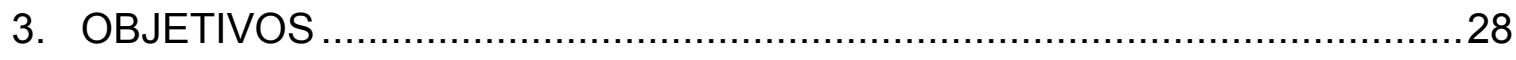

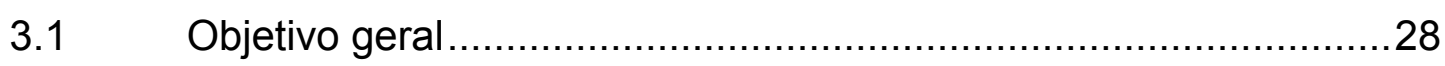

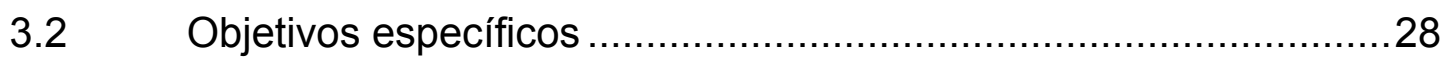

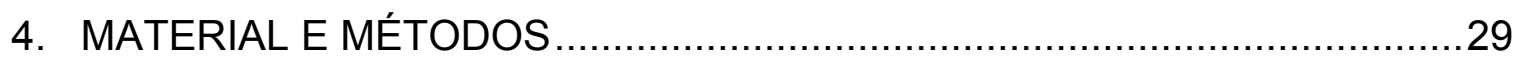

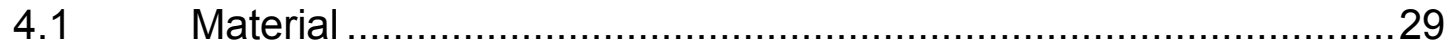

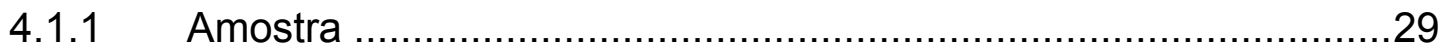

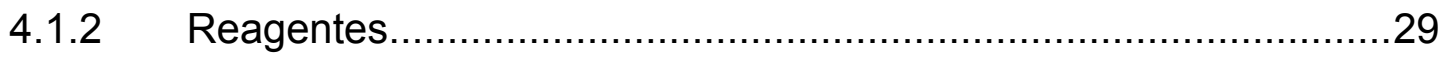

4.1.3 Modelos utilizados ........................................................... 30

4.1.3.1 Modelo humano - Delineamento experimental........................ 30

4.1.3.2 Preparo da formulação láctea usada na suplementação ............34

4.1.3.3 Modelo animal - Delineamento experimental ........................... 35 
4.1.3.4 Preparo das rações utilizadas no modelo animal

4.2 Métodos: Formulação láctea e rações

4.2.1 Determinação da composição centesimal da formulação láctea e das rações .38

4.2.2 Caracterização da fração lipídica (formulação láctea e rações) para obtenção do perfil de ácidos graxos 40

4.2.3 Quantificação do colesterol do Dry $n-3^{\circledR}$ 41

4.2.4 Determinação de $\alpha$-tocoferol no composto Dry $n-3^{\circledR}$. .42

4.2.5 Determinação de ácido ascórbico no composto Dry $n-3^{\circledR}$.............43

4.3 Métodos: Amostras biológicas .....................................................4

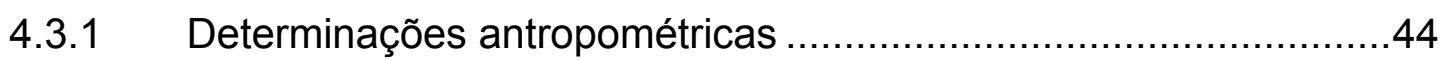

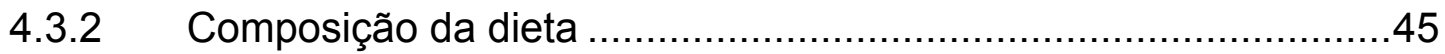

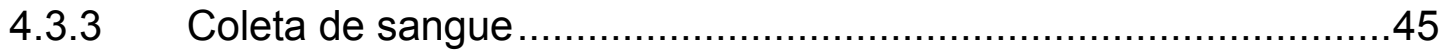

4.3.4 Medidas das variáveis bioquímicas ...........................................

4.3.5 Caracterização do perfil de ácidos graxos no plasma.....................46

4.3.6 Avaliação da lipoperoxidação de homogenato de cérebro .............48

4.3.7 Avaliação da lipoperoxidação do plasma (TBARS) ........................49

4.3.8 Determinação da capacidade antioxidante do plasma pelo

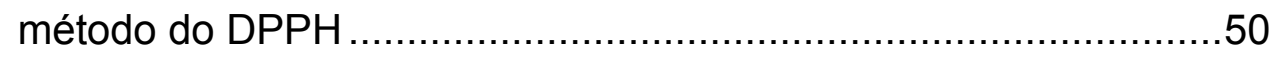

4.3.9 Análises de $\alpha$-tocoferol no plasma..............................................51

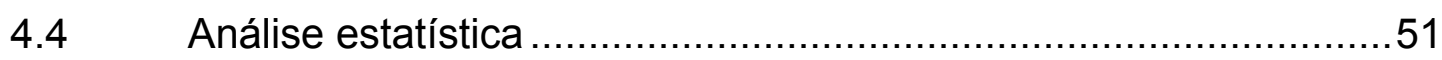

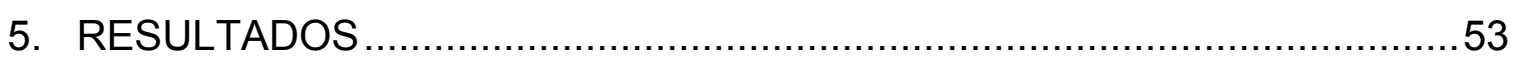

5.1 Determinações na formulação láctea utilizada no modelo

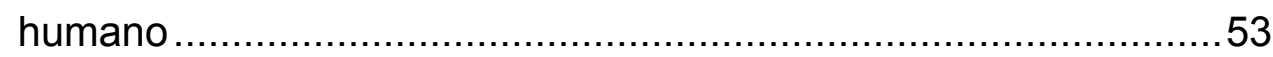

5.1.1 Composição nutricional da formulação láctea................................53

5.1.2 Medidas antropométricas, concentrações das lipoproteínas séricas, glicose e parâmetros oxidativos ……………………......54

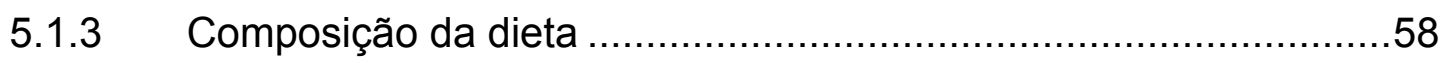

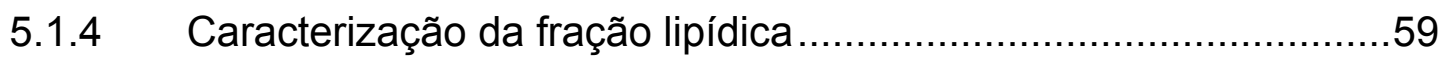

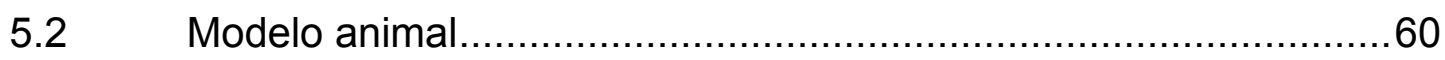

5.2.1 Composição centesimal aproximada e caracterização dos

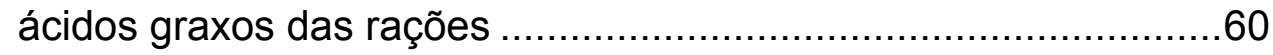

5.2.2 Composição de ácidos graxos no plasma dos animais .................62 
5.2.3 Ganho de peso, ingestão dietética e concentração de MDA no plasma dos animais submetidos a diferentes dietas

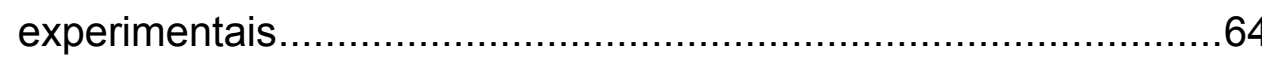

5.2.4 Perfil lipídico sérico dos grupos experimentais (CONTROLE, SO e FO) - modelo animal .....................................................6

5.2.5 Concentração de MDA em homogenato de cérebro.......................68

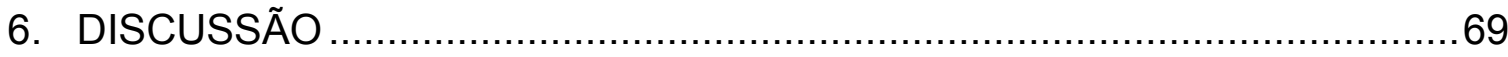

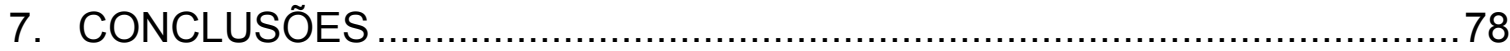

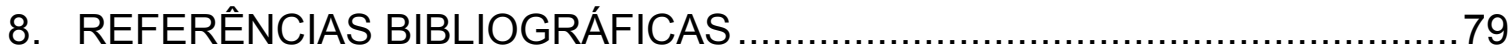

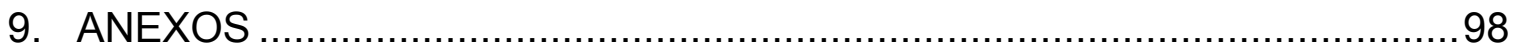




\section{LISTA DE FIGURAS}

Figura 1. Estrutura de uma molécula do triacilglicerol........................... 6

Figura 2. Estrutura de uma molécula de ácido graxo polinsaturado............ 6

Figura 3. Esquema da dessaturação e elongação do ácido linoléico e do

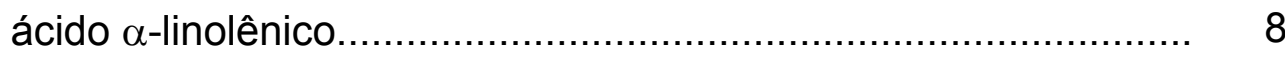

Figura 4. Estrutura química dos ácidos graxos EPA e DHA..................... 9

Figura 5. Esquema da síntese dos eicosanóides................................. 12

Figura 6. Formação de uma lesão avançada da aterosclerose................... 16

Figura 7. Esquema das fontes que levam a formação de espécies reativas e mecanismos de defesa..................................... 18

Figura 8. Produtos dos danos por radicais livres............................... 25

Figura 9. Exemplos de alimentos funcionais suplementados com ácidos graxos polinsaturados Omega-3..................................... 27

Figura 10. Delineamento experimental - modelo humano....................... 31

Figura 11. Embalagens contendo o suplemento................................. 35

Figura 12. Delineamento experimental - modelo animal........................ 36

Figura 13. Dispersão apresentada pelos indivíduos do grupo OMEGA....... 56

Figura 14. Dispersão dos indivíduos em três dimensões (análise multivariada de correspondência) ................................... 57

Figura 15. Concentrações séricas de colesterol total nos animais................ 66

Figura 16. Concentrações séricas da HDL nos animais............................ 67

Figura 17. Concentrações séricas e TG nos animais.............................. 67

Figura 18. Formação de MDA no homogenato de cérebro........................ 68 


\section{LISTA DE TABELAS}

Tabela 1. Características antropométricas no baseline, concentrações dos lipídios sanguíneos e glicose dos indivíduos em jejum separados em subgrupos pela análise de cluster

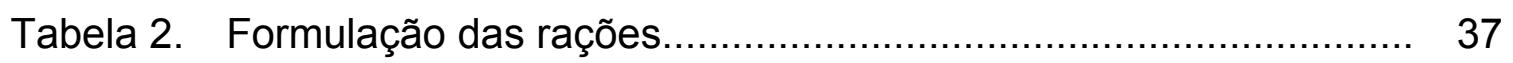

Tabela 3. Composição química das duas formulações lácteas.................. 53

Tabela 4. Medidas antropométricas, concentrações séricas de lipídios e glicose e parâmetros oxidativos plasmáticos obtidos nos indivíduos, antes e depois de seis semanas de intervenção.........

Tabela 5. Composição da dieta (diária) dos grupos experimentais antes e depois da intervenção.

Tabela 6. Proporção dos ácidos graxos no plasma (\%) dos grupos experimentais antes e depois da intervenção.

Tabela 7. Composição química centesimal e proporção dos ácidos graxos presentes nas rações experimentais.

Tabela 8. Proporção dos ácidos graxos (\%) determinada no plasma dos animais

Tabela 9. Ganho de peso, ingestão dietética e concentração de MDA plasmática em ratos alimentados por diferentes dietas experimentais 


\section{LISTA DE ABREVIATURAS}

\begin{tabular}{|c|c|}
\hline AA & Ácido araquidônico \\
\hline ACAT2 & Acil CoA: colesterol aciltransferase 2 \\
\hline AHA & American Heart Association \\
\hline AL & Ácido linoléico \\
\hline ALA & Ácido $\alpha$-linolênico \\
\hline Apo B & Apolipoproteína B \\
\hline DCV & Doenças cardiovasculares \\
\hline DHA & Ácido docosahexaenóico \\
\hline EPA & Ácido eicosapentaenóico \\
\hline ERN & Espécies reativas de nitrogênio \\
\hline ERO & Espécies reativas de oxigênio \\
\hline ERS & Espécies reativas de enxofre \\
\hline FDA & Food and Drug Administration \\
\hline GPx & Glutationa peroxidase \\
\hline $\mathrm{H}_{2} \mathrm{O}_{2}$ & Peróxido de hidrogênio \\
\hline HDL & Lipoproteína de alta densidade \\
\hline HEPE & Ácido hidroxieicosatetraenóico \\
\hline HPETE & Ácido hidroperoxieicosatetraenóico \\
\hline HPLC & Cromatografia líquida de alta eficiência \\
\hline но॰ & Radical hidroxila \\
\hline ICAM - 1 & Molécula de adesão intercelular -1 \\
\hline IDL & Lipoproteína de densidade intermediária \\
\hline IL - 1 & Interleucina - 1 \\
\hline IL - 6 & Interleucina - 6 \\
\hline IMC & Índice de massa corporal \\
\hline $\mathbf{L}^{\bullet}$ & Radical lipídico \\
\hline LDL & Lipoproteína de baixa densidade \\
\hline LDL-ox & Lipoproteína de baixa densidade oxidada \\
\hline LO & Radical alcoxila \\
\hline LOO` & Radical peroxila \\
\hline LOOH & Hidroperóxido lipídico \\
\hline $.0 x$ & Enzima lipoxigenase \\
\hline
\end{tabular}


LT Leucotrieno

LX Lipoxina

MDA Malondialdeído

No $\quad$ Óxido nítrico

n-3 PUFA Ácido graxo polinsaturado Omega-3

${ }^{1} \mathrm{O}_{2} \quad$ Oxigênio singlete

${ }^{3} \mathrm{O}_{2} \quad$ Oxigênio fundamental (triplete)

$\mathrm{O}_{2}{ }^{\circ-} \quad$ Radical superóxido

ONOO- Peróxinitrito

PG Prostaglandina

PGI Prostaciclina

PPAR $\alpha \quad$ Receptor ativado por proliferador de peroxissomo - $\alpha$

PON Paraxonase

PUFA Ácido graxo polinsaturado

SREBP-1 Proteína ligante do elemento regulatório de esterol - 1

SOD Superóxido dismutase

TBARS Substância reativas ao ácido tiobarbitúrico

TG Triacilglicerol

TNF- $\alpha \quad$ Fator de necrose tumoral $-\alpha$

TX Tromboxano

VCAM - 1 Molécula de adesão de célula vascular - 1

VLDL Lipoproteína de muito baixa densidade 


\section{RESUMO}

Ácidos graxos polinsaturados Omega-3 (n-3 PUFA) tais como o ácido eicosapentaenóico (C20:5 n-3, EPA) e docosahexaenóico (C22:6 n-3, DHA) reduzem a concentração plasmática de triacilgliceróis em humanos. Entretanto, uma alta proporção desses ácidos graxos na dieta poderia favorecer a susceptibilidade das células à peroxidação, aumentando o risco de desenvolvimento de doenças cardiovasculares. Embora modelos animais não sejam recomendados para avaliar o efeito de n-3 PUFA nas lipoproteínas plasmáticas, estes têm sido amplamente utilizados como modelo para avaliação de dano oxidativo. Diferenças nos procedimentos metodológicos também têm gerado dificuldade na comparação de resultados. Desta forma, o objetivo deste estudo foi aplicar os mesmos procedimentos metodológicos para comparar o efeito da suplementação de n-3 PUFA nos biomarcadores plasmáticos de estresse oxidativo utilizando um modelo humano e um modelo animal. Indivíduos foram aleatoriamente distribuídos em dois grupos num delineamento paralelo duplo cego e receberam uma suplementação de 460,0 mg/dia de n-3 PUFA (OMEGA) contendo 240,0 mg de EPA + 160,0 mg de DHA + $60,0 \mathrm{mg}$ de outros n-3 PUFAs, ou óleo de soja (PLACEBO) durante 6 semanas. Ratos Wistar também foram distribuídos em dois grupos e receberam uma dieta contendo 192,5 mg/dia de n-3 PUFA (FO) sendo 116,3 mg de EPA + 61,5 mg de DHA + 14,7 mg de outros n-3 PUFAs ou óleo de soja (SO) durante 3 semanas. Indivíduos do grupo OMEGA apresentaram maior concentração de malondialdeído (MDA) no plasma medido por TBARS quando comparado aos respectivos valores no baseline. A suplementação com n-3 PUFA não alterou a concentração plasmática de $\alpha$-tocoferol e a atividade antioxidante determinada pelo método DPPH. Apesar dos animais terem recebido doses 10 vezes maiores de n-3 PUFA (2,9 mg/kcal) quando comparadas aos humanos (0,3 mg/kcal) não foram observadas alterações entre os grupos FO e SO para as concentrações de MDA no plasma e no homogenato de cérebro. Em resumo, pode-se sugerir que o modelo animal usado neste estudo parece não ser o mais adequado para avaliar o estresse oxidativo após intervenções dietéticas com n-3 PUFAs em função de diferenças no metabolismo e nos mecanismos de proteção antioxidante observados entre os dois modelos.

Palavras-chave: Peixe. Omega. Oxidação. DPPH. Malondialdeído. Ratos Wistar. Humanos. 


\begin{abstract}
Omega-3 polyunsaturated fatty acids ( $n-3$ PUFA) such as eicosapentaenoic (C20:5 n-3, EPA) and docosahexaenoic (C22:6 n-3, DHA) reduce plasma triacylglycerol concentration in humans. However, higher proportion of these fatty acids in the diet could raise cells lipoperoxidation susceptibility, increasing the cardiovascular disease risk. Although animal models are not recommended to evaluate the effect of n-3 PUFA in plasma lipoproteins, they have been widely used as model for oxidative damage. Difference in methodological proceedings has also caused difficulties to compare data among assays. Thus, the objective of this study was to apply the same methodology to investigate the effect of $n-3$ PUFA supplementation on oxidative biomarkers in animal and human model. Individuals were randomly assigned in two groups in a parallel double blind design and received a supplement of $460.0 \mathrm{mg} /$ day n-3 PUFA (OMEGA) containing $240.0 \mathrm{mg}$ EPA + $160.0 \mathrm{mg}$ DHA +60.0 mg other n-3 PUFAs, or soybean oil (PLACEBO) during 6 weeks. Wistar rats were also assigned in two groups and received a diet containing 192.5 mg/day n-3 PUFA (FO) containing $116.3 \mathrm{mg}$ EPA + 61.5 mg DHA + $14.7 \mathrm{mg}$ other $\mathrm{n}-3$ PUFAs or soybean oil (SO) for 3 weeks. Individuals in OMEGA group showed higher malondialdehyde (MDA) concentration in plasma measured by TBARS when compared to their baseline values. N-3 PUFA supplementation did not change plasma $\alpha$-tocopherol concentration and antioxidant activity determined by DPPH method. Although animals have received a 10 -fold higher dose of n-3 PUFA ( $2.9 \mathrm{mg} / \mathrm{kcal})$ than humans $(0.3 \mathrm{mg} / \mathrm{kcal})$, no alteration was observed between $\mathrm{FO}$ and SO groups for plasma and brain homogenate MDA concentration. In summary, it can be suggested that the model used in this study doesn't seem appropriate to evaluate oxidative stress after dietetic interventions with n-3 PUFA due to physiological differences involved in lipid metabolism and antioxidant protection observed between both models.
\end{abstract}

Key words: Fish. Omega. Oxidation. DPPH. Malondialdehyde. Wistar rats. Humans. 


\section{INTRODUÇÃO}

A oxidação de componentes dos alimentos é a essência da produção metabólica de energia. Tais componentes perdem elétrons que são captados pelos transportadores. Estes por sua vez são novamente oxidados pelo oxigênio nas mitocôndrias, produzindo grande quantidade de ATP através da fosforilação oxidativa. Apesar das vantagens desse processo, $21 \%$ do oxigênio causam danos para os organismos aeróbios, sendo esse dano atribuído à formação de espécies reativas de oxigênio ou EROs (HALLIWELL e GUTTERIDGE, 1999). Evidências experimentais têm, direta ou indiretamente, sugerido que seis espécies de oxigênio seriam as principais responsáveis pelos danos oxidativos em humanos: ânion superóxido $\left(\mathrm{O}_{2}{ }^{\circ}\right)$, peróxido de hidrogênio $\left(\mathrm{H}_{2} \mathrm{O}_{2}\right)$, radicais peroxila $\left(\mathrm{ROO} 0^{*}\right)$, radical hidroxila $\left(\mathrm{HO}^{\circ}\right)$, oxigênio singlete $\left({ }^{1} \mathrm{O}_{2}\right)$ e peroxinitrito (ONOO). Para neutralizar o ataque dessas EROs, células vivas têm um sistema de defesa biológico composto de antioxidantes enzimáticos e não-enzimáticos (SIES, STAHL e SEVANIAN, 2005; HUANG, OU e PRIOR, 2005). Um distúrbio no balanço "pró-oxidante/antioxidante" em favor do primeiro, conduz a potenciais danos, sendo essa condição comumente conhecida por estresse oxidativo (SIES, 1991). O estresse oxidativo pode alcançar todas as moléculas-alvo como DNA, proteínas, carboidratos e lipídios, tendo um papel importante na progressão da lesão em tecidos associados ao desenvolvimento de diversas patologias (HALLIWELL e GUTTERIDGE, 1999).

Algumas doenças cardiovasculares, tais como o infarto do miocárdio e o derrame são secundários à condição da aterosclerose (HALLIWELL e GUTTERIDGE, 1999). Muitos dos fatores de riscos e algumas das conseqüências da aterosclerose têm sido associados à evidência do estresse oxidativo in vivo (GRIENDLING e FITZGERALD, 2003). A oxidação da lipoproteína de baixa densidade (LDL) tem sido considerada como importante fator de risco para o desenvolvimento da aterosclerose (BERLINER e HEINECKE, 1996; SIES, STAHL e SEVANIAN, 2005). As moléculas de lipídios contendo maior número de duplas ligações são mais susceptíveis a perda do hidrogênio para as EROs, porque as ligações $\pi$ são mais fracas e sua energia é menor que das ligações $\sigma$ (FRANKEL, 2005). Geralmente, quanto mais duplas ligações estão presentes em um ácido graxo insaturado maior será sua susceptibilidade a oxidar em sistemas biológicos 
(HIGDON et al., 2001). Ácidos graxos polinsaturados Omega-3 tais como eicosapentaenóico (C20:5n-3, EPA) e docosahexaenóico (C22:6n-3, DHA) contendo cinco e seis duplas ligações respectivamente em sua estrutura, fornecem mais substrato ao ataque dos radicais livres. Entretanto, estes ácidos graxos reduzem a mortalidade total e a morte súbita em pacientes com doença coronariana (BUCHER et al., 2002) pela inibição da formação de eicosanóides pró-inflamatórios, reduzindo à susceptibilidade a arritmia ventricular cardíaca, retardando o crescimento da placa aterosclerótica e promovendo o relaxamento endotelial induzido pelo óxido nítrico (KRIS-ETHERTON et al., 2003a). Outros mecanismos incluem a redução plasmática das lipoproteínas de muito baixa densidade (VLDL) e do triacilglicerol (TG) e a maior produção de lipoproteínas de baixa densidade (LDL) maiores e menos aterogênicas (TINKER et al., 1999; SONG, FUJIMOTO e MIYAZAWA, 2000; FRENOUX et al., 2001; HUDERT et al., 2006). O consumo de ácidos graxos polinsaturados Omega-3 de óleo de peixe, mas não do ácido graxo $\alpha$-linolênico, de 0,5 a 1,8 $\mathrm{g} / \mathrm{dia}$, reduz significativamente a mortalidade devido a todas as formas de disfunção cardíaca (KRIS-ETHERTON et al., 2003a; WANG et al., 2006). Devido a estes efeitos benéficos, uma maior ingestão desses ácidos graxos (EPA e DHA) através do consumo de óleo de peixe tem sido recomendada. Recentemente, o Food and Drug Administration (FDA) aprovou a alegação qualificada de saúde para o uso de EPA e DHA em alimentos convencionais e suplementos dietéticos (FDA, 2004).

Embora mais insaturações aumentem a susceptibilidade dos ácidos graxos polinsaturados a oxidarem in vitro, não está estabelecido que isso também ocorra in vivo (THOLSTRUP et al., 2004). De fato, ainda não se sabe se o maior consumo de EPA e DHA aumentaria ou não o estresse oxidativo em humanos e animais. Além disso, populações específicas como a dos esquimós, onde os benefícios dos ácidos graxos polinsaturados Omega-3 foram inicialmente observados (BANG e DYERBERG, 1972), estão submetidas a diferentes fatores ambientais e dietéticos que alteram o estresse oxidativo quando comparadas às populações ocidentais. Trata-se de um tema controverso, uma vez que vários estudos relatam aumento (HAU et al., 1996), redução (BARBOSA et al., 2003) ou nenhuma alteração (HIGDON et al., 2001; THOLSTRUP et al., 2004) dos mesmos biomarcadores para o estresse oxidativo após a ingestão de ácidos graxos polinsaturados Omega-3. 
Apesar de roedores não serem recomendados para avaliar os efeitos de ácidos graxos polinsaturados Omega-3 nas lipoproteínas em função das diferenças no metabolismo lipídico em relação aos humanos (HARRIS, 1996), esse modelo animal tem sido amplamente aplicado na avaliação do estresse oxidativo após a ingestão de ácidos graxos polinsaturados Omega-3. Outra limitação para comparar o efeito dos fatores dietéticos no estresse oxidativo é a metodologia selecionada para avaliar os biomarcadores. Ironicamente, não há até o momento nenhum procedimento experimental validado que possa medir de forma confiável a capacidade antioxidante em amostras biológicas (HUANG, OU e PRIOR, 2005). Desta forma, o objetivo deste estudo foi de comparar a resposta de um modelo humano e de um modelo animal à suplementação com ácidos graxos polinsaturados Omega-3, utilizando-se os mesmos biomarcadores determinados pelos mesmos procedimentos metodológicos em ambos os modelos. 


\section{REVISÃO BIBLIOGRÁFICA}

\subsection{Lipídios}

Os lipídios são formados por um conjunto de substâncias que apesar de quimicamente diferentes entre si, exibem uma característica comum que é a insolubilidade em água e solubilidade em solventes orgânicos que incluem acetona, éter e clorofórmio. Juntamente com as proteínas e carboidratos, os lipídios são componentes essenciais das estruturas biológicas e são conhecidos como biomoléculas. Os lipídios se encontram distribuídos em todos os tecidos, principalmente nas membranas celulares e nas células adiposas (DEVLIN, 2002). As membranas biológicas são essenciais e atuam como barreiras especializadas na permeabilidade para as células e suas organelas (PALSDOTTIR e HUNTE, 2004). Além disso, alguns lipídios mesmo que em pequenas quantidades, desempenham papéis fisiológicos importantes como cofatores enzimáticos (vitamina K), transportadores de elétrons (ubiquinona), hormônios (eicosanóides e esteróis) e mensageiros intracelulares (diacilglicerol e inositol) (LEHNINGER, NELSON e COX, 2002).

\subsubsection{Classificação e estrutura química}

De acordo com VOET, VOET e PRATT (2002), os lipídios são classificados como:

Ácidos graxos: $\quad$ é o grupo mais abundante de lipídios nos seres vivos, são compostos derivados dos ácidos carboxílicos e podem ser classificados como saturados ou insaturados.

Triacilgliceróis: conhecidos como gorduras neutras, são ésteres de glicerol com ácidos graxos. 
Glicerofosfolipídios: também chamados fosfoglicerídios, são os principais componentes das membranas biológicas, onde dois ácidos graxos estão unidos em ligação éster ao primeiro e ao segundo carbono do glicerol, e um grupo altamente polar está ligado através de uma ligação fosfodiéster ao terceiro carbono. Os glicerofosfolipídios se ordenam em bicamadas sendo assim indispensáveis à formação das membranas.

Esfingolipídios: a segunda maior classe de lipídios na estrutura das membranas biológicas, são compostos de uma molécula de um ácido graxo, uma molécula do amino-álcool de cadeia longa - esfingosina e um grupo polar, mas em contraste com os glicerofosfolipídios, eles não contêm a molécula de glicerol.

Esteróis:

representam uma grande e importante classe de lipídios estruturais. O colesterol é o componente esterol mais importante nos animais sendo caracterizado pela estrutura em anel complexa com grupos laterais individuais, está presente nas membranas celulares e em pouca quantidade em suas organelas. O colesterol é o precursor de hormônios esteróides, ácidos e sais biliares.

\subsubsection{Triacilgliceróis e ácidos graxos}

Os triacilgliceróis (TG) são lipídios constituídos de ácidos graxos e estão presentes em maior proporção na dieta consumida pelos seres humanos. São compostos por três ácidos graxos esterificados a uma molécula de glicerol (Figura 1). O tipo de ácido graxo e o padrão de ligação com o glicerol conferem uma maior heterogeneidade aos triacilgliceróis (LEHNINGER, NELSON e COX, 2002). Os triacilgliceróis representam à forma mais concentrada de energia disponível para os tecidos biológicos e exibem baixa toxicidade biológica quando comparados aos ácidos graxos, mesmo em concentrações elevadas no plasma sanguíneo (GIBBONS, ISLAM e PEASE, 2000). 


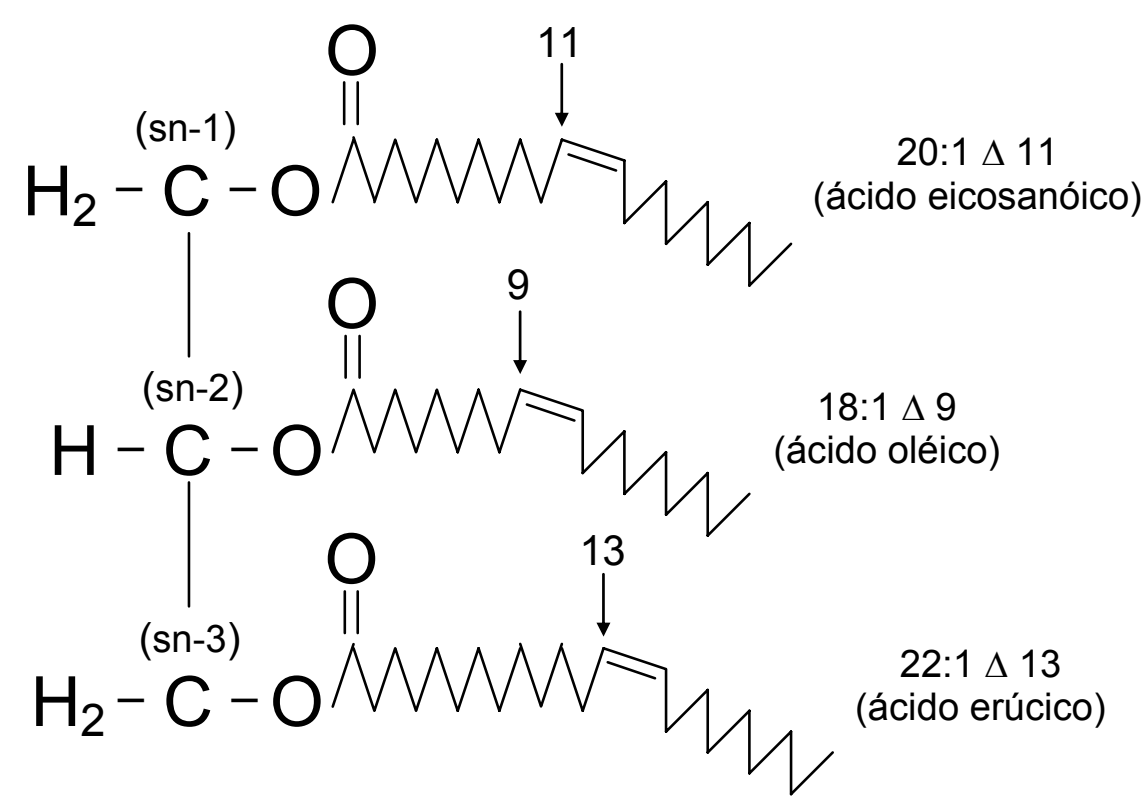

Figura 1. Estrutura de uma molécula do triacilglicerol (modificado de TAYLOR, KUNST e MACKENZIE, 1993).

Os ácidos graxos são cadeias de hidrocarbonetos contendo um grupo metila, um grupo carboxila e um número par de carbonos, variando entre 4 e 26 átomos. As propriedades da gordura da dieta são primariamente determinadas pela composição de seus ácidos graxos, que podem ser classificados como saturados, monoinsaturados e polinsaturados (ROCHE, 1999).

Os ácidos graxos saturados são aqueles que não possuem duplas ligações na cadeia. Além da variação no comprimento da cadeia, os ácidos graxos diferem quanto ao número e arranjo das duplas ligações. O sistema mais usual de identificação da posição da dupla ligação ao longo da cadeia é contando-se o carbono da primeira dupla ligação mais próxima do grupo metila (Figura 2). Para que contenha uma única dupla ligação, um ácido graxo deve apresentar no mínimo 12 átomos de carbono e estes são denominados monoinsaturados. A adição posterior de duplas ligações produz um ácido graxo polinsaturado (PUFA). O número de duplas ligações na cadeia do ácido graxo está relacionado com o comprimento de sua cadeia, pois a dupla ligação ocorre a cada três átomos de carbono (MURRAY et al., 2000).

$\mathrm{H}_{3} \mathrm{C}-\mathrm{C}-\mathrm{C}-\mathrm{C}-\mathrm{C}-\mathrm{C}=\mathrm{C}-\mathrm{C}-\mathrm{C}=\mathrm{C}-\mathrm{C}-\mathrm{C}=\mathrm{C}-\mathrm{C}-\mathrm{C}=\mathrm{C}-\mathrm{C}-\mathrm{C}-\mathrm{C}-\mathrm{COOH}$

Figura 2. Estrutura de uma molécula de ácido graxo polinsaturado (ácido araquidônico - AA; 20:4 n-6). 


\subsection{3 Ácidos graxos polinsaturados}

Os ácidos graxos polinsaturados podem adotar duas configurações geométricas distintas que tem implicações nas propriedades físicas e na forma da molécula. A configuração cis apresenta os dois átomos de hidrogênio adjacentes à dupla do mesmo lado da molécula, enquanto a configuração trans apresenta os hidrogênios em lados opostos (ROCHE, 1999).

Os ácidos graxos polinsaturados Omega-3 são representados pelas séries n-6 (ou Omega-6) e n-3 (ou Omega-3), dependendo do local onde a dupla ligação mais próxima da extremidade metila está posicionada. Como os seres humanos são incapazes de sintetizar n-6 e n-3, esses ácidos graxos são chamados de essenciais e devem ser obtidos através da dieta. Estas famílias de ácidos graxos são quimicamente e biologicamente distintas, sendo a família dos ácidos graxos polinsaturados Omega-6 a mais comumente encontrada. Os exemplos mais simples dos ácidos graxos Omega-6 e Omega-3 são os ácidos linoléico (LA; 18:2 n-6) e $\alpha$-linolênico (ALA; 18:3 n-3) respectivamente (ROCHE, 1999; LEE e LIP, 2003; CALDER, 2004a).

Nos seres humanos, o ácido linoléico pode ser elongado e dessaturado em ácido araquidônico e o ácido $\alpha$-linolênico ( $A L A)$ em EPA e DHA, conforme demonstrado na Figura 3. Os estudos geralmente concordam que menos de $5 \%$ do ALA é convertido em DHA no organismo humano (LEE e LIP, 2003). 
OMEGA-6

\section{OMEGA-3}

LA

Ácido linoléico

(18:2)

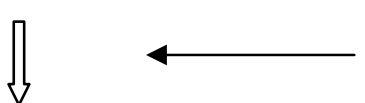

Ácido $\gamma$-linolênico

$(18: 3)$

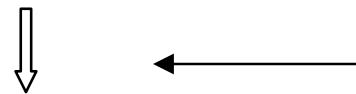

Dihomo $\gamma$-linolênico

(20:3)
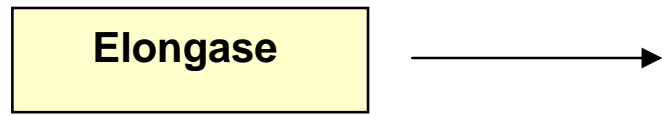

(18:4)

\section{$\Delta 6$ Dessaturase}

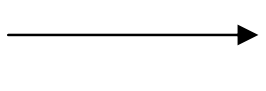

Ácido $\alpha$-linolênico

$(18: 3)$<smiles>[C]=C</smiles><smiles>C=[Tl]</smiles>

(20:4)

$\Delta 6$ Dessaturase

AA

Araquidônico

(20:4)<smiles>C1=CC=C1</smiles>
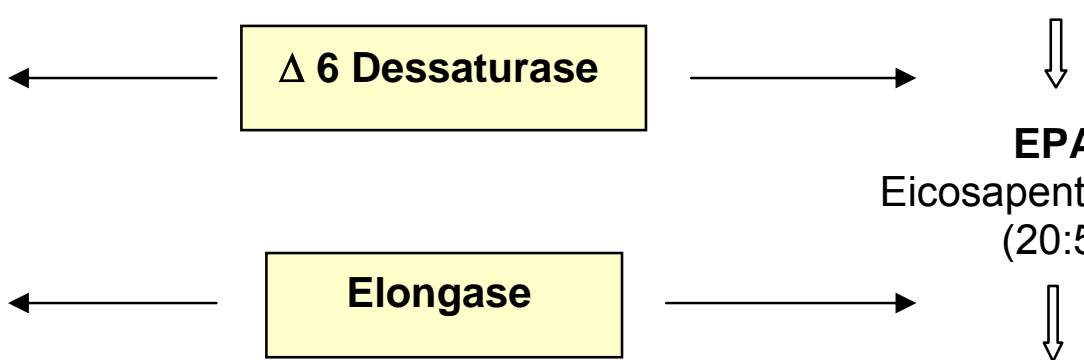

EPA

Eicosapentaenóico (20:5)

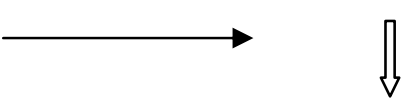

(22:4)<smiles>[C]=C</smiles>

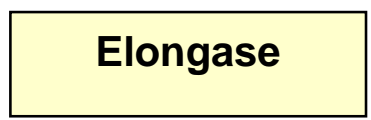

(22:5)
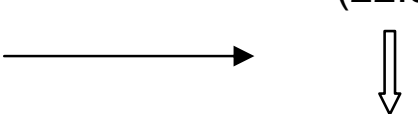

(24:5)

$(24: 4)$<smiles>[CH]=C</smiles>

$\Delta 6$ Dessaturase
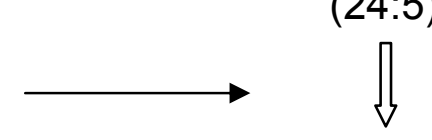

$(24: 5)$

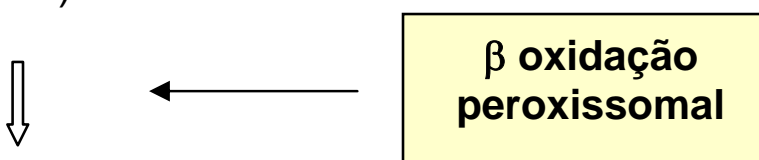

$(24: 6)$

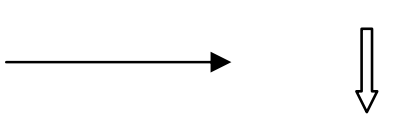

DHA

Docosahexaenóico

$(22: 6)$

Figura 3. Esquema da dessaturação e elongação do ácido linoléico e do ácido $\alpha$-linolênico (modificado de SALEM, 1999). 
No organismo humano, os produtos da família Omega-6 (ácido araquidônico) levam à formação de eicosanóides das séries 2 e 4, compostos caracterizados pela ação pró-inflamatória e pró-agregadora enquanto que os produtos da família Omega-3 (EPA e DHA), representados na Figura 4, são precursores de eicosanóides das séries 3 e 5 com ação anti-agregadora, antiplaquetária e antiinflamatória. Ambas as famílias produzem os eicosanóides, prostaglandinas, tromboxanos e leucotrienos (LEE e LIP, 2003; HARRIS, 2004).

$$
\mathrm{H}_{3} \mathrm{C}-\mathrm{C}-\mathrm{C}=\mathrm{C}-\mathrm{C}-\mathrm{C}=\mathrm{C}-\mathrm{C}-\mathrm{C}=\mathrm{C}-\mathrm{C}-\mathrm{C}=\mathrm{C}-\mathrm{C}-\mathrm{C}=\mathrm{C}-\mathrm{C}-\mathrm{C}-\mathrm{C}-\mathrm{COOH}
$$

(EPA; 20:5n-3)

$\mathrm{H}_{3} \mathrm{C}-\mathrm{C}-\mathrm{C}=\mathrm{C}-\mathrm{C}-\mathrm{C}=\mathrm{C}-\mathrm{C}-\mathrm{C}=\mathrm{C}-\mathrm{C}-\mathrm{C}=\mathrm{C}-\mathrm{C}-\mathrm{C}=\mathrm{C}-\mathrm{C}-\mathrm{C}=\mathrm{C}-\mathrm{C}-\mathrm{C}-\mathrm{COOH}$

(DHA; 22:6n-3)

Figura 4. Estrutura química dos ácidos graxos eicosapentaenóico (EPA) e docosahexaenóico (DHA) (HOLUB e HOLUB, 2004).

Os ácidos graxos polinsaturados Omega-6 são predominantes em todas as dietas, especialmente na dieta ocidental (SIMOPOULOS, 2002). As famílias Omega-6 e Omega-3 competem pelas mesmas enzimas no processo de elongação e dessaturação (Figura 3) e não se convertem uma na outra (LEE e LIP, 2003). Portanto, a eficiência na bioconversão irá depender da proporção entre Omega-6 e Omega-3 presentes na dieta (SIMOPOULOS, 2001).

As fontes alimentares do ácido linoléico (LA) incluem os óleos vegetais como, girassol, soja e milho (CALVANI e BENATTI, 2003; HOLUB e HOLUB, 2004), enquanto que os ácidos graxos polinsaturados Omega-3 (EPA e DHA), são encontrados quase que exclusivamente nos peixes de águas muito frias como o salmão, arenque e sardinha (KRIS-ETHERTON, HARRIS e APPEL, 2003a). EPA e DHA são sintetizados por organismos marinhos unicelulares e a sua concentração depende da composição do fitoplâncton local (SANTOS, GIANNINI e FONSECA, 2001), sendo então transferidos aos peixes através da cadeia alimentar (CALDER, 1998; HARRIS, 2004).

Os ácidos graxos polinsaturados têm efeito nos diversos processos fisiológicos e em doenças crônicas, bem como na regulação dos níveis de lipídios 
do plasma, função cardiovascular e imune, desenvolvimento neuronal e função visual. A ingestão de ácidos graxos polinsaturados Omega-3 e sua distribuição às células do organismo promovem efeitos na função e na composição da membrana, na síntese de eicosanóides e na sinalização e regulação da expressão gênica (GIL, 2002; LEE e LIP, 2003; CALDER, 2004a).

$\mathrm{Na}$ década de 70, BANG e DYERBERG (1972) realizaram os primeiros estudos epidemiológicos que associavam o consumo de ácidos graxos polinsaturados Omega-3 com as doenças cardiovasculares. Este estudo demonstrou que apesar da população esquimó consumir uma dieta rica em gordura, a incidência de doenças coronarianas era baixa em comparação com a população urbana.

\subsubsection{Recomendação de ingestão de ácidos graxos polinsaturados}

Diferentes normas científicas baseiam-se em diferentes recomendações de consumo com relação ao tipo e a quantidade de ácidos graxos polinsaturados Omega-3. Por exemplo, o Scientific Committee for Food (1993) e a Food and Agriculture Organization/World Health Organization (1998), fazem recomendações apenas para ALA, compreendendo que os seres humanos possuem as enzimas que participam do processo de elongação e dessaturação do ALA para formar EPA e DHA. Sendo assim, EPA e DHA não são essenciais e, portanto não há nenhuma recomendação para níveis ótimos de ingestão para estes ácidos graxos. Entretanto, a British Nutrition Foundation (1992) reconhece que este processo de conversão é relativamente ineficiente e que existem funções biológicas adicionais e benefícios à saúde que são exclusivos ao EPA e DHA, considerando-os "condicionalmente essenciais" e recomendações específicas são feitas para ambos (ROCHE, 1999). O projeto EURODIET recomendou que $5 \%$ do total de energia ingerida, equivalente a $125 \mathrm{kcal}$ de uma dieta de $2.500 \mathrm{kcal}$, devem ser provenientes de ácidos graxos polinsaturados Omega-6 e 1\% (25 kcal) de ácidos graxos polinsaturados Omega-3 (HOLM, 2003). Atualmente a dieta ocidental é "deficiente" em ácidos graxos polinsaturados Omega-3, sendo a relação entre Omega-6 e Omega-3 (n6/n3) da ordem de 15 a 20:1, quando o ideal seria de 1 a $4: 1$ (SIMOPOULOS, 2001). 
Segundo KRIS-ETHERTON, HARRIS e APPEL (2003a), a American Heart Association (AHA) recomenda:

- Adultos devem consumir peixes (particularmente peixes gordos) no mínimo duas vezes por semana por se tratar de uma boa fonte protéica com baixa quantidade de gordura saturada. Especialmente espécies mais gordas como cavala, truta, arenque, sardinha, atum e salmão, que fornecem quantidades significativas dos dois tipos de ácidos graxos polinsaturados Omega-3, EPA e DHA. O AHA também recomenda a ingestão de tofu, nozes e óleo de canola que contém ALA.

- Para pacientes com doenças cardiovasculares, recomenda-se $1,0 \mathrm{~g}$ de EPA e DHA (combinados) por dia. Esta quantidade pode ser obtida pelo consumo de peixes gordurosos ou cápsulas de ácidos graxos polinsaturados Omega-3.

- Um suplemento de EPA e DHA pode ser útil para pacientes com hipertrigliceridemia. De 2,0 a $4,0 \mathrm{~g}$ de EPA e DHA por dia podem reduzir a concentração de triacilgliceróis de $20 \%$ a $40 \%$.

O Food and Drug Administration (FDA, 2004) anunciou uma alegação qualificada recomendando que os consumidores não excedam a ingestão de $3,0 \mathrm{~g}$ por dia de EPA e DHA e não mais de 2,0 g por dia através de um suplemento dietético.

\subsubsection{Biossíntese dos eicosanóides}

Eicosanóides é um termo que compreende mediadores lipídicos biologicamente ativos, assim denominados por terem como seus precursores os ácidos graxos polinsaturados de cadeia longa contendo 20 unidades de carbono (GIL, 2002). São representados por uma família que apresenta oxigênio em sua estrutura e são derivados dos ácidos diomo- $\gamma$-linolênico, araquidônico (AA) e eicosapentaenóico. Os eicosanóides incluem prostaglandinas (PGs), 
prostaciclinas (PGI) e tromboxanos (TXs) os quais são denominados de prostanóides, bem como os leucotrienos (LTs), lipoxínas (LXs), ácidos hidroxieicosatetraenóico (HEPEs) e hidroperoxieicosatetraenóico (HPETEs) (CALDER, 1998) .

O principal precursor destes compostos é o ácido araquidônico (CALDER, 1998), sendo este o ácido graxo mais comumente encontrado nos fosfolipídios da membrana celular (GIL, 2002). Os eicosanóides produzidos a partir do ácido araquidônico têm funções biológicas mais potentes que aqueles produzidos a partir dos ácidos diomo- $\gamma$-linolênico e eicosapentaenóico. As PGs e TXs têm estruturas cíclicas e são geradas por oxidação catalisada pelas enzimas cicloxigenases, enquanto que as enzimas 5,12 , ou 15-lipoxigenases catalisam a formação de LTs, LXs, HEPEs e HPETEs (CALDER, 1998; TAPIERO et al., 2002). A Figura 5 apresenta a síntese dos eicosanóides a partir dos ácidos graxos polinsaturados Omega-3 e Omega-6. Os ácidos araquidônico e eicosapentaenóico competem pelas enzimas cicloxigenases e lipoxigenases para a conversão nos respectivos eicosanóides.

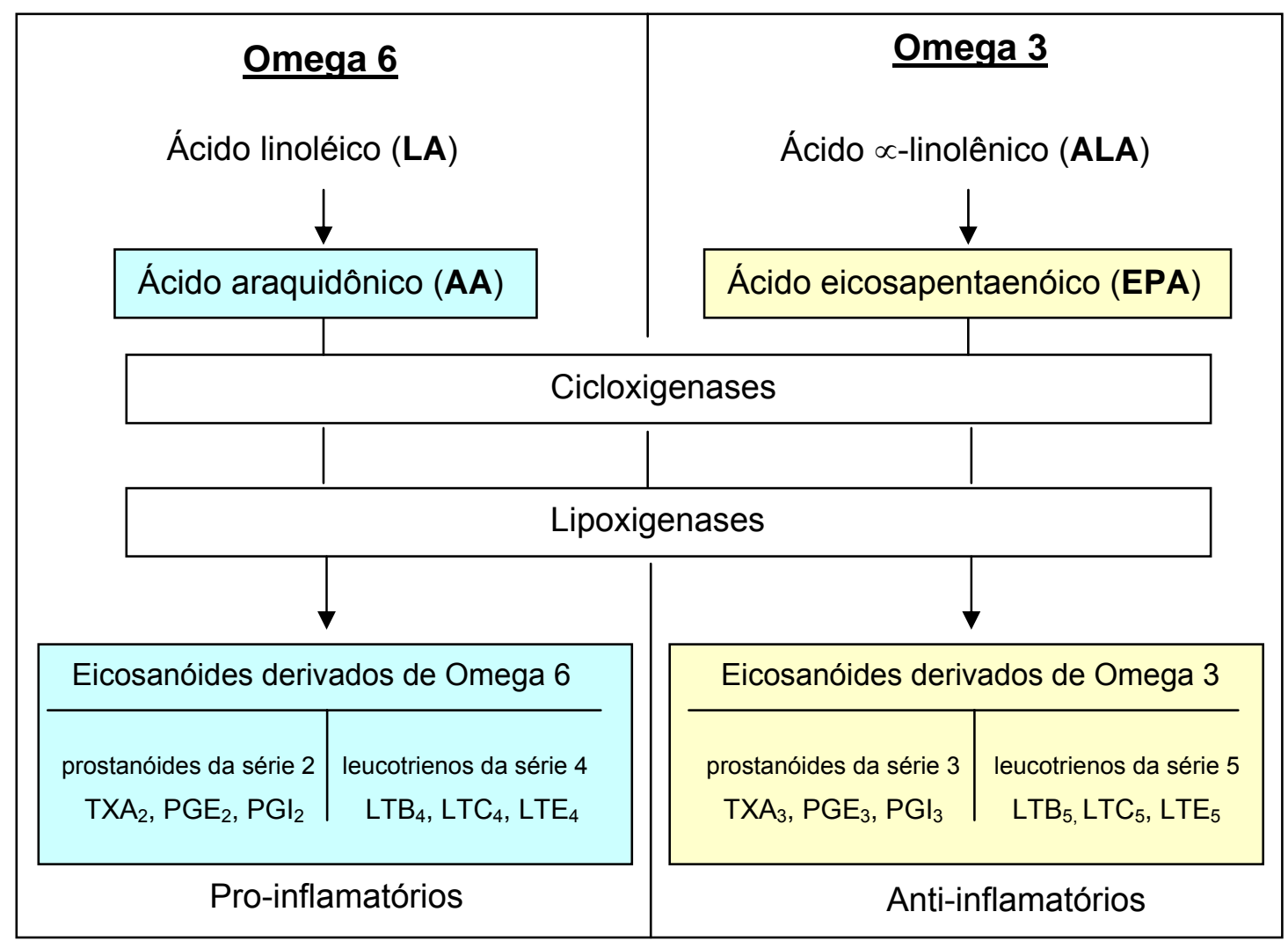

Figura 5. Esquema da síntese dos eicosanóides. Ácido araquidônico e ácido eicosapentaenóico competem pelas enzimas cicloxigenases e lipoxigenases (modificado de DIN, NEWBY e FLAPAN, 2005). 
A síntese de PGs é iniciada pela hidrólise do AA na posição sn-2 dos fosfolipídios (SPITELLER, 2005), onde a ação da cicloxigenase sobre o AA liberado da membrana celular produz tromboxanos da série $2\left(\mathrm{TXA}_{2}\right)$, um potente agregador plaquetário e prostaglandinas da série $2\left(\mathrm{PGl}_{2}\right)$ um potente inibidor de agregação plaquetária. EPA é prontamente incorporado aos fosfolipídios da membrana celular e atua como substrato para a cicloxigenase que produz tromboxanos $\left(\mathrm{TXA}_{3}\right)$ e prostaglandinas $\left(\mathrm{PGI}_{3}\right)$ ambos da série 3 que possuem estruturas diferentes daquelas produzidas pelo $\mathrm{AA}$, e com diferente potencial biológico. $T X A_{3}$ tem o efeito pró-agregatório mais fraco com relação ao $T X A_{2}$ e em contraste, $\mathrm{PGl}_{2}$ e $\mathrm{PGl}_{3}$ têm potenciais anti-agregadores similares (CALDER, 2004b). Portanto os eicosanóides modulam o sistema inflamatório e homeostásico.

\subsection{Doenças arteriais coronarianas}

\subsubsection{Doenças cardiovasculares}

As doenças cardiovasculares (DCV) lideram as taxas de morbidade e mortalidade na maioria dos países e tornaram-se alvo de vários estudos devido a seus altos custos sociais e econômicos (REDDY, 2002).

Segundo relatório da Organização Mundial de Saúde, 16,7 milhões de pessoas morrem de doenças cardiovasculares a cada ano, representando cerca de um terço de todos os óbitos no mundo. O relatório afirma que as doenças cardiovasculares tornaram-se epidêmicas e causarão a mortalidade de 24 milhões de pessoas por ano até 2030 (WHO, 2004).

Estimativas da mortalidade por doenças cardiovasculares por região indicam que os países em desenvolvimento contribuem com uma parcela maior de mortalidade relacionada a estas causas do que os países desenvolvidos (REDDY E YUSUF, 1998), sendo responsáveis por 70\% dessas ocorrências (LOPEZ, 1993). O Brasil ocupa lugar de destaque na lista dos países cuja causa de mortalidade, em números absolutos, se dá em razão de doenças cardiovasculares (BRASIL, 2004). 
A aterosclerose é a principal causa de doenças coronarianas, cerebrais e de vasos arteriais periféricos (BRASIL, 2004). Estudos citam que a aterosclerose é um processo inflamatório (ROSS, 1999; MORENO e MITJAVILA, 2003) que poderia ser atenuado pelo consumo de ácidos graxos polinsaturados Omega-3 em razão das propriedades antiinflamatórias que estes apresentam no organismo humano (GIL, 2002; CALDER, 2004a; CALDER, 2004b).

\subsubsection{Aterosclerose}

Aterosclerose, principal causa de ataque cardíaco e infarto, representa $50 \%$ de mortalidade nos Estados Unidos, Europa e Japão (MORENO e MITJAVILA, 2003). Apesar destas altas taxas, durante os últimos 30 anos tem-se presenciado um declínio da mortalidade por causas cardiovasculares, em países desenvolvidos, enquanto que elevações relativamente rápidas e substanciais têm ocorrido em países em desenvolvimento, dentre os quais o Brasil (SANTOS, GIANNINI e FONSECA, 2001).

Trata-se de uma doença multifatorial na qual um dos principais fatores de risco é o envelhecimento. Outros fatores de riscos conhecidos e bem estabelecidos são caracterizados pela pressão arterial elevada, obesidade, hiperlipidemia, ingestão de alimentos ricos em colesterol oxidado e lesão ao endotélio (SPITELLER, 2005).

ROSS (1999) propôs a teoria de que a disfunção endotelial conduz à aterosclerose e as possíveis causas incluem elevada concentração de LDL oxidada, presença de radicais livres resultantes de tabagismo, diabetes, alterações genéticas, concentrações elevadas de homocisteína no plasma e microorganismos infecciosos. HIGUCHI et al., (2002) detectaram a presença de Micoplasma pneumoniae e Clamídia pneumoniae em placas ateroscleróticas rotas.

A disfunção endotelial é seguida pela atração de monócitos da circulação, que entram na parede do vaso e se diferenciam em macrófagos. Os monócitos ativados e macrófagos podem lesar as células vizinhas pela secreção de radical superóxido $\left(\mathrm{O}_{2}{ }^{\bullet-}\right)$, peróxido de hidrogênio $\left(\mathrm{H}_{2} \mathrm{O}_{2}\right)$, enzimas hidrolíticas e possivelmente óxido nítrico $\left(\mathrm{NO}^{\circ}\right)$. $\mathrm{O} \mathrm{NO}^{\bullet}$ é gerado pelas células do endotélio 
vascular, sendo um radical livre relativamente estável, que reage rapidamente com $\circ \mathrm{O}_{2}{ }^{--}$para formar peróxinitrito ( $\left.\mathrm{ONOO}^{-}\right)$, uma espécie reativa de nitrogênio que promove a peroxidação de metade dos lipídios da LDL (PENNATHUR et al., 2004).

A aterosclerose envolve uma série de reações que ocorrem no tecido conectivo vascular em resposta a uma lesão local (GIL, 2002). O processo de aterogênese tem sido considerado por consistir no acúmulo de lipídios dentro da parede arterial, no entanto, o processo é mais complexo e está relacionado com uma série de respostas celulares e moleculares altamente específicas (ROSS, 1999). As lesões da aterosclerose ocorrem principalmente em artérias elásticas e musculares de grande e médio calibre, conduzindo à isquemia cardíaca e cerebral, resultando no infarto, podendo estar presente durante todo o ciclo de vida do indivíduo (ROSS, 1999; NELSON et al., 2005).

O processo aterosclerótico envolve a entrada, modificação e acúmulo de lipoproteínas plasmáticas, recrutamento e proliferação das células na parede arterial e avança através de uma série de estágios a partir do aparecimento de uma lesão ou estria gordurosa, comum também em bebês e crianças (ROSS, 1999). A lesão é composta pela maior parte de células espumosas, que são constituídas de macrófagos que incorporaram lipoproteínas de baixa densidade oxidadas (LDL-ox). A estria gordurosa evolui para a complexa placa fibrosa, que consiste de uma área rica em macrófagos, células musculares lisas e linfócitos $T$, coberta por uma capa fibrosa. Em seguida ocorre a formação da placa complicada que são placas fibrosas que foram alteradas pela necrose, deposição de cálcio, sangramento e trombose (Figura 6) (HALLIWELL e GUTTERIDGE, 1999; ROSS, 1999; VIOLI, MICHELETTA e IULIANO, 2002). 


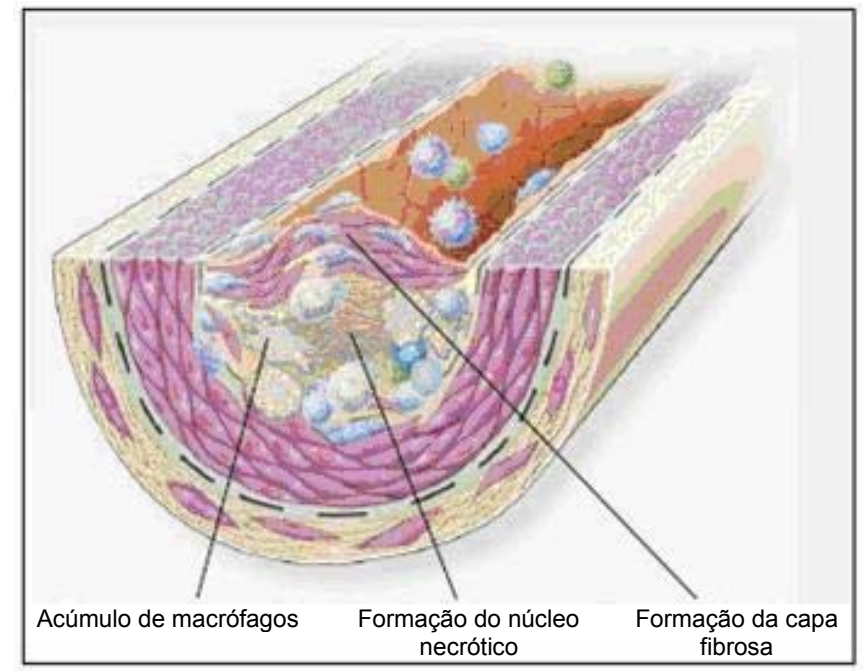

Figura 6. Formação de uma lesão avançada da aterosclerose (ROSS, 1999).

\subsubsection{LDL modificada e aterosclerose}

Recentemente, várias pesquisas têm relatado a hipótese de que o estresse oxidativo, em particular a oxidação das LDL por radicais livres, teriam um papel importante na aterogênese (ROSS, 1999; VIOLI, MICHELETTA e IULIANO, 2002; MORENO e MITJAVILA, 2003). A LDL é uma partícula grande, com o núcleo constituído de aproximadamente 170 moléculas de triacilgliceróis e 3.600 moléculas de éster de colesterol. O núcleo é circundado por uma camada de aproximadamente 700 moléculas de fosfolipídios e 600 de colesterol livre. Encaixada nesta camada está uma proteína, apolipoproteína B (apo B). Esta proteína permite o reconhecimento pelas células endoteliais via grupamentos lisina. A oxidação dos grupos amino livres dos resíduos de lisina da apo B contribuem para a aterogênese (SPITELLER, 2005).

A maioria das moléculas de colesterol do núcleo da LDL está esterificada com ácidos graxos polinsaturados, principalmente ácido linoléico e em menor quantidade com o ácido araquidônico (SPITELLER, 2005). Estes ácidos graxos são altamente susceptíveis à oxidação devido às duplas ligações presentes na cadeia (MORENO e MITJAVILA, 2003).

Estudos epidemiológicos recentes têm relatado que a suplementação com ácidos graxos polinsaturados Omega-3 teria uma correlação inversa com a incidência da aterosclerose (NESTEL et al., 2002; MORENO e MITJAVILA, 2003; 
ERKKILÄ et al., 2004; MCLAUGHLIN et al., 2005). Desta forma, o consumo destes ácidos graxos deveria ser especialmente estimulado para indivíduos classificados como de alto risco para DCV (ERKKILÄ et al., 2003; CALDER, 2004b). Entretanto, outros estudos têm relatado a maior susceptibilidade dos ácidos graxos polinsaturados Omega-3 à oxidação (REAVEN e WITZTUM, 1996; SONG e MIYAZAWA, 2001; FINNEGAN et al., 2003), o que favoreceria o desenvolvimento da aterosclerose (MURALIDHAR et al., 2004). Esta maior susceptibilidade se deve a representação eletrônica das duplas ligações que consistem de ligação simples $\sigma$ e de uma ligação $\pi$ que possui um par de elétrons ocupando posições acima e abaixo do plano. As ligações $\pi$ são mais fracas e têm menor energia porque os elétrons estão fracamente ligados entre os dois núcleos e também mais expostos. Os elétrons $\pi$ são consequentemente responsáveis pela maior reatividade do composto insaturado e são mais prontamente polarizáveis que os elétrons da ligação $\sigma$ (FRANKEL, 2005).

\subsubsection{Estresse oxidativo}

O estresse oxidativo é caracterizado como um distúrbio no estado de equilíbrio dos sistemas pró-oxidantes/antioxidantes em células intactas. Quando ocorrem eventos oxidativos adicionais, os sistemas pró-oxidantes podem aumentar com relação aos antioxidantes, resultando em danos oxidativos (SIES, STAHL e SEVANIAN, 2005).

A causa pode ser devida à exposição ambiental aos oxidantes, ingestão inadequada de antioxidantes ou alterações enzimáticas, resultando em níveis patológicos de danos oxidativos. Há uma forte evidência de que o estresse oxidativo tem um papel importante na patogênese de muitas doenças (BAGCHI e PURI, 1998). Algumas fontes endógenas e exógenas de EROs e mecanismos de defesa, estão sumarizadas na Figura 7. 


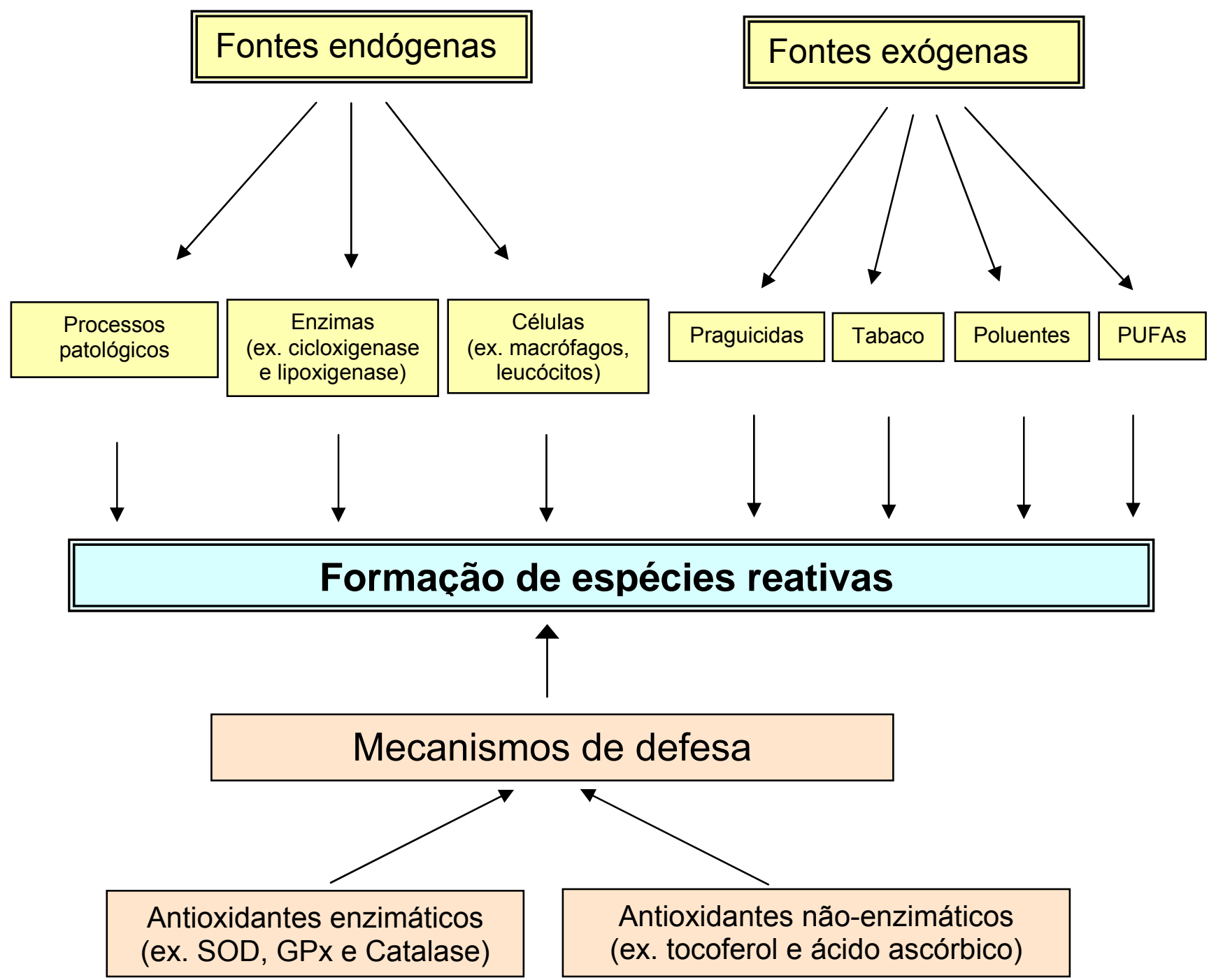

Figura 7. Esquema das principais fontes que levam a formação de espécies reativas e mecanismos de defesa. SOD = Superóxido dismutase e GPx = Glutationa peroxidase.

Acredita-se que uma dieta rica em frutas e hortaliças forneça uma variedade de antioxidantes vegetais que possam atuar de forma benéfica. Por outro lado, substâncias como praguicidas, toxinas vegetais e derivadas de microorganismos, bem como lipídios polinsaturados podem produzir efeitos pró-oxidantes em humanos (THOMAS, 2003).

Em um organismo, a existência de um desequilíbrio em favor da geração excessiva de radicais livres, ou em detrimento da velocidade de remoção destas espécies, é conhecida como estresse oxidativo e pode conduzir à oxidação maciça de substratos biológicos. A cronicidade desse estresse oxidativo, no ambiente celular, pode causar severos problemas metabólicos e estar envolvida 
na origem e no desenvolvimento de numerosas doenças (LUCESOLI e FRAGA, 1995). Os agentes pró-oxidantes mais importantes são as espécies reativas de oxigênio (ERO), embora existam também espécies reativas de nitrogênio (ERN) e enxofre (ERS), podendo ser considerados tóxicos ao funcionamento adequado da célula (HALLIWELL e GUTTERIDGE, 1984).

O termo radical livre é freqüentemente usado para designar qualquer átomo ou molécula com existência independente, contendo um ou mais elétrons não pareados nos orbitais externos. Isto determina uma atração para um campo magnético, o que pode torná-lo altamente reativo, capaz de reagir com qualquer composto situado próximo à sua órbita externa, passando a ter uma função oxidante ou redutora (HALLIWEEL e GUTTERIDGE, 1999).

A geração de radicais livres constitui uma ação contínua e fisiológica, cumprindo funções biológicas essenciais. São formados em um cenário de reações de óxido-redução, provocando ou resultando dessas reações. Podem ceder o elétron solitário e serem oxidados ou podem receber outro elétron e serem reduzidos (FERREIRA e MATSUBARA, 1997). Estas reações ocorrem no citoplasma, nas mitocôndrias ou na membrana e o seu alvo celular (proteínas, lipídeos, carboidratos e moléculas de DNA) está relacionado com seu local de formação (ANDERSON et al., 2000).

O oxigênio atmosférico, embora seja um radical, não é reativo com moléculas biológicas, pois seus dois orbitais eletrônicos apresentam restrição de spin. A principal via de metabolismo do oxigênio no organismo envolve a sua completa redução à água, incorporando quatro elétrons ao final da cadeia respiratória. Porém, de 1 a $3 \%$ deste oxigênio sofre redução por um número menor de elétrons, ao longo da cadeia respiratória, gerando elementos intermediários reativos (ERO): radical superóxido, peróxido de hidrogênio e radical hidroxila, que são correspondentes aos passos de uma redução por um, dois ou três elétrons, respectivamente (JORDÃO Jr. et al., 1998).

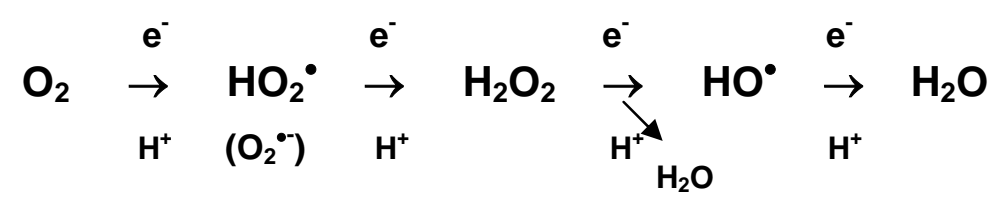


Dentre os radicais livres (espécies reativas de oxigênio), o radical superóxido $\left(\mathrm{O}_{2}{ }^{--}\right)$, radical hidroxila $\left(\mathrm{HO}^{*}\right)$ e peróxido de hidrogênio $\left(\mathrm{H}_{2} \mathrm{O}_{2}\right)$ são formados em todas as células aeróbias, enquanto a espécie mais reativa, $\left({ }^{1} \mathrm{O}_{2}\right)$ oxigênio singlete, é formada pela excitação do oxigênio fundamental $\left({ }^{3} \mathrm{O}_{2}\right)$, pela energia térmica ou fotoquímica, dissipada por substâncias "sensibilizadoras" quando irradiadas com luz em comprimento de onda específico (ABDALLA, 2000).

\section{Radical superóxido}

$\mathrm{O}$ radical superóxido $\left(\mathrm{O}_{2}{ }^{--}\right)$é formado continuamente através de diversos processos celulares onde ocorre a redução de um elétron do oxigênio, não sendo particularmente ativo podendo difundir-se por distâncias consideráveis a partir de seu local de produção (THOMAS, 2003).

$$
\mathrm{O}_{2} \stackrel{\mathrm{e}^{-}}{\rightarrow} \mathrm{O}_{2}
$$

$\mathrm{Na}$ presença simultânea de peróxido de hidrogênio $\left(\mathrm{H}_{2} \mathrm{O}_{2}\right)$, o radical superóxido pode ser um precursor de espécies oxidantes mais potentes, através da reação de Haber-Weiss:

$$
\mathrm{O}_{2}^{\bullet-}+\mathrm{H}_{2} \mathrm{O}_{2} \rightarrow \mathrm{OH}^{-}+\mathrm{HO}^{\bullet}+\mathrm{O}_{2}
$$

Esta reação ocorre em duas etapas, sendo catalisada por íons $\mathrm{Fe}^{3+}$. O radical superóxido participa da redução do ferro à sua forma ferrosa $\left(\mathrm{Fe}^{3+}+\mathrm{O}_{2}{ }^{--} \rightarrow \mathrm{Fe}^{2+}+\mathrm{O}_{2}\right)$, que por sua vez, reduz o peróxido de hidrogênio, através da chamada reação de Fenton:

$$
\mathrm{Fe}^{2+}+\mathrm{H}_{2} \mathrm{O}_{2} \rightarrow \mathrm{Fe}^{3+}+\mathrm{OH}^{-}+\mathrm{HO}^{-}
$$




\section{Peróxido de hidrogênio}

$O$ peróxido de hidrogênio $\left(\mathrm{H}_{2} \mathrm{O}_{2}\right)$ apresenta poder oxidante indireto, gerando radical hidroxila $\left(\mathrm{HO}^{\circ}\right)$ e interagindo com o radical superóxido $\left(\mathrm{O}_{2}{ }^{\circ}\right)$. Nesse caso, ele torna-se um potente oxidante e, em concentrações suficientes, pode degradar qualquer célula, sendo que na presença de ferro sua toxidade pode aumentar de 10 a 1000 vezes (EATON, 1991). O peróxido de hidrogênio é gerado pelas mesmas fontes que produzem o radical superóxido, pois tanto a reação enzimática (superóxido dismutase):

$$
2 \mathrm{O}_{2}^{-}+2 \mathrm{H} \stackrel{\text { SOD }}{\rightarrow} \mathrm{O}_{2}+\mathrm{H}_{2} \mathrm{O}_{2}
$$

como a sua redução produzem peróxido de hidrogênio

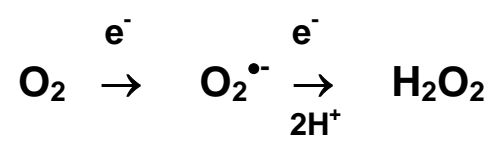

e este é capaz de difundir-se por distâncias consideráveis e atravessar facilmente membranas (WILHELM et al., 2003).

\section{Radical hidroxila}

O radical hidroxila $\left(\mathrm{HO}^{\circ}\right)$ é considerado um poderoso e não seletivo oxidante que pode reagir com todos os tipos de macromoléculas biológicas, produzindo derivados que não podem ser regenerados através do metabolismo celular. É freqüentemente reconhecido como o mais importante por sua habilidade em iniciar a lipoperoxidação (FERREIRA e MATSUBARA, 1997) e apresenta meia vida mais curta (YU, 1994; DEL MAESTRO, 1980). É importante destacar que quanto mais curta for a meia vida de um radical livre, maior será a instabilidade de sua configuração eletrônica, e portanto, maior será a rapidez com que irá retirar elétrons de outras moléculas (HALLIWELL e GUTTERIDGE, 1984). 


\section{Oxigênio singlete}

$\mathrm{O}$ oxigênio singlete $\left({ }^{1} \mathrm{O}_{2}\right)$ constitui uma forma muito reativa com elétrons pareados no orbital reativo, sendo formado pela oxidação dos outros intermediários reativos de oxigênio. Pode ser formado pelo peróxido de hidrogênio que reage com o ânion superóxido ou com ácido hipocloroso dentro das células e tecidos (THOMAS, 2003; LEE, KOO e MIN, 2004). Sendo assim, serão importantes alvos biológicos, moléculas fundamentais como ácidos graxos insaturados, proteínas e DNA.

Estas várias espécies de oxigênio indicam a complexidade das reações que podem resultar do estresse oxidativo. Fatores como o local de produção, a disponibilidade de metais de transição e a ação de enzimas determinam o destino de cada espécie de radical e sua disponibilidade para reagir com moléculas celulares (THOMAS, 2003).

\section{Peroxidação dos lipídios}

A peroxidação de lipídios é definida como "a deterioração oxidativa de lipídios polinsaturados". Os ácidos graxos polinsaturados são, devido a suas múltiplas duplas ligações, excelentes alvos para o ataque de radicais livres (HALLIWELL e GUTTERIDGE, 1999; NORBERG e ARNÉR, 2001).

A membrana das células e organelas celulares contém grandes quantidades de ácidos graxos polinsaturados, tornando-as um dos componentes celulares mais atingidos pelas espécies reativas de oxigênio (EROs). Esse processo promove alterações na estrutura e na permeabilidade das membranas celulares. Há perda da seletividade iônica, liberação do conteúdo das organelas e formação de produtos citotóxicos, culminando com a morte celular (FERREIRA e MATSUBARA, 1997; HALLIWELL e GUTTERIDGE, 1999; YOSHIDA et al., 2003).

A lipoperoxidação é uma reação em cadeia, representada pelas etapas de iniciação, propagação e terminação. Estas etapas estão apresentadas nas reações seguintes, onde $L$ representa o lipídio (GARDĖS-ALBERT, JORE e FERRADINI, 1991): 


$$
\begin{aligned}
& \mathrm{LH} \stackrel{\stackrel{\mathrm{HO}^{\circ}}{\longrightarrow}}{\longrightarrow} \mathrm{L}^{\bullet} \text { (Iniciação) } \\
& \mathrm{L}^{\bullet}+\mathrm{O}_{2} \longrightarrow \mathrm{LOO}^{\bullet} \text { (Propagação) } \\
& \mathrm{LH}+\mathrm{LOO}^{\bullet} \longrightarrow \mathrm{L}^{\bullet}+\mathrm{LOOH} \text { (Propagação) } \\
& \mathrm{LOO}^{\bullet}+\mathrm{L}^{\cdot} \longrightarrow \text { LOOL (Terminação) } \\
& \mathrm{LOO}^{\circ}+\mathrm{LOO}^{\circ} \longrightarrow \mathrm{LOOL}+\mathrm{O}_{2} \text { (Terminação) }
\end{aligned}
$$

A reação acima se inicia pela remoção do elétron do hidrogênio ligado ao carbono metilênico do ácido graxo polinsaturado (LH) presente na membrana celular. Tal remoção pode ser realizada pelo $\mathrm{HO}^{\circ}$ ou pelo $\mathrm{LO}^{\circ}$ (radical alcoxila), com conseqüente formação do $\mathrm{L}^{\bullet}$ (radical lipídico). $\mathrm{Na}$ primeira equação de propagação, o $\mathrm{L}^{\bullet}$ reage rapidamente com $\circ \mathrm{O}_{2}$, resultando em $\mathrm{LOO}^{\bullet}$ (radical peroxila), que, por sua vez, seqüestra novo hidrogênio do ácido graxo polinsaturado, formando novamente o $L^{\bullet}$ na segunda equação de propagação. $O$ término da lipoperoxidação ocorre quando os radicais ( $\mathrm{L}^{\bullet}$ e $\mathrm{LOO}^{\circ}$ ) produzidos nas etapas anteriores interagem formando moléculas não-radicais.

$\mathrm{O} \alpha$-tocoferol impede a propagação das reações por radicais livres através da sua atuação como scavenger do radical peroxila, protegendo especialmente ácidos graxos polinsaturados dentro dos fosfolipídios da membrana e nas lipoproteínas do plasma. Os radicais peroxila reagem mil vezes mais rápidos com a vitamina $E$ do que com os ácidos graxos polinsaturados. A hidroxila do grupo fenólico do tocoferol reage com um radical peroxila orgânico para formar o correspondente hidroperóxido orgânico ( $\mathrm{LOOH}$ ) e o radical do tocoferil pode reagir com outro radical tocoferil para formar produtos não reativos como os dímeros de tocoferol (DRIs, 2000).

A peroxidação lipídica está entre os efeitos deletérios mediados pelo ataque de radicais livres nas moléculas biológicas e que mais tem sido estudado (KARTEN et al., 1997; VIOLI, MICHELETTA e IULIANO, 2002; YOSHIDA et al., 2003). Muitos produtos da peroxidação lipídica têm sido encontrados na lesão aterosclerótica e no plasma (ERDOGAN et al., 2004), demonstrando seu 
envolvimento na progressão de várias desordens e doenças (YOSHIDA et al., 2003).

Além da oxidação da LDL, a lipoproteína de muito baixa densidade (VLDL) e a apolipoproteína $B$ (apo B), que é a principal lipoproteína aterogênica, citocinas e moléculas de adesão também têm sido avaliadas como biomarcadores da aterosclerose (SALGADO FILHO et al., 2005). As citocinas como, por exemplo, TNF- $\alpha$, IL-1 e IL-6, são liberadas pelas células imunes que iniciam e ampliam as reações inflamatórias, e as moléculas de adesão como as ICAM-1, VCAM-1 e E-selectina, atuam na resposta aos sinais recebidos pelas citocinas promovendo a aderência das células imunes ao endotélio (KACIMI et al., 1998).

A oxidação no plasma decorrente da peroxidação lipídica, pode ser avaliada através da medida de concentração dos produtos formados nesse processo, como por exemplo, hidroperóxidos, dienos conjugados, aldeídos, isoprostanos e outros (JACKSON, 1999).

\subsection{Métodos para avaliação do estresse oxidativo in vivo}

De acordo com CAO e PRIOR (1998), os organismos vivos desenvolveram um complexo sistema antioxidante para neutralizar as espécies reativas e reduzir seus danos. Devido à dificuldade de avaliar cada antioxidante separadamente assim como suas interações, vários métodos têm sido propostos, porém nenhum foi validado até o momento. Segundo BRAY (2000), os métodos usados para avaliar o estresse oxidativo são baseados em cinco diferentes estratégias:

1) medida de produtos gerados por danos oxidativos em amostras biológicas;

2) medida do equilíbrio entre o sistema pró-oxidante e o antioxidante;

3) avaliação da vulnerabilidade de amostras biológicas à oxidação após a adição de um pró-oxidante externo;

4) detecção de eventos primários como a ativação de fatores de transcrição que antecedem o dano oxidativo;

5) abordagem clínica que utiliza de métodos não invasivos como a ressonância magnética para diagnosticar manifestações primárias resultantes do estresse oxidativo. 
Os produtos de oxidação sobre lipídios, DNA e proteínas podem ser usados como biomarcadores e estão resumidamente apresentados na Figura 8.

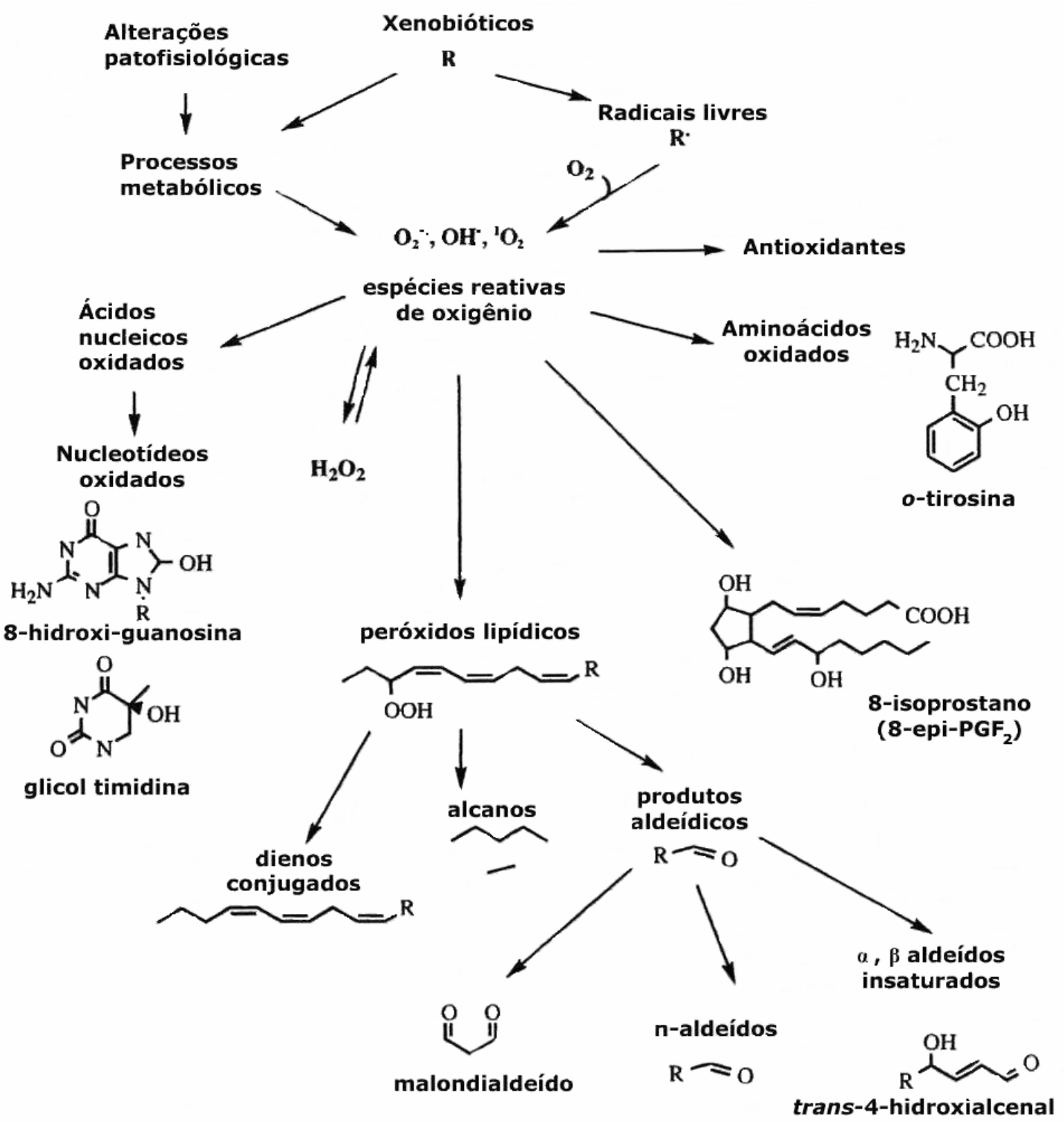

Figura 8. Produtos da ação de EROs sobre diferentes substratos. Radicais livres podem reagir com diferentes macromoléculas celulares, tais como DNA, membranas celulares ou proteínas, que eventualmente podem levar a formação de vários compostos (modificado de ZWART et al., 1999). 


\subsection{Alimentos funcionais}

Durante a última década tem-se observado um maior interesse do consumidor por alimentos mais saudáveis. Este interesse surgiu em função da preocupação com o bem estar físico e a redução do risco de doenças degenerativas decorrentes do estresse, fatores genéticos, tabagismo, sedentarismo e principalmente hábitos alimentares inadequados. Neste contexto, surgiram os chamados "Alimentos Funcionais" que podem ser definidos como alimentos que promovem benefícios à saúde além da nutrição básica (INTERNATIONAL FOOD INFORMATION COUNCIL, 2004).

Os alimentos funcionais contêm componentes bioativos que podem ser provenientes de fontes vegetais como as fibras solúveis da aveia, as isoflavonas da soja, o licopeno do tomate, a alicina do alho, as catequinas do chá, os fenóis dos vinhos ou provenientes de fontes animais como, por exemplo, as proteínas do soro do leite e os ácidos graxos polinsaturados Omega-3, obtidos a partir de certas espécies de peixes (JONES, 2002).

Estudos têm sugerido que ácidos graxos polinsaturados Omega-3, tais como ácido eicosapentaenóico EPA (20:5) e ácido docosahexaenóico DHA (22:6), podem reduzir o risco de aterosclerose e das doenças cardiovasculares devido à ação anti-arrítmicas, antitrombótica, antiinflamatória, melhora da função endotelial, redução da pressão sanguínea e redução da concentração de triacilgliceróis (KRIS-ETHERTON, HARRIS e APPEL, 2003b; HALSTED, 2003; FDA, 2004; SCHMIDT et al., 2005; HARRIS e SCHACKY, 2004; HINO et al., 2004; ENGLER et al., 2004; MCLAUGHLIN et al., 2005).

Entretanto, ainda não há um consenso se o maior aporte dietético de ácidos graxos polinsaturados Omega-3 aumenta o estresse oxidativo no organismo e quais seriam as conseqüências desse aumento no desenvolvimento da aterosclerose na população ocidental, cujo consumo real de peixe está muito abaixo do recomendado e a exposição aos fatores promotores de estresse como os poluentes pode ser muito mais elevada.

Atualmente, vários alimentos têm sido suplementados com ácidos graxos polinsaturados Omega-3 em diferentes dosagens com o objetivo de explorar comercialmente a alegação funcional (Figura 9). 

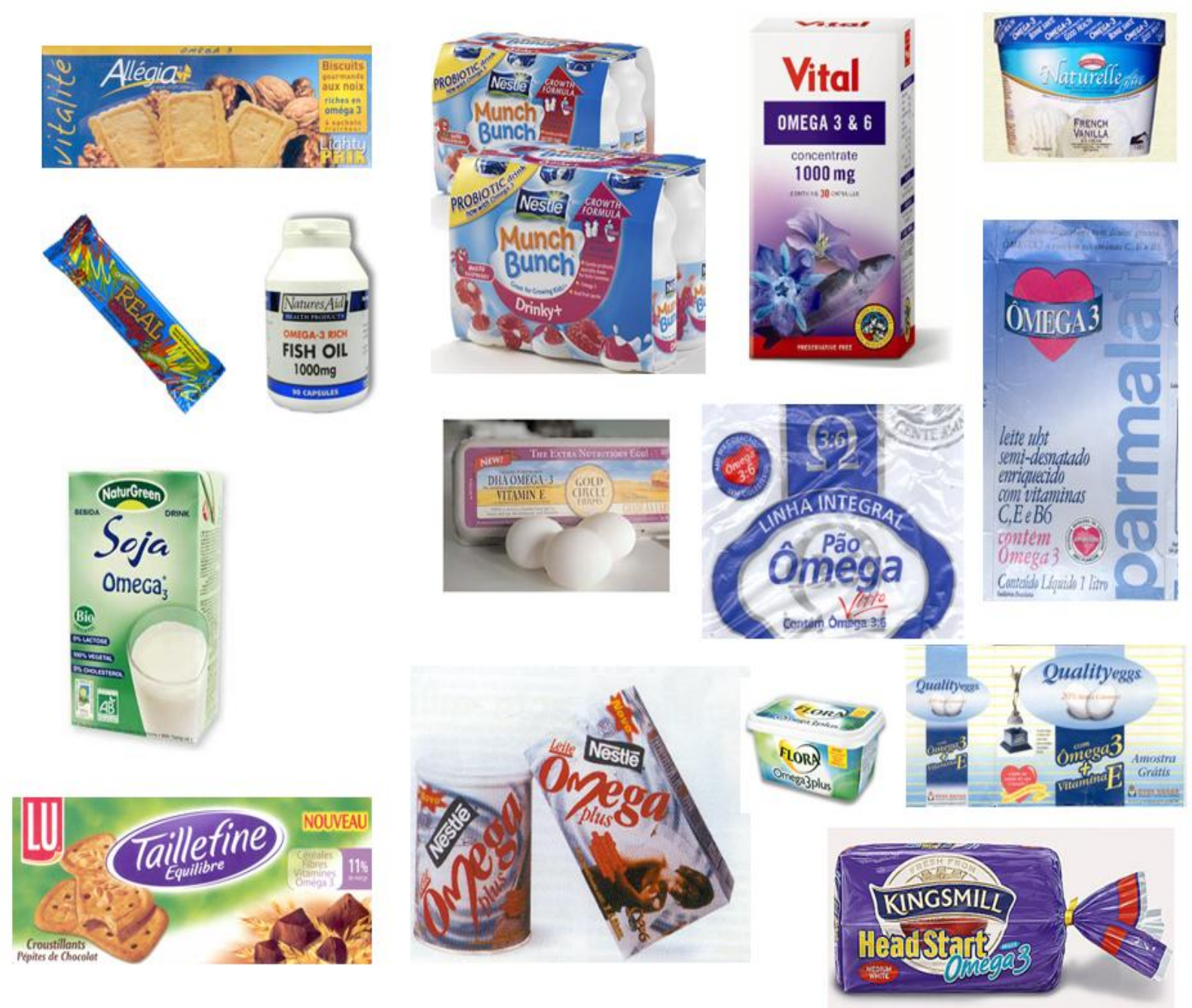

Figura 9. Exemplos de alimentos funcionais suplementados com ácidos graxos polinsaturados Omega-3. 


\section{OBJETIVOS}

\subsection{Objetivo geral}

Avaliar as alterações nos mesmos biomarcadores do estresse oxidativo em humanos e animais suplementados com os ácidos graxos polinsaturados Omega-3.

\subsection{Objetivos específicos}

- Avaliar alterações em lipoproteínas séricas e biomarcadores oxidativos no plasma de humanos suplementados com uma dosagem de Omega-3 equivalente ao consumo de peixe de 2 vezes/semana (0,3 mg de n-3 PUFA/kcal);

- Determinar alterações em lipoproteínas séricas e biomarcadores oxidativos no plasma e no cérebro de roedores (ratos Wistar) suplementados com 2,9 mg de n-3 PUFA/kcal;

- Comparar e discutir as diferenças observadas nesses dois modelos. 


\section{MATERIAL E MÉTODOS}

\subsection{Material}

\subsubsection{Amostra}

Ácidos graxos polinsaturados Omega-3 (Dry $n-3^{\circledR} 18: 12$ ), foram adquiridos junto à BASF Health and Nutrition S/A (Ballerup, Denmark). Dry n- ${ }^{\circledR}$ é apresentado na forma de pó, composto por óleos marinhos microencapsulados, contendo $25 \%$ de lipídios, sendo $18 \%$ EPA (45mg/g), 12\% DHA (30mg/g) e 5\% de outros ácidos graxos polinsaturados Omega-3. As partículas microencapsuladas contêm óleo de peixe envolvido em uma matriz de gelatina, açúcar e amido, estabilizada com ascorbato de sódio, ácido ascórbico e $\alpha$-tocoferol.

\subsubsection{Reagentes}

Foram utilizados os seguintes reagentes: colesterol (C8667); $5 \alpha$-colestane (C8003); TBA ou 4,6 dihidroxipirimidina-2-tiol (T5500); BHT ou 2,6-di-tert-butil-4-metilfenol (B1378); DPPH ou 2,2-difenil-1-picrilhidrazil (D0132); TROLOX ou 6-hidroxi-2,5,7,8-tetrametilcroman-2-ácido carboxílico (238813); TEP ou 1,1,3,3 - tetraethoxypropane (T-9889); BSA ou albumina sérica bovina (A7906); $\alpha$-tocoferol (T3251); ácido ascórbico (A7506) adquiridos da Sigma Chemical Co. (Sigma-Aldrich Corp., St. Louis, MO, USA) e n-Hexano grau HPLC (1.04391) da Merck S.A. (Indústrias Químicas do Brasil). Os demais reagentes utilizados apresentaram grau de pureza analiticamente compatível. 


\subsubsection{Modelos utilizados}

O presente estudo foi realizado utilizando-se modelo humano e animal, ambos suplementados com ácidos graxos polinsaturados Omega-3 durante seis e três semanas respectivamente.

\subsubsection{Modelo humano - Delineamento experimental}

Noventa e nove indivíduos sadios de ambos os sexos, com idade entre 19 e 47 anos, sem evidência clínica ou bioquímica atual ou pregressa de doenças renais, hepáticas e diabetes, que não estivessem fazendo uso de suplementos à base de ácidos graxos ou vitaminas há mais de 90 dias e sem tomar qualquer tipo de medicamento hipolipidêmico, foram entrevistados quanto à concordância em participar do estudo, segundo as normas do Comitê de Ética (Anexo 1). Embora não houvesse evidência de risco para o consumo de ácidos graxos polinsaturados Omega-3 na dosagem recomendada neste estudo, todos os indivíduos foram aconselhados a interromper o consumo, caso sentissem algum desconforto clínico, como dores abdominais ou problemas gastrintestinais. Os critérios de exclusão para o estudo foram de indivíduos que tomavam suplementos nutricionais ou outro medicamento conhecido por interferir no metabolismo lipídico tais como drogas hipolipidêmicas, $\beta$-bloqueadores, corticosteróides ou diuréticos nos 90 dias que antecederam a seleção, mulheres gestantes ou amamentando e indivíduos com doença endócrina ou hepática, diabetes, sendo tratadas por angina ou arritmia, ou com histórico pessoal de infarto do miocárdio ou derrame.

O leite foi escolhido como o veículo porque é tomado diariamente, sendo também um meio eficiente para a absorção de gordura e de compostos solúveis em lipídios em função de sua dispersão em micelas (CARRERO et al., 2004). As amostras foram gentilmente elaboradas em uma unidade industrial (Crialimentos Indústria e Comércio Ltda., Jundiaí, SP) sob as recomendações de Boas Práticas de Fabricação (BPF), e foram estocadas à temperatura ambiente até o momento do consumo. A Figura 10 apresenta um esquema do delineamento experimental. 
Recrutamento e seleção dos voluntários $n=99$
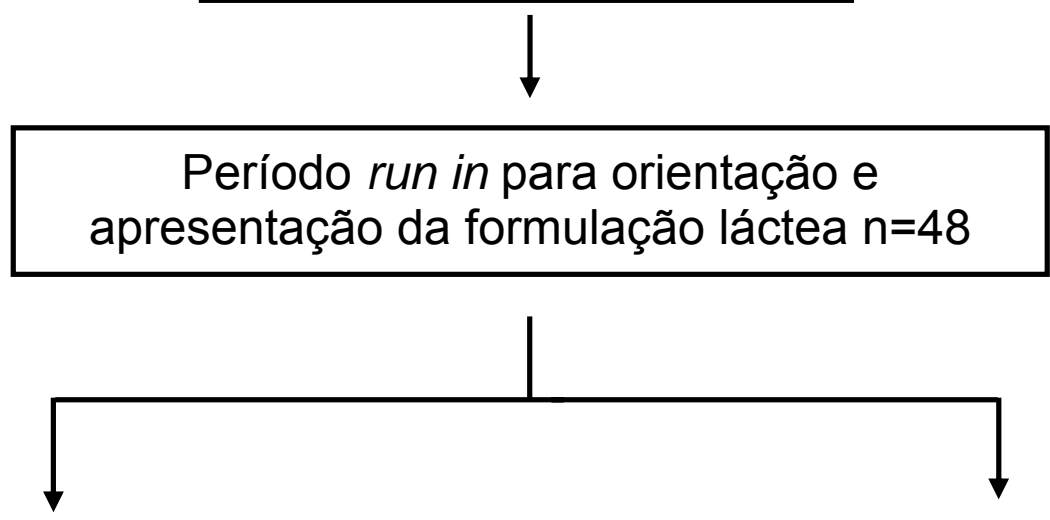

\section{PLABEBO $n=24$ formulação láctea com 460mg de óleo de soja}

OMEGA $n=24$ formulação láctea com $460 \mathrm{mg}$ de ácidos graxos polinsaturados Omega-3

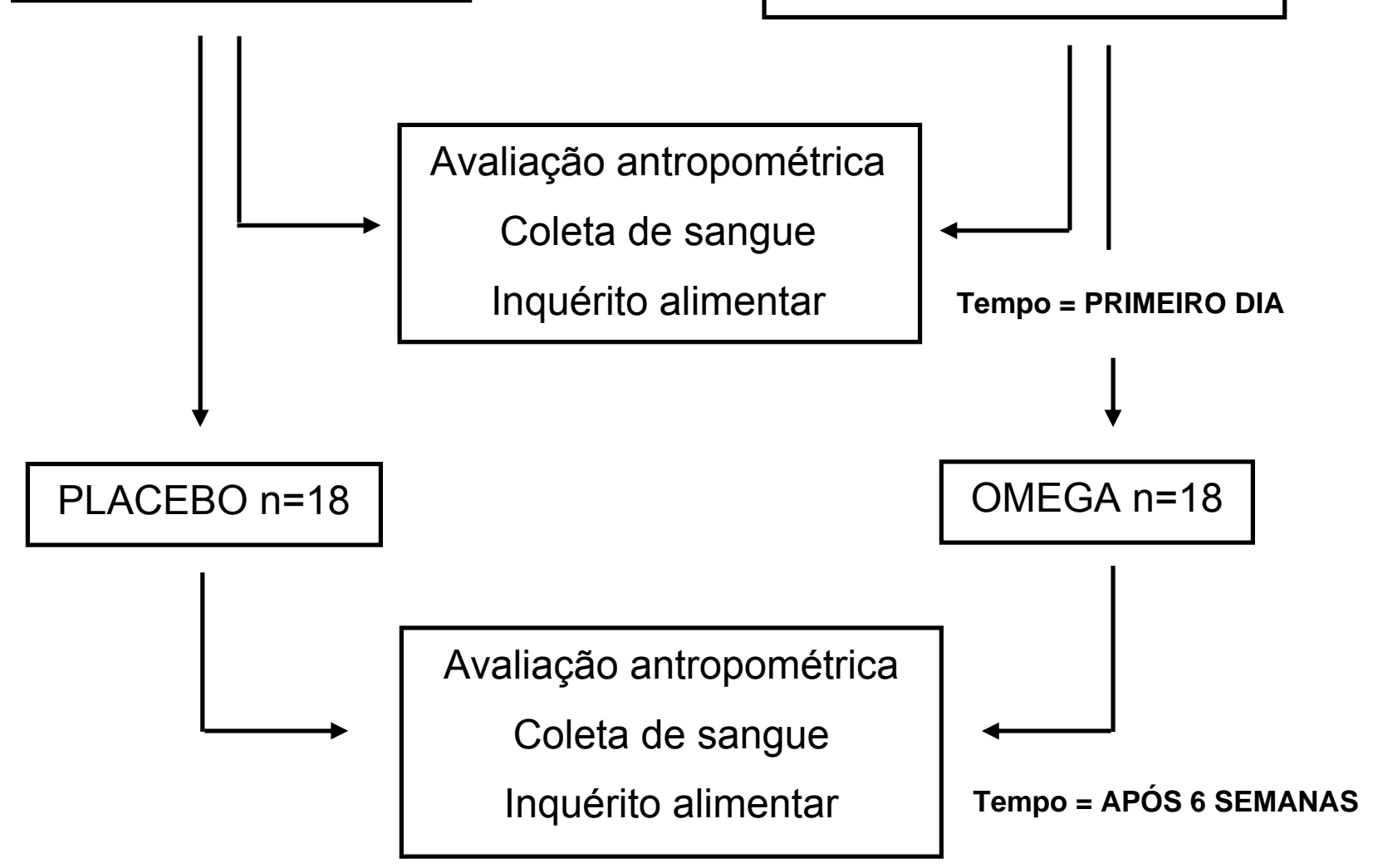

Figura 10. Delineamento experimental aplicado no modelo humano 
Durante um período inicial de uma semana (run in), os indivíduos selecionados receberam amostra da formulação PLACEBO, responderam ao questionário (Anexo 2), foram orientados quanto ao consumo do alimento e conscientizados quanto aos demais procedimentos durante 0 período experimental, como da manutenção de seus hábitos dietéticos e nível de atividade física. Ao final desse período pré-intervenção, os indivíduos foram submetidos às avaliações antropométricas iniciais, inquérito alimentar com registro alimentar de 3 dias (Anexo 3) elaborado segundo HERBERT et al., (1999), antes e depois da intervenção.

Inicialmente os indivíduos foram separados em três grupos (clusters) de acordo com suas medidas antropométricas e a concentração plasmática de lipídios e glicose, conforme pode ser observado na Tabela 1. 
Tabela 1. Características antropométricas no baseline, concentrações dos lipídios séricos e glicose dos indivíduos em jejum separados em subgrupos pela análise de cluster.

\begin{tabular}{|c|c|c|c|c|c|c|c|}
\hline Valores* & Cluster I & Cluster II & Cluster III & $p$ & Ideal & Limite & Alto risco \\
\hline $\mathrm{N}^{\circ}$ de Indivíduos ${ }^{\dagger}$ & 36 & 35 & 28 & - & - & - & - \\
\hline Idade (anos) & $25,3 \pm 4,9^{a}$ & $36,2 \pm 11,5^{b}$ & $42,7 \pm 13,8^{b}$ & $<0,001$ & - & - & - \\
\hline IMC $\left(\mathrm{kg} / \mathrm{m}^{2}\right)$ & $21,6 \pm 2,2^{a}$ & $25,4 \pm 3,4^{b}$ & $28,4 \pm 5,4^{b}$ & $<0,001$ & _ & - & - \\
\hline \multicolumn{8}{|l|}{ Circunferência da } \\
\hline cintura $(\mathrm{cm})$ & $69,9 \pm 5,7^{\mathrm{a}}$ & $78,9 \pm 8,7^{b}$ & $91,0 \pm 10,8^{c}$ & $<0,001$ & - & - & - \\
\hline Colesterol (mg/dL) & $164,3 \pm 22,4^{a}$ & $189,9 \pm 22,4^{b}$ & $225,6 \pm 42,2^{c}$ & $<0,001$ & $<200$ & $200-240$ & $>240$ \\
\hline $\mathrm{LDL}(\mathrm{mg} / \mathrm{dL})$ & $105,3 \pm 20,4^{a}$ & $124,9 \pm 19,2^{b}$ & $160,5 \pm 41,8^{\mathrm{c}}$ & $<0,001$ & $<129$ & $130-159$ & $>160$ \\
\hline $\mathrm{HDL}(\mathrm{mg} / \mathrm{dL})$ & $46,3 \pm 7,5^{\mathrm{a}}$ & $48,6 \pm 11,8^{a}$ & $37,6 \pm 7,9^{b}$ & $<0,001$ & $>40$ & - & - \\
\hline TG $(\mathrm{mg} / \mathrm{dL})$ & $63,6 \pm 21,9^{a}$ & $82,1 \pm 24,6^{b}$ & $137,3 \pm 59,7^{c}$ & $<0,001$ & $<150$ & $150-199$ & $>200$ \\
\hline Glicose (mg/dL) & $83,5 \pm 11,8^{\mathrm{ab}}$ & $78,5 \pm 6,4^{a}$ & $88,7 \pm 12,0^{b}$ & 0,003 & $70-110$ & - & - \\
\hline Nível relativo de risco ${ }^{\ddagger}$ & Baixo & Médio & Alto & - & - & - & - \\
\hline Nível lipidêmico§ & Normolipidêmico & $\begin{array}{l}\text { Moderadamente } \\
\text { hiperlipidêmico }\end{array}$ & $\begin{array}{l}\text { Moderadamente } \\
\text { hiperlipidêmico }\end{array}$ & - & - & - & - \\
\hline
\end{tabular}

IMC, Índice de massa corporal; HDL, Lipoproteína de alta densidade; LDL, Lipoproteína de baixa densidade; TG, triacilglicerol.

* Média \pm DP. Valores seguidos pela mesma letra na linha não são significativamente diferentes $(p<0,05)$.

† Número total de indivíduos (63 mulheres, 36 homens).

‡De acordo com as concentrações de LDL e a classificação do American Heart Association (2006).

$\S$ De acordo com FINNEGAN et al., (2003). 
Maior detalhamento sobre o método estatístico aplicado na distribuição dos clusters está descrito em CASTRO et al., (2007).

A partir de cada um desses três clusters, 48 indivíduos foram aleatoriamente distribuídos em 2 grupos experimentais: OMEGA $(n=24)$ recebendo a formulação láctea suplementada com ácidos graxos polinsaturados Omega-3 e PLACEBO $(n=24)$ recebendo a formulação láctea com óleo de soja em lugar dos ácidos graxos polinsaturados Omega-3.

Foi recomendado o consumo de uma dose da bebida ( $40 \mathrm{~g}$ de mistura em pó diluída em $200 \mathrm{~mL}$ de água), que representou uma suplementação estimada da ordem de $460 \mathrm{mg}$ de ácidos graxos polinsaturados Omega-3 (aproximadamente $240 \mathrm{mg}$ EPA + $160 \mathrm{mg}$ DHA + $60 \mathrm{mg}$ de outros ácidos graxos polinsaturados Omega-3). Uma vez por semana durante o período experimental, os participantes foram contactados, alguns pessoalmente e outros por telefone, para assegurar a aderência. Os indivíduos que apresentaram participação menor que $90,5 \%$ à intervenção (<38 dias) foram excluídos $(n=3)$. Nove voluntários desistiram do estudo em função do sabor residual de peixe na formulação contendo EPA e DHA $(n=7)$ e da baixa tolerância geral ao consumo de leite ao longo do experimento $(n=2)$.

\subsubsection{Preparo da formulação láctea usada na suplementação}

A formulação láctea foi preparada utilizando-se leite desnatado $(54 \mathrm{~g} / 100 \mathrm{~g})$, leite integral $(11 \mathrm{~g} / 100 \mathrm{~g})$, extrato de malte $(5 \mathrm{~g} / 100 \mathrm{~g})$, essência de baunilha $(0,4 \mathrm{~g} / 100 \mathrm{~g})$, malto-dextrina $(7,3 \mathrm{~g} / 100 \mathrm{~g})$, cacau em pó solúvel $(12 \mathrm{~g} / 100 \mathrm{~g})$, edulcorantes aspartame $(0,2 \mathrm{~g} / 100 \mathrm{~g})$, acesulfame de potássio $(0,02 \mathrm{~g} / 100 \mathrm{~g})$ e Dry $\mathrm{n}-3^{\circledR}(10 \mathrm{~g} / 100 \mathrm{~g})$. Dry $\mathrm{n}-3^{\circledR}$ contém $25 \%$ de óleo, sendo $35 \%$ na forma de ácidos graxos polinsaturados Omega-3. No preparo, $40 \mathrm{~g}$ do produto em pó deveriam ser diluídos em $200 \mathrm{~mL}$ de água. Na formulação PLACEBO foi utilizado óleo de soja comercial no lugar de óleo de peixe. Todos os indivíduos foram instruídos a consumir um frasco/dia $(200 \mathrm{~mL})$. As amostras foram codificadas com três dígitos e colocadas em frascos plásticos contendo $40 \mathrm{~g}$ de pó (Figura 11). 


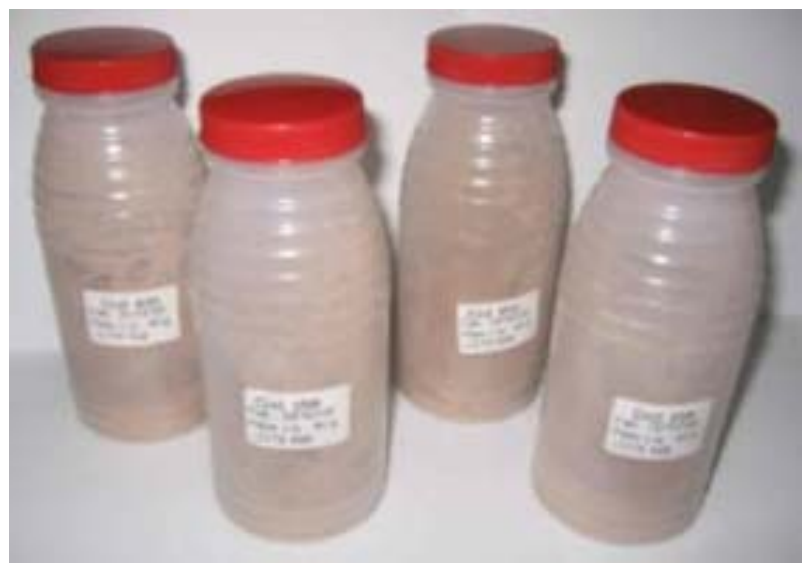

Figura 11. Embalagens contendo o suplemento.

\subsubsection{Modelo animal - Delineamento experimental}

Foram utilizados 49 ratos machos com 5 semanas de idade pesando 132,3 \pm $7,6 \mathrm{~g}$ da linhagem Wistar Hannover (Rattus norvegicus, variedade Albinus Rodentia), provenientes do Biotério de Criação e Experimentação da Faculdade de Ciências Farmacêuticas - USP. Durante todo o período os animais permaneceram acondicionados em gaiolas individuais de aço inoxidável, em ambiente com temperatura de $22-24^{\circ} \mathrm{C}$, umidade relativa de $55 \pm 10 \%$ e iluminação apropriada com ciclo claro/escuro de $12 \mathrm{~h}$ tendo livre acesso ao consumo de ração e água. Preliminarmente, todos os grupos receberam uma dieta controle (AIN93M) conforme proposta por REEVES, NIELSEN e FAHEY (1993), durante o período de aclimatação de 1 dia. O protocolo experimental foi aprovado pelo Comitê de Ética da Faculdade de Ciências Farmacêuticas (Anexo 4).

Os animais foram divididos em 4 grupos experimentais. Um dos grupos $(n=7)$ foi sacrificado no primeiro dia para obtenção dos dados basais (baseline). Os outros três grupos ( $n=14$ em cada grupo) receberam a ração CONTROLE e as rações experimentais (SO e FO) durante vinte e um dias, sendo que no $11^{\circ} \mathrm{dia}, 7$ animais de cada um dos grupos (CONTROLE, SO e FO) foram sacrificados. Os outros animais continuaram recebendo as respectivas rações até completarem os vinte e um dias, quando também foram sacrificados. O acompanhamento de ganho de peso, consumo da dieta e volume de fezes foi realizado a cada dois dias. A Figura 12 apresenta um esquema simplificado do delineamento experimental. 


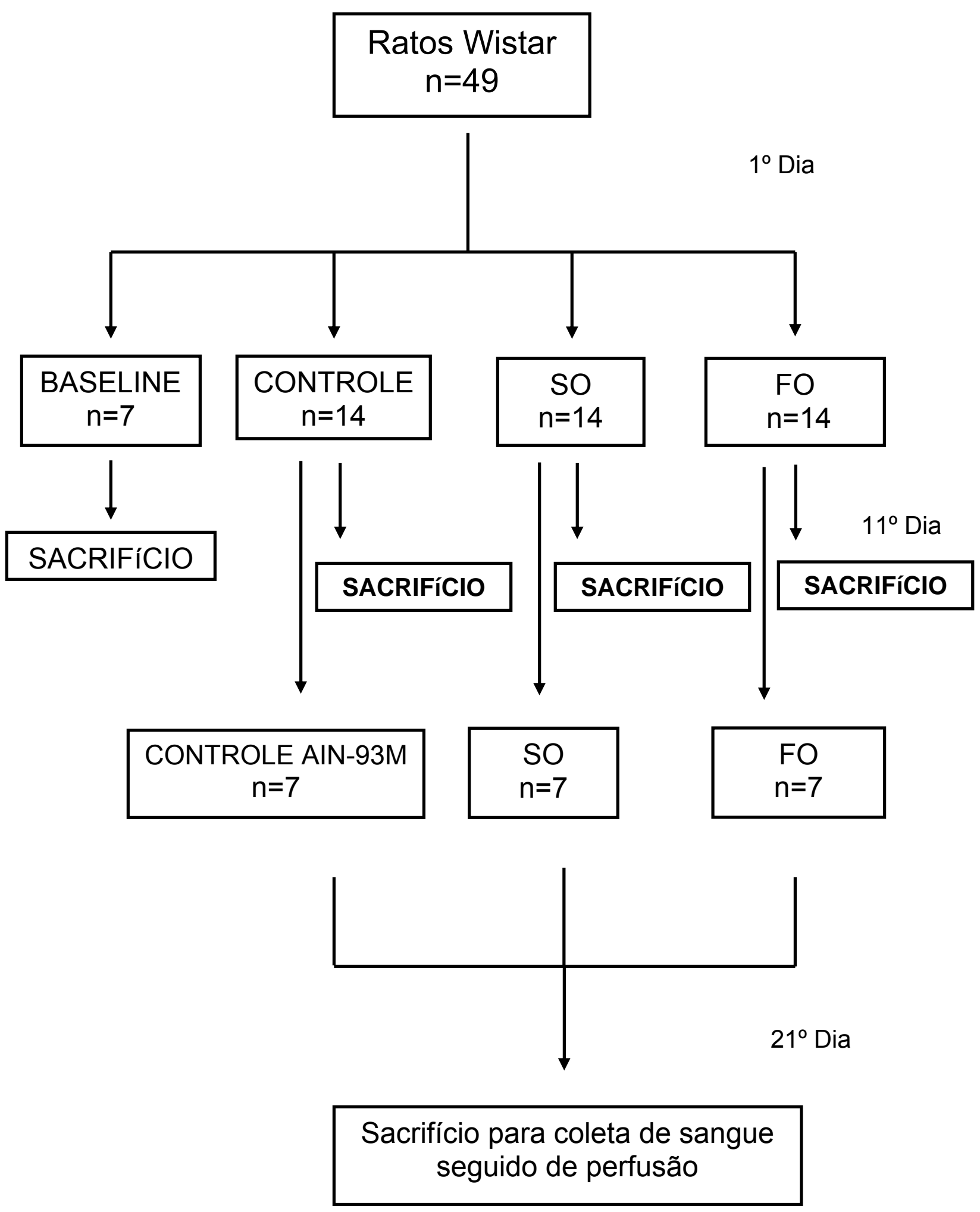

Figura 12. Delineamento experimental utilizado no modelo animal 


\subsubsection{Preparo das rações utilizadas no modelo animal}

As rações foram preparadas com o auxílio de um homogeneizador em " $Y$ " (MARCONI) modelo MA-201/5MO, onde os ingredientes pertencentes a cada ração foram misturados durante 15 minutos. A ração CONTROLE (AIN93M) foi preparada conforme proposto por REEVES, NIELSEN e FAHEY (1993), e as rações SO (Soybean oil) e FO (Fish oil), além dos ingredientes básicos, variavam de acordo com a quantidade de óleo de soja e a presença de Dry n-3 ${ }^{\circledR}$ respectivamente com relação à ração CONTROLE (Tabela 2).

Tabela 2. Formulação das rações (g/100g).

\begin{tabular}{|c|c|c|c|}
\hline NUTRIENTES $^{1}$ & CONTROLE $^{2}$ & So & FO \\
\hline Caseína & 14,00 & 14,00 & 11,00 \\
\hline DL Metionina & 0,18 & 0,18 & 0,18 \\
\hline Amido de Milho & 46,57 & 42,57 & 33,57 \\
\hline Dextrina & 15,50 & 15,50 & 15,50 \\
\hline Sacarose & 10,00 & 10,00 & 10,00 \\
\hline Mix-Vitamínico & 1,00 & 1,00 & 1,00 \\
\hline Mix-Mineral & 3,50 & 3,50 & 3,50 \\
\hline Bitartarato de Colina & 0,25 & 0,25 & 0,25 \\
\hline Celulose & 5,00 & 5,00 & 5,00 \\
\hline Óleo de soja & 4,00 & 8,00 & 4,00 \\
\hline Dry n-3 ${ }^{\circledR 3}$ & - & - & 16,00 \\
\hline TOTAL & 100 & 100 & 100 \\
\hline \multicolumn{4}{|c|}{$\begin{array}{l}1 \text { Caseína (Sigma C7078), DL-Metionina (Sigma M9500), Bitartarato de colina (Sigma C1629), Fibra de } \\
\text { celulose média (Sigma C6288), Amido de milho e Dextrina (Corn Products Brasil Ing. Ind. Ltda.), Mix de } \\
\text { Vitaminas e Minerais (Rhoster Indústria e Comércio Ltda.) e Óleo de soja (Cargill Agrícola S/A) de } \\
\text { acordo com REEVES, NIELSEN e FAHEY (1993) para animais adultos. } \\
{ }^{2} \text { CONTROLE: AIN-93M (REEVES, NIELSEN e FAHEY, 1993). } \\
{ }^{3} \text { Dry n-3 }{ }^{\circledR}: \text { BASF Health and Nutrition, contendo } 25 \% \text { de lipídios, sendo aproximadamente } 18 \% \text { EPA, } 12 \% \\
\text { DHA e } 5 \% \text { de outros ácidos graxos polinsaturados Omega-3 e } 20,83 \% \text { de proteína (gelatina). } \\
\text { Informações cedidas pelo fabricante. }\end{array}$} \\
\hline
\end{tabular}


A fração lipídica das rações foi alterada em relação ao recomendado (AIN-93M) que é de $4 \mathrm{~g} / 100 \mathrm{~g}$ para $8 \mathrm{~g} / 100 \mathrm{~g}$ nas rações SO e FO. Consequentemente alterou-se a quantidade de amido para que o total energético fosse o mesmo nas três rações e a caseína foi reduzida de 14,0 g no grupo do SO para $11,0 \mathrm{~g}$ no grupo $\mathrm{FO}$ em função da gelatina utilizada no microencapsulamento do Dry $n-3^{\circledR}$ mantendo assim as rações isoprotéicas. Essa redução não limitou a oferta de aminoácidos essenciais aos animais: 96\% Treonina, 117\% Valina, 107\% Isoleucina, 138\% Leucina, 131\% Lisina, 89\% Triptofano, 123\% Metionina + Cistina e $141 \%$ Fenilalanina + Tirosina, calculados de acordo com SARWAR et al., (2000).

\subsection{Métodos: Formulação láctea e rações}

\subsubsection{Determinação da composição centesimal da formulação láctea e das rações}

\section{Determinação da umidade}

A determinação de umidade da amostra foi obtida através do método gravimétrico de secagem em estufa a $105^{\circ} \mathrm{C}$ (AOAC, 1995), que é baseado na perda de peso da amostra submetida ao aquecimento sucessivo em estufa a $105^{\circ} \mathrm{C}$ até a obtenção de peso constante. A análise foi realizada em triplicata e os resultados expressos em $\mathrm{g} / 100 \mathrm{~g}$ de amostra.

\section{Determinação de lipídios totais}

Os lipídios totais foram determinados pelo método de Soxhlet (AOAC, 1995). A análise foi realizada em triplicata e os resultados expressos em $\mathrm{g} / 100 \mathrm{~g}$ de amostra. Uma vez que os lipídios presentes no composto Dry $n-3^{\circledR}$ não são extraídos com éter etílico a proporção do mesmo foi computado no cálculo total com base em informações descritas pelo fabricante, somando-se 2,5 g/100 g nos valores obtidos pelo método de Soxhlet. 


\section{Determinação de proteínas totais}

$\mathrm{Na}$ determinação de proteínas totais foi utilizado o método de micro-Kjeldahl (AOAC, 1995), onde o nitrogênio presente na amostra foi convertido em proteína por multiplicação pelo fator 6,25. A análise foi efetuada em triplicata e os resultados expressos em $\mathrm{g} / 100 \mathrm{~g}$ de amostra.

\section{Determinação de fibras}

Os ingredientes usados nas formulações foram analisados pelo método enzimático e gravimétrico (AOAC, 1990) modificado por PROSKY et al., (1985). As amostras em quadruplicata $(1,0 \mathrm{~g})$ foram digeridas em banho-maria a $60^{\circ} \mathrm{C}$ com $\alpha$-amilase $(\mathrm{pH} \mathrm{6,0)}$ ), protease ( $\mathrm{pH} 7,5)$ e amiloglicosidase $(\mathrm{pH} \mathrm{4,3)}$ para remover a proteína e o amido. $\mathrm{O}$ hidrolisado foi filtrado à vácuo em cadinhos com solução do extran e lã de vidro para separar a fração solúvel da insolúvel. Quatro volumes de $98 \%$ de etanol foram adicionados para precipitar a fibra dietética solúvel. O resíduo foi filtrado, lavado com $78 \%$ de etanol, $95 \%$ de etanol e acetona, seco e pesado. Uma duplicata foi analisada para proteína e outra foi incinerada a $525^{\circ} \mathrm{C}$ para a determinação de cinzas.

\section{Determinação de cinzas}

A fração cinzas foi determinada gravimetricamente, com base na perda de peso da amostra submetida ao aquecimento a $550^{\circ} \mathrm{C}$ (AOAC, 1995). A análise foi realizada em triplicata e os resultados expressos em g/100 g de amostra. 


\subsubsection{Caracterização da fração lipídica (formulação láctea e rações) para obtenção do perfil de ácidos graxos}

\section{Obtenção da fração lipídica}

A fração lipídica do composto Dry $n-3^{\circledR}$ e das rações foi obtida segundo o método descrito por BLIGH e DYER (1959). Três gramas da amostra seca foram misturados com $12 \mathrm{~mL}$ de água destilada, e em seguida homogeneizados em vórtex por 4 minutos com uma mistura de solventes composta de $45 \mathrm{~mL}$ de metanol/clorofórmio (2:1). A mistura foi filtrada em funil de Buckner e o filtrado coletado em kitassato. $\mathrm{O}$ resíduo foi homogeneizado novamente com $15 \mathrm{~mL}$ de clorofórmio por 4 minutos. $\mathrm{O}$ filtrado recolhido foi transferido para uma proveta de $100 \mathrm{~mL}$ com tampa esmerilhada e o seu volume aferido para adicionar $1 / 4$ deste volume obtido de $\mathrm{KCl} 0,88 \%$ em água. A fase superior foi desprezada por aspiração à vácuo e a fase inferior filtrada em sulfato de sódio anidro e evaporado em rota-evaporador, com temperatura monitorada a $30^{\circ} \mathrm{C}$. O extrato obtido foi ressuspenso em $5 \mathrm{~mL}$ de clorofórmio para posterior esterificação dos ácidos graxos.

\section{Esterificação, identificação e quantificação dos ácidos graxos por cromatografia a gás}

Os ácidos graxos totais do composto Dry $n-3^{\circledR}$ e das rações foram determinados por cromatografia a gás, conforme descrito por HARTMAN e LAGO (1973).

Para esterificação e posterior análise cromatográfica, foram utilizados $1,5 \mathrm{~mL}$ do extrato obtido através da extração da fração lipídica e evaporado em atmosfera do nitrogênio. Em seguida, foram adicionados $2 \mathrm{~mL}$ de $\mathrm{NaOH}$ metanólico a 0,5 N e a amostra homogeneizada foi mantida em banho-maria fervente por 5 minutos. À amostra fria, foi adicionado $6 \mathrm{~mL}$ da mistura de esterificação (constituída de cloreto de amônio - 51,2 g, metanol - 1.536,0 mL e ácido sulfúrico concentrado $76,8 \mathrm{~mL}$ ), levemente agitada e levada ao banho fervente por mais 3 minutos. Em seguida, a amostra foi esfriada novamente, adicionados $5 \mathrm{~mL}$ de solução saturada de cloreto de sódio e agitada levemente. A fração dos metil ésteres foi extraída 
com duas porções sucessivas de $2 \mathrm{~mL}$ de $\mathrm{n}$-hexano. $\mathrm{Na}$ fase superior extraída, foram adicionados $5 \mathrm{~mL}$ de solução saturada de cloreto de sódio. Em seguida, a fase superior foi evaporada em atmosfera de nitrogênio e ressuspensa em $0,5 \mathrm{~mL}$ de hexano grau HPLC para a determinação dos ácidos graxos por cromatografia a gás.

A identificação foi realizada em um cromatógrafo a gás SHIMADZU, GC-17A, equipado com uma coluna capilar (Supelcowax: Supelco, Bellefonte, PA, USA) fundida de silicone com $30 \mathrm{~m}$ de comprimento e $0,25 \mathrm{~mm}$ de diâmetro interno e um detector de ionização em chama. Hélio foi usado como gás de arraste $(1 \mathrm{~mL} / \mathrm{min})$ e os ácidos graxos foram separados usando um gradiente de 80 a $150^{\circ} \mathrm{C}\left(10^{\circ} \mathrm{C} / \mathrm{min}\right)$, com um acréscimo de $6^{\circ} \mathrm{C} / \mathrm{min}$ até atingir $230^{\circ} \mathrm{C}$, permanecendo nesta temperatura por 30 minutos. A temperatura da câmara injetora e do detector foi de $250^{\circ} \mathrm{C}$. Os ácidos graxos foram identificados pelas áreas de pico relativo à área de pico da mistura padrão de trinta e sete ésteres metílicos de ácidos graxos (Sigma Chemical Co.) complementados com uma mistura padrão "n-3 PUFA" contendo dezenove componentes (Supelco, Inc). Os resultados foram expressos em $\%$ do total de ácidos graxos presentes. A composição de ácidos graxos das formulações consumidas no modelo humano foi estimada a partir da análise cromatográfica do composto Dry $n-3^{\circledR}$ e da proporção de ácidos graxos dos demais ingredientes lipídicos (leite integral, cacau em pó e óleo de soja) obtida através das tabelas USDA (www.nal.usda.gov/fnic/foodcomp). Os valores foram ajustados à concentração de lipídios determinados analiticamente.

\subsubsection{Quantificação do colesterol do Dry n-3 ${ }^{\circledR}$}

A fração do colesterol do produto Dry $n-3^{\circledR}$ foi determinada usando o mesmo equipamento de cromatografia a gás descrito no ítem 4.2.2, com uma coluna capilar fundida de silicone com $30 \mathrm{~m}$ de comprimento e $0,25 \mathrm{~mm}$ de diâmetro interno ( $\mathrm{J}$ e W, Db-5 5\%-Fenil Metilpolisiloxano). As temperaturas do injetor e do detector foram de $300^{\circ} \mathrm{C}$. Hélio foi usado como gás de arraste $(1 \mathrm{~mL} / \mathrm{min})$ a uma temperatura de $265^{\circ} \mathrm{C}$ por 20 minutos. 
As amostras foram preparadas de acordo com o método proposto por NAEEMl et al., (1995), onde um grama da amostra foi colocado em um tubo Sorvall com tampa selante, adicionados $25 \mu \mathrm{L}$ da solução $5 \alpha$-colestane (C8003 Sigma) e $5 \mathrm{~mL}$ da solução saturada metanólica de $\mathrm{KOH}$ e levada em banho-maria à $80^{\circ} \mathrm{C}$ por 30 minutos. À solução fria foram adicionados $5 \mathrm{~mL}$ de ciclohexano agitando-se vigorosamente por 1 minuto. Em seguida a solução foi centrifugada em centrífuga (SORVAL Instrument modelo RC 5C) a $15.000 \mathrm{rpm}$ por 15 minutos e $1 \mu \mathrm{L}$ da fase superior foi injetada no cromatógrafo.

\subsubsection{Determinação de $\alpha$-tocoferol no composto Dry $n-3^{\circledR}$}

A determinação de $\alpha$-tocoferol no composto Dry $n-3^{\circledR}$ foi realizada em HPLC conforme descrito por PRESOTO, RIOS E ALMEIDA-MURADIAN (2000), com algumas modificações.

Inicialmente, foram pesados cinco gramas da amostra em tubo de ensaio de $50 \mathrm{~mL}$ com tampa de rosca seguido de saponificação com $20 \mathrm{~mL}$ de $\mathrm{KOH}$ aquoso (1:1) durante uma noite em local protegido de luz. A extração ocorreu através da adição de $20 \mathrm{~mL}$ de acetona e agitação vigorosa manual durante 1 minuto. Em seguida a mistura foi submetida à filtração à vácuo em filtro de vidro sinterizado. Este processo foi repetido quatro vezes sendo o filtrado transferido para um funil de separação contendo éter de petróleo (P.E. $30^{\circ}-60^{\circ} \mathrm{C}$ ). A solução foi lavada cinco vezes com água destilada para completa remoção da acetona. O extrato etéreo foi recolhido, seco com sulfato de sódio anidro, filtrado e concentrado em rotaevaporador a vácuo sob temperatura de $35^{\circ} \mathrm{C}$. O resíduo obtido, contendo $\alpha$-tocoferol, foi totalmente evaporado em atmosfera de nitrogênio, ressuspenso em $5 \mathrm{~mL}$ da fase móvel composta por $\mathrm{n}$-hexano e isopropanol (98:2), filtrado em membrana Millipore de porosidade 0,22 $\mu \mathrm{m}$ e injetado no cromatógrafo. 


\section{Identificação e quantificação por cromatografia líquida}

A identificação foi realizada em HPLC da marca SHIMADZU composto por um injetor manual e um detector de fluorescência (RF-10AXL), programado para $295 \mathrm{~nm}$ de excitação e $330 \mathrm{~nm}$ de emissão. A separação foi realizada em coluna de sílica Shim-pack CLC-Sil (M) $25 \mathrm{~cm}$ utilizando fase móvel, previamente filtrada e degaseificada, composta de n-hexano e isopropanol (98:2) com fluxo de $1,5 \mathrm{~mL} /$ minuto. O tempo de corrida foi de 10 minutos e o volume de injeção foi de $20 \mu \mathrm{L}$ de amostra. $\mathrm{O} \alpha$-tocoferol foi identificado por comparação do tempo de retenção do padrão sintético ( $\alpha$-tocoferol T3251 - Sigma) e a quantificação realizada através de padronização externa, por comparação das áreas dos picos da amostra e do padrão. As análises foram realizadas em triplicata e o resultado expresso com $\mathrm{mg}$ de $\alpha$-tocoferol / $\mathrm{g}$ de óleo de peixe.

\subsubsection{Determinação de ácido ascórbico no composto Dry n-3 ${ }^{\circledR}$}

Os ácidos ascórbico e desidroascórbico foram determinados conforme descrito por PASTERNAK et al., (2005) com modificações. Este método baseia-se na separação por polaridade de compostos em fase reversa (fase móvel mais polar que fase estacionária).

O procedimento iniciou-se com a obtenção de um grama da amostra que foi homogeneizado com solução a $3 \%$ de ácido metafosfórico em proporção apropriada durante 1 minuto em homogeneizador por esmagamento (Potter). $\mathrm{O}$ homogenato foi centrifugado em centrífuga (SORVAL Instrument modelo RC $5 \mathrm{C}$ ) a $12.000 \times \mathrm{g}$ por 10 minutos a $4^{\circ} \mathrm{C}$, o volume do sobrenadante foi medido e $\mathrm{O}$ precipitado desprezado. O sobrenadante foi filtrado através de uma membrana Millipore de porosidade $0,45 \mu \mathrm{m}$. Para a determinação do ácido ascórbico reduzido, um "vial" foi preparado com $250 \mu \mathrm{L}$ da amostra filtrada, adicionado de $250 \mu \mathrm{L}$ de ácido metafosfórico a $3 \%$ e $500 \mu \mathrm{L}$ da fase móvel $(\mathrm{KCl} 2 \mathrm{mM}, \mathrm{pH} 2,5)$. Para a determinação do ácido ascórbico total, outro "vial" foi preparado com $250 \mu \mathrm{L}$ da amostra filtrada adicionado de $250 \mu \mathrm{L}$ de ditiotreitol (DTT) e após 30 minutos adicionou-se $500 \mu \mathrm{L}$ da fase móvel $(\mathrm{KCl} 2 \mathrm{mM}, \mathrm{pH} 2,5)$. O conteúdo de 
ácido desidroascórbico foi determinado pela diferença entre o conteúdo de ácido ascórbico reduzido e o conteúdo de ácido ascórbico total.

\section{Identificação e quantificação por cromatografia líquida}

Os extratos foram analisados em HPLC da marca HP equipado com coluna

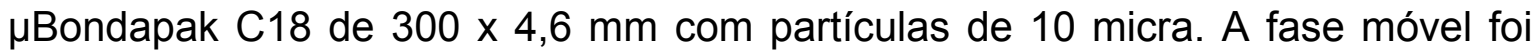
$\mathrm{KCl} 2 \mathrm{mM} \mathrm{pH} \mathrm{2,5} \mathrm{(acertado} \mathrm{com} \mathrm{ácido} \mathrm{metafosfórico).} \mathrm{O} \mathrm{volume} \mathrm{de} \mathrm{injeção} \mathrm{foi} \mathrm{de}$ $10 \mu \mathrm{L}$ e a temperatura da coluna de $35^{\circ} \mathrm{C}$. A taxa de fluxo de $0,8 \mathrm{~mL} /$ minuto e o tempo de corrida de 6 minutos para a separação do ácido ascórbico reduzido e de 8 minutos para separação de ácido ascórbico total. A detecção realizada por UV a $245 \mathrm{~nm}$. A curva padrão foi obtida com ácido ascórbico reduzido (padrão Sigma, grau de pureza de 98,9\%) em concentrações variando entre 0,005 a $0,200 \mathrm{mg}$, nas mesmas condições descritas. As determinações foram realizadas em triplicata e o resultado expresso em $\mathrm{mg}$ de ácido ascórbico / g de óleo de peixe.

\subsection{Métodos: Amostras biológicas}

\subsubsection{Determinações antropométricas}

Foram realizadas avaliações antropométricas, através de medidas de peso e altura. O peso corpóreo foi medido em uma balança digital com sensibilidade de 100g. A altura foi verificada com estadiômetro e a circunferência da cintura foi medida com fita métrica flexível com precisão de $1 \mathrm{~mm}$, colocada horizontalmente no ponto médio entre a borda inferior da última costela e a crista ilíaca, sendo ambas as medidas expressas em "cm". O índice de massa corporal (IMC) foi obtido pelo cálculo do peso corporal dividido pelo quadrado da altura $\left(\mathrm{kg} / \mathrm{m}^{2}\right)$, determinados para cada indivíduo antes e depois do experimento. 


\subsubsection{Composição da dieta}

O cálculo nutricional da dieta de cada indivíduo foi realizado através do registro alimentar de 3 dias (2 dias da semana e 1 dia do final de semana). A composição dos nutrientes da dieta foi obtida através do rótulo de alguns produtos locais e da tabela da "USDA" (www.nal.usda.gov/fnic/foodcomp).

\subsubsection{Coleta de sangue}

Amostras de sangue dos indivíduos foram obtidas após $12 \mathrm{~h}$ de jejum no início (baseline) e após 6 semanas de intervenção. O sangue foi coletado com seringas e transferido para tubos Vacutainer (Becton Dickinson, $N J$ ), que continham $1 \% \mathrm{~K}_{2}$ EDTA $(5 \mathrm{~mL})$, tubos vazios $(10 \mathrm{~mL}$ ) e para tubos com $7,5 \mathrm{mg}$ $\mathrm{NaF}+15 \mathrm{mg} \mathrm{Na}{ }_{2}$ EDTA $(5 \mathrm{~mL}$ ). As amostras foram imediatamente centrifugadas a $4.000 \mathrm{rpm}$ por 10 minutos para separar plasma e soro. O soro foi usado imediatamente para determinar as concentrações de colesterol total (CT), HDL e triacilgliceróis $(T G)$. As concentrações de $L D L$ foram calculadas usando a fórmula de FRIEDEWALD, LEVY e FREDRICKSON (1972). O plasma foi coletado em tubos contendo $\mathrm{NaF}$ e usado para a determinação de glicose enquanto que as amostras do plasma ( $\mathrm{K}_{2} \mathrm{EDTA}$ ) foram imediatamente congeladas sob o nitrogênio líquido e armazenadas a $-80^{\circ} \mathrm{C}$ para as análises dos ácidos graxos e biomarcadores do estresse oxidativo.

A coleta de sangue dos animais ocorreu no primeiro dia (baseline) e ao final do ensaio. Cada animal foi previamente anestesiado para a coleta sangüínea com um $1 \mathrm{~mL}$ de uma mistura composta por $4,5 \mathrm{~mL}$ de cloridrato de xilazina a $2 \%$, $4,5 \mathrm{~mL}$ de cloridrato de cetamina a $10 \%$ e $1,8 \mathrm{~mL}$ de acepromazina a $0,2 \%$ diluídos em $7,2 \mathrm{~mL}$ de água destilada. A coleta foi feita por punção na veia cava inferior. $O$ sangue foi coletado em seringas e transferido para tubos Vacutainer (Becton Dickinson, $\mathrm{NJ}$ ) que continham $\mathrm{K}_{2} \operatorname{EDTA}(5 \mathrm{~mL}$ ) para obtenção do plasma e tubos sem anticoagulante para obtenção do soro. Os tubos foram centrifugados (centrífuga SORVAL Instrument, modelo RC-5C) a 4.000 rpm por 10 minutos. O plasma e o soro foram congelados imediatamente em nitrogênio líquido e 
armazenados em tubos de eppendorff devidamente identificados, a temperatura de $-80^{\circ} \mathrm{C}$ para análises posteriores.

\subsubsection{Medidas das variáveis bioquímicas}

Foram utilizados os métodos colorimétricos enzimáticos da Labtest Diagnostica SA (Lagoa Santa, MG) para a determinação do colesterol sérico (Liquiform Cat.76 colesterol esterase, colesterol oxidase e peroxidase), da HDL (Cat.13, pela precipitação com ácido fototungstênio e $\mathrm{MgCl}_{2}$ ) e das concentrações de TG (GPO-ANA, Cat. 59 pelo glicerol 3-fosfato oxidase). A análise de glicose plasmática foi realizada usando glicose oxidase automática GOD Trinder colorimétrico (Glicose PAP Liquiform). O valor das leituras foi determinado usando um espectrofotômetro da Micronal B-380 (São Paulo).

\subsubsection{Caracterização do perfil de ácidos graxos no plasma}

A fração lipídica foi extraída do plasma de acordo com FOLCH, LEES e SLOANG STANLEY (1957), onde $1 \mathrm{~mL}$ do plasma foi homogeneizado com $10 \mathrm{~mL}$ de metanol durante 2 minutos. Em seguida, foram adicionados $20 \mathrm{~mL}$ de clorofórmio e homogeneizado por mais 5 minutos. A mistura foi filtrada em funil de Buckner, o filtrado coletado em kitassato e o resíduo lavado com $30 \mathrm{~mL}$ de clorofórmio/metanol (2:1). O filtrado recolhido foi transferido para uma proveta de $100 \mathrm{~mL}$ com tampa esmerilhada e o seu volume aferido para adicionar $1 / 4$ deste volume obtido de $\mathrm{KCl}$ 0,88\% em água. A fase superior foi desprezada por aspiração à vácuo e a fase inferior filtrada em sulfato de sódio anidro e evaporado em rota-evaporador, com temperatura monitorada a $30^{\circ} \mathrm{C}$. O extrato obtido foi ressuspenso em 2,5 mL de clorofórmio para posterior esterificação dos ácidos graxos. 


\section{Esterificação, identificação e quantificação dos ácidos graxos no plasma por cromatografia a gás}

Os ácidos graxos do plasma foram determinados por cromatografia a gás, conforme descrito por HARTMAN e LAGO (1973).

Para esterificação e posterior análise cromatográfica, foram utilizados $2,0 \mathrm{~mL}$ do extrato obtido através da extração da fração lipídica e evaporado em atmosfera de nitrogênio. Em seguida, foram adicionados $0,5 \mathrm{~mL}$ de $\mathrm{NaOH}$ metanólico a $0,5 \mathrm{~N}$, a amostra foi homogeneizada e mantida em banho-maria fervente por 5 minutos. À amostra fria, foi adicionado $1,5 \mathrm{~mL}$ da mistura de esterificação (composta por cloreto de amônio, metanol e ácido sulfúrico), levemente agitada e levada ao banho fervente por mais 3 minutos. Em seguida, à amostra fria foram adicionados $1,5 \mathrm{~mL}$ da solução saturada de cloreto de sódio e agitado levemente. A fração dos metil ésteres foi extraída com duas porções sucessivas de $0,5 \mathrm{~mL}$ de hexano (grau HPLC). $\mathrm{Na}$ fase superior extraída, foram adicionados $1 \mathrm{~mL}$ de solução saturada de cloreto de sódio. Em seguida, a fase superior foi evaporada em atmosfera de nitrogênio e ressuspenso em $120 \mu \mathrm{L}$ de hexano (grau HPLC) para a determinação dos ácidos graxos por cromatografia a gás.

A composição de ácidos graxos foi determinada em um cromatógrafo a gás SHIMADZU, GC-17A, equipado com uma coluna capilar Supelcowax 10 de $30 \mathrm{~m}$ de comprimento e $0,25 \mathrm{~mm}$ de diâmetro interno. Hélio foi utilizado como gás de arraste, com fluxo de $1 \mathrm{~mL} / \mathrm{min}$. As temperaturas do injetor e do detector eram $250^{\circ} \mathrm{C}$ e $270^{\circ} \mathrm{C}$, respectivamente. A programação de temperatura da coluna foi de $170^{\circ} \mathrm{C}$ inicial com um acréscimo de $1^{\circ} \mathrm{C} / \mathrm{min}$, até atingir um platô de $225^{\circ} \mathrm{C}$, permanecendo nesta temperatura por 10 minutos. Uma mistura padrão de trinta e sete ésteres metil de ácidos graxos (Sigma Chemical Co.) complementados com uma mistura padrão de "n-3 PUFA" contendo dezenove componentes (Supelco, Inc) foi usada para identificar os picos. Os resultados foram expressos como \% do total de ácidos graxos presentes na amostra. 


\subsubsection{Avaliação da lipoperoxidação de homogenato de cérebro}

Após a coleta de sangue, os animais foram perfundidos com $240 \mathrm{~mL}$ de solução de $\mathrm{NaCl} 0,9 \%$ à de $5^{\circ} \mathrm{C}$. O cérebro de cada animal foi imediatamente removido, pesado, cortado em pequenos pedaços e homogeneizado com 4 volumes de solução tampão fosfato de sódio $(\mathrm{pH} 7,4)$ por dois minutos em um homogeneizador (MARCONI, modelo MA-099), sendo em seguida centrifugados (centrífuga HITACHI modelo CF-15R) a $4.000 \mathrm{rpm}$ por 15 minutos a $4^{\circ} \mathrm{C}$. O sobrenadante foi armazenado em tubos de eppendorff, congelado imediatamente em nitrogênio líquido e mantido à $-80^{\circ} \mathrm{C}$ para posterior análise.

\section{Determinação das substâncias reativas ao ácido tiobarbitúrico (TBARS) nas amostras de homogenato de cérebro}

As determinações foram realizadas de acordo com STOCKS et al., (1974), na qual alíquotas de $1 \mathrm{~mL}$ do sobrenadante (homogenato) e $3 \mathrm{~mL}$ de solução tampão fosfato de sódio $(\mathrm{pH} 7,4)$ foram colocadas em tubos de ensaio com tampa de rosca e agitados no vórtex por 15 segundos. Em seguida um dos tubos foi colocado em banho-maria a $37^{\circ} \mathrm{C}$ com agitação de 1 minuto a cada 10 minutos e o outro tubo na geladeira, ambos pelo período de $1 \mathrm{~h}$. Após retirar do banho e da geladeira, foram adicionados a cada tubo $1 \mathrm{~mL}$ de solução composta de $3,75 \mathrm{~g}$ de TCA (ácido tricloroacético), 93,75 mg de TBA (ácido tiobarbitúrico) e 5,0 mg BHT (hidroxitolueno butilado) diluídas em $25 \mathrm{~mL}$ de $\mathrm{HCl} 0,25 \mathrm{~N}$. Em seguida foram novamente agitados no vórtex durante 15 segundos. Os tubos foram levados ao banho-maria fervente por 15 minutos e depois resfriados em gelo para então serem centrifugados a $3.000 \mathrm{rpm}$ por 15 minutos. O sobrenadante foi utilizado para realizar a leitura da absorbância em espectrofotômetro da marca SHIMADZU, modelo UVmini1240, em comprimento de onda de $532 \mathrm{~nm}$. As determinações foram realizadas em duplicata.

Para a quantificação das substâncias reativas ao ácido tiobarbitúrico (TBARS), foi usado TEP (1,1,3,3 - tetraetoxipropano) para elaboração da curva padrão. Pesou-se 22,03 mg de TEP que foi diluído em $10 \mathrm{~mL}$ de $\mathrm{HCl} 0,1 \mathrm{~N}$, e levado ao banho fervente em tubo com tampa de rosca por 5 minutos, em seguida 
transferido para um balão volumétrico de $1 \mathrm{~L}$ e o volume completado com água destilada. Foram utilizadas $1 \mathrm{~mL}$ de solução contendo TCA/TBA/BHT e concentrações de TEP de $0 \mu \mathrm{L}$ a $250 \mu \mathrm{L}$ com intervalos de $50 \mu \mathrm{L}$ entre elas

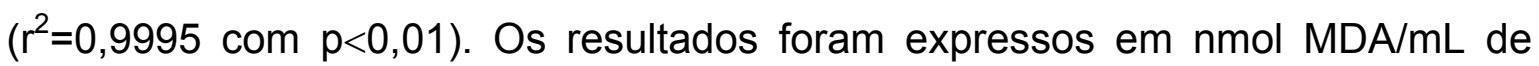
homogenato.

\section{Quantificação da concentração de proteína nas amostras de homogenato}

Para a determinação da concentração de proteína nas amostras de homogenato de cérebro, foi empregado o método LOWRY et al., (1951), na qual uma alíquota de $50 \mu \mathrm{L}$ do homogenato foi tomada e completada para $1 \mathrm{~mL}$ com água destilada, acrescentou-se $2,5 \mathrm{~mL}$ de mistura alcalina em tubo de ensaio, em seguida o tubo foi agitado em vórtex. Após 5 minutos foi acrescentado $300 \mu \mathrm{L}$ de reagente de Follin Ciocalteau e agitado em vórtex. A leitura em espectrofotômetro foi realizada a $660 \mathrm{~nm}$ após 30 minutos. A determinação foi realizada em triplicata e um branco foi preparado com $1 \mathrm{~mL}$ de água destilada. BSA (albumina bovina sérica) obtido da SIGMA código A7906 foi utilizada como padrão ( $r^{2}=0,9899$ com $\mathrm{p}<0,01)$. Os resultados foram expressos em $\mathrm{mg}$ de proteína por $\mathrm{mL}$ de homogenato. Desta forma os resultados de TBARS puderam ser expressos como nmol MDA / mg de proteína.

\subsubsection{Avaliação da lipoperoxidação do plasma (TBARS)}

O plasma foi analisado de acordo com a metodologia descrita por WINTERBOURN, GUTTERIDGE e HALLIWELL (1985) com modificações. Alíquotas de $500 \mu \mathrm{L}$ de plasma foram transferidos para tubos com tampa de rosca e em seguida acrescentou-se $500 \mu \mathrm{L}$ de $\mathrm{HCl} 25 \%(\mathrm{v} / \mathrm{v}), 45 \mu \mathrm{L}$ de BHT a $2 \%(\mathrm{p} / \mathrm{v})$ em etanol e $500 \mu \mathrm{L}$ de TBA $1 \%$ (p/v) em NaOH 0,05M. A mistura foi agitada em vórtex e os tubos foram levados em banho-maria fervente por 10 minutos. Em seguida, os tubos foram resfriados em gelo e acrescentou-se 1,5 $\mathrm{mL}$ de álcool n-butílico. A mistura foi centrifugada a $4.000 \mathrm{rpm}$ à temperatura de $20^{\circ} \mathrm{C}$ por 10 
minutos. Finalmente, tomou-se o sobrenadante para ser realizada a leitura da absorbância em comprimento de onda a $532 \mathrm{~nm}$. Neste ensaio, TEP foi utilizado para elaboração da curva padrão. Os resultados foram expressos como $\mu \mathrm{Mol}$ MDA/L de plasma.

\subsubsection{Determinação da capacidade antioxidante do plasma pelo método do DPPH}

O procedimento foi baseado no método descrito por BRAND-WILLIAMS, CUVELIER e BERSET (1995) na qual uma alíquota de $1,25 \mathrm{mg}$ de DPPH que foi diluída em $100 \mathrm{~mL}$ de etanol, mantida sob refrigeração e protegida da luz. Em tubos apropriados para centrífuga foram adicionados $3,9 \mathrm{~mL}$ da solução de DPPH e em seguida acrescentou-se $100 \mu \mathrm{L}$ do plasma. Os tubos foram agitados no vórtex e deixados em repouso por 30 minutos. Em seguida foram centrifugados a $10.000 \mathrm{rpm}$ à temperatura de $20^{\circ} \mathrm{C}$ por 15 minutos e o sobrenadante utilizado para a realização da leitura em espectrofotômetro a $515 \mathrm{~nm}$. Os resultados foram expressos como atividade antioxidante (\%), onde

$$
\mathrm{AOA}=100-\left[\frac{\left[\mathrm{DPPH}_{\mathrm{R}}\right]_{\mathrm{t}}}{\left[\mathrm{DPPH}_{\mathrm{R}}^{-}\right]_{\mathrm{B}}} \cdot 100\right]
$$

sendo $\left[\mathrm{DPPH}_{\mathrm{R}}^{*}\right]_{\mathrm{t}}$ e $\left[\mathrm{DPPH}_{\mathrm{R}}^{\circ}\right]_{\mathrm{B}}$ a concentração de $\mathrm{DPPH}^{\circ}$ remanescente após 30 minutos, avaliadas na amostra (t) e no branco (B) preparado com água destilada. 


\subsubsection{Análises de $\alpha$-tocoferol no plasma}

As concentrações de $\alpha$-tocoferol plasmático foram medidas por cromatografia líquida de alta eficiência (HPLC) com detecção UV-Vis ( $\lambda=285 \mathrm{~nm}$ ), de acordo com o método proposto por Wang e Huang (2002). O $\alpha$-tocoferol foi extraído do plasma $(0,7-2,5 \mathrm{~mL})$ através da mistura com acetato de etila $(1 \mathrm{~mL}) \mathrm{e}$ hexano (3 mL) em um agitador vórtex. Em seguida, $10 \mathrm{~mL}$ da fase móvel foram adicionados à mistura e a mesma foi filtrada. O sobrenadante foi separado após a centrifugação $\left(3.000 \mathrm{rpm}, 10\right.$ minutos, $\left.25^{\circ} \mathrm{C}\right)$, sendo a camada superior evaporada sob atmosfera de nitrogênio. Após a evaporação dos extratos combinados, o resíduo foi reconstituído com metanol $(50 \mu \mathrm{L})$ e analisado em cromatógrafo líquido (Hewlett-Packard, sistema equipado com um detector diodo da Série HP). O software ChemStation HP foi usado para a integração do pico e para os cálculos. As amostras $(20 \mu \mathrm{L})$ foram injetadas $\left(10^{\circ} \mathrm{C}\right)$ e isocraticamente eluídas (taxa de fluxo: 1,0 $\mathrm{mL} / \mathrm{min})$ com a fase móvel metanol-água (90:10, v/v). Uma coluna C18

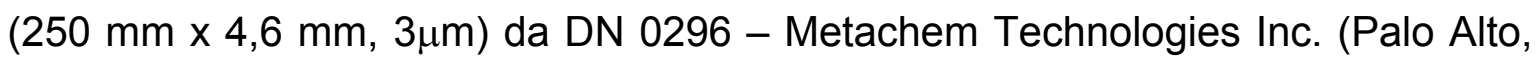
CA) foi usada para separar os compostos. Os dados foram expressos em $\mathrm{ng} / \mathrm{mL}$ de plasma.

\subsection{Análise estatística}

Inicialmente todos os resultados foram submetidos a testes de homogeneidade de variâncias (Hartley, Cochran e Bartlett). Diferenças entre os grupos PLACEBO e OMEGA no ensaio com humanos foram identificadas através de teste $\mathrm{t}$ para variáveis independentes. Análise de Variância para Medidas Repetidas (ANOVA) seguida de teste post-hoc Tukey HSD foi utilizada para comparar os resultados dos dois grupos antes e depois da intervenção. No ensaio com animais, diferenças entre os três grupos experimentais (CONTROLE, SO e FO) foram avaliadas através de ANOVA univariada seguida de teste post-hoc Tukey HSD. Análise de variância para medidas repetidas também foi aplicada para comparar os valores entre os grupos antes e depois da intervenção. Um valor $\alpha$ de 0,05 foi adotado neste estudo. Análise multivariada de correspondência 
múltipla foi aplicada no ensaio realizado com o modelo humano. Variáveis numéricas foram categorizadas considerando-se:

- Idade: maior ou menor de 30 anos

- Circunferência da cintura: maior ou menor que $75 \mathrm{~cm}$

- TG: $\quad$ elevado $=\geq 200 \mathrm{mg} / \mathrm{dL}$

$$
\text { normal }=<200 \mathrm{mg} / \mathrm{dL}
$$

- LDL: $\quad$ elevado $=\geq 160 \mathrm{mg} / \mathrm{dL}$

normal $=<160 \mathrm{mg} / \mathrm{dL}$

- HDL: $\quad$ baixo $=<40 \mathrm{mg} / \mathrm{dL}$

normal $=\geq 40 \mathrm{mg} / \mathrm{dL}$

- Glicemia: elevada $=\geq 110 \mathrm{mg} / \mathrm{dL}$ normal $=70$ a $110 \mathrm{mg} / \mathrm{dL}$

As demais variáveis categóricas foram descritas como:

- Sexo $\rightarrow$ feminino / masculino

- Tabagismo $\rightarrow$ presente / ausente

- Exercício físico $\rightarrow$ sedentário / praticante (suave, moderado ou intenso)

- Consumo de álcool $\rightarrow$ presente / ausente

- Pressão arterial $\rightarrow$ elevada / normal

- Reposição hormonal $\rightarrow$ presente / ausente

Indivíduos pertencentes aos dois grupos OMEGA e PLACEBO $(n=36)$ foram agrupados de acordo com 9 variáveis ativas. Tabagismo, consumo de bebida alcoólica e reposição hormonal não foram consideradas nessa análise em função do número reduzido de casos positivos, 3, 1 e 2 respectivamente. A classificação OMEGA e PLACEBO foi adotada como variável suplementar, usada para identificação do efeito do tratamento. Cálculos e gráficos foram elaborados utilizando-se o software estatístico Statistica versão 7.1 (Statisoft South América, Tulsa, OK). 


\section{RESULTADOS}

\subsection{Determinações na formulação láctea utilizada no modelo humano}

\subsubsection{Composição nutricional da formulação láctea}

A composição química aproximada da formulação experimental à base de leite está apresentada na Tabela 3.

Tabela 3. Composição química das duas formulações lácteas.

\begin{tabular}{|c|c|c|c|}
\hline NUTRIENTES $^{1}$ & PLACEBO & OMEGA & $\overline{p^{2}}$ \\
\hline Umidade $(\mathrm{g} / 100 \mathrm{~g})$ & $4,9 \pm 0,5$ & $4,6 \pm 0,5$ & 0,250 \\
\hline Proteína $(\mathrm{g} / 100 \mathrm{~g}) \mathrm{N} \times 6,25$ & $27,3 \pm 1,6$ & $26,8 \pm 1,3$ & 0,588 \\
\hline Cinzas (g/100g) & $6,3 \pm 0,1$ & $6,3 \pm 0,1$ & 0,317 \\
\hline Carboidratos $(\mathrm{g} / 100 \mathrm{~g})$ & 50,5 & 45,1 & - \\
\hline Fibras solúveis $(\mathrm{g} / 100 \mathrm{~g})$ & $0,4 \pm 0,0$ & $0,5 \pm 0,1$ & 0,255 \\
\hline Fibras insolúveis $(\mathrm{g} / 100 \mathrm{~g})$ & $2,9 \pm 0,2$ & $8,1 \pm 1,5$ & 0,005 \\
\hline Lipídios (g/100g) & $7,6 \pm 0,6$ & $8,9 \pm 0,9$ & 0,104 \\
\hline Ácidos graxos saturados (\% de lipídios) & 44,5 & 53,5 & - \\
\hline Ácidos graxos monoinsaturados (\% de lipídios) & 28,9 & 29,8 & - \\
\hline Ácidos graxos polinsaturados (\% de lipídios) & 26,5 & 16,7 & - \\
\hline EPA $(g / 100 g)$ & ND & $0,6 \pm 0,0$ & $<0,01$ \\
\hline DHA (g/100g) & ND & $0,4 \pm 0,0$ & $<0,01$ \\
\hline Outros n-3 PUFA (g/100g) & ND & $0,2 \pm 0,0$ & $<0,01$ \\
\hline Colesterol (mg/100g) & $11,4 \pm 1,7$ & $17,1 \pm 2,7$ & $<0,01$ \\
\hline $\mathrm{n}-3$ PUFA total $(\mathrm{g} / 100 \mathrm{~g})$ & ND & $1,2 \pm 0,0$ & $<0,01$ \\
\hline Energia (kcal) & 379,6 & 365,0 & - \\
\hline
\end{tabular}


A formulação OMEGA apresentou uma maior proporção de colesterol, decorrente da presença natural deste composto na gordura de peixes. $O$ conteúdo de fibra insolúvel também apresentou um aumento significativo comparado com o PLACEBO. Isto pode ser devido à presença de alguns ingredientes não descritos usados no encapsulamento do composto Dry n-3 $3^{\circledR}$. Entretanto, essas diferenças podem ser consideradas desprezíveis em relação ao aporte dietético total dos indivíduos.

Os valores observados de suplementação diária de ácidos graxos polinsaturados Omega-3 $(1,2 \mathrm{~g} / 100 \mathrm{~g})$ obtidos a partir da análise cromatográfica dos ácidos graxos (Tabela 3) foram superiores àqueles estimados a partir das informações descritas pelo fabricante do composto (Dry n-3 18,12)1. Essa diferença pode ter ocorrido em função da maior proporção de ácido eicosapentaenóico, docosahexaenóico, $\alpha$-linolênico e docosapentaenóico identificados através da cromatografia e da própria contribuição de ácido $\alpha$-linolênico presente nos demais ingredientes utilizados no preparo das formulações, tais como cacau e leite em pó integral. As concentrações de ácido ascórbico e $\alpha$-tocoferol obtidas através da análise cromatográfica no composto Dry $\mathrm{n}-3$ foram de $204,16 \pm 8,12 \mathrm{mg} / \mathrm{g}$ de óleo e $0,08 \mathrm{mg} \pm 0,01 \mathrm{mg} / \mathrm{g}$ de óleo, respectivamente.

\subsubsection{Medidas antropométricas, concentrações das lipoproteínas séricas, glicose e parâmetros oxidativos}

As variáveis, perfil antropométrico (idade, índice de massa corporal e circunferência da cintura), concentrações séricas de colesterol total, LDL, HDL, TG e glicose em jejum, foram avaliadas neste estudo e estão apresentadas na Tabela 4.

${ }^{1}$ Dry $n-3$ contendo $25 \%$ de lipídios, sendo $35 \%$ destes n-3 PUFA.

Foram adicionados $10 \mathrm{~g}$ de Dry n-3 (0,9 g de n-3 PUFA) em $100 \mathrm{~g}$ de formulação. 
Tabela 4. Medidas antropométricas, concentrações séricas de lipídios e glicose e parâmetros oxidativos plasmáticos obtidos nos indivíduos, antes e depois de seis semanas de intervenção ${ }^{1}$.

\begin{tabular}{|c|c|c|c|c|c|}
\hline & \multicolumn{2}{|c|}{ PLACEBO } & \multicolumn{2}{|c|}{ OMEGA } & \multirow[t]{2}{*}{$p^{2}$} \\
\hline & Início & Após 6 semanas & Início & Após 6 semanas & \\
\hline Peso corporal (kg) & $70,7 \pm 15,0$ & $70,2 \pm 14,8$ & $67,2 \pm 18,8$ & $66,8 \pm 18,5$ & 0,087 \\
\hline Altura (m) & $166,8 \pm 8,7$ & - & $166,5 \pm 8,1$ & - & 0,763 \\
\hline IMC $\left(\mathrm{kg} / \mathrm{m}^{2}\right)$ & $25,2 \pm 4,1$ & $25,2 \pm 4,0$ & $24,1 \pm 6,0$ & $24,0 \pm 5,8$ & 0,078 \\
\hline Circunferência da cintura $(\mathrm{cm})$ & $81,5 \pm 12,5$ & $82,9 \pm 13,2$ & $76,7 \pm 14,3$ & $78,0 \pm 14,8$ & 0,864 \\
\hline Glicose (mg/dL) & $85,2 \pm 13,3$ & $87,7 \pm 11,3$ & $84,2 \pm 10,7$ & $89,2 \pm 13,7$ & 0,561 \\
\hline Colesterol total (mg/dL) & $195,6 \pm 34,9$ & $191,8 \pm 41,2$ & $190,4 \pm 41,3$ & $194,2 \pm 39,3$ & 0,374 \\
\hline LDL (mg/dL) & $132,2 \pm 36,0$ & $126,4 \pm 38,2$ & $125,1 \pm 37,6$ & $120,3 \pm 37,6$ & 0,920 \\
\hline $\mathrm{HDL}(\mathrm{mg} / \mathrm{dL})$ & $45,9 \pm 11,1^{a}$ & $39,1 \pm 7,2^{b}$ & $44,8 \pm 8,7^{\mathrm{ab}}$ & $42,7 \pm 10,5^{\mathrm{ab}}$ & $<0,01$ \\
\hline Triacilglicerol $(\mathrm{mg} / \mathrm{dL})^{3}$ & $75,8 \pm 11,9^{a}$ & $111,4 \pm 13,6^{b}$ & $90,6 \pm 12,3^{\mathrm{ab}}$ & $112,3 \pm 14,0^{\mathrm{ab}}$ & $<0,01$ \\
\hline \% de inibição da oxidação (DPPH) & $12,0 \pm 15,4$ & $15,5 \pm 20,6$ & $16,2 \pm 17,0$ & $12,2 \pm 17,5$ & 0,570 \\
\hline MDA plasmático ( $\mu \mathrm{Mol} / \mathrm{L})$ & $2,8 \pm 0,2^{\mathrm{ab}}$ & $2,8 \pm 0,2^{\mathrm{ab}}$ & $2,2 \pm 0,2^{a}$ & $2,9 \pm 0,2^{b}$ & 0,047 \\
\hline$\alpha$-tocoferol plasmático $(\mathrm{ng} / \mathrm{mL})^{4}$ & $446,7 \pm 311,5$ & $1027,4 \pm 101,4$ & $660,6 \pm 398,3$ & $578,5 \pm 327,1$ & 0,284 \\
\hline
\end{tabular}

${ }^{1}$ Valores expressos como média \pm DP $(n=18 /$ grupo). Valores seguidos da mesma letra na linha não diferem significativamente $(p<0,05)$.

${ }^{2}$ Valor da probabilidade obtido por ANOVA.

${ }^{3}$ Valores expressos como média \pm DP $(n=17)$

${ }^{4}$ Valores expressos como média \pm DP $(n=5)$. 
As concentrações séricas de HDL diminuíram e de triacilgliceróis aumentaram significativamente durante a intervenção no grupo PLACEBO.

Os indivíduos suplementados com ácidos graxos polinsaturados Omega-3 apresentaram um aumento na concentração plasmática de MDA em relação aos valores observados no início (baseline). A Figura 13 apresenta a dispersão desses dados, onde verifica-se a normalidade na distribuição indicando não se tratar de casos isolados dentro do grupo.

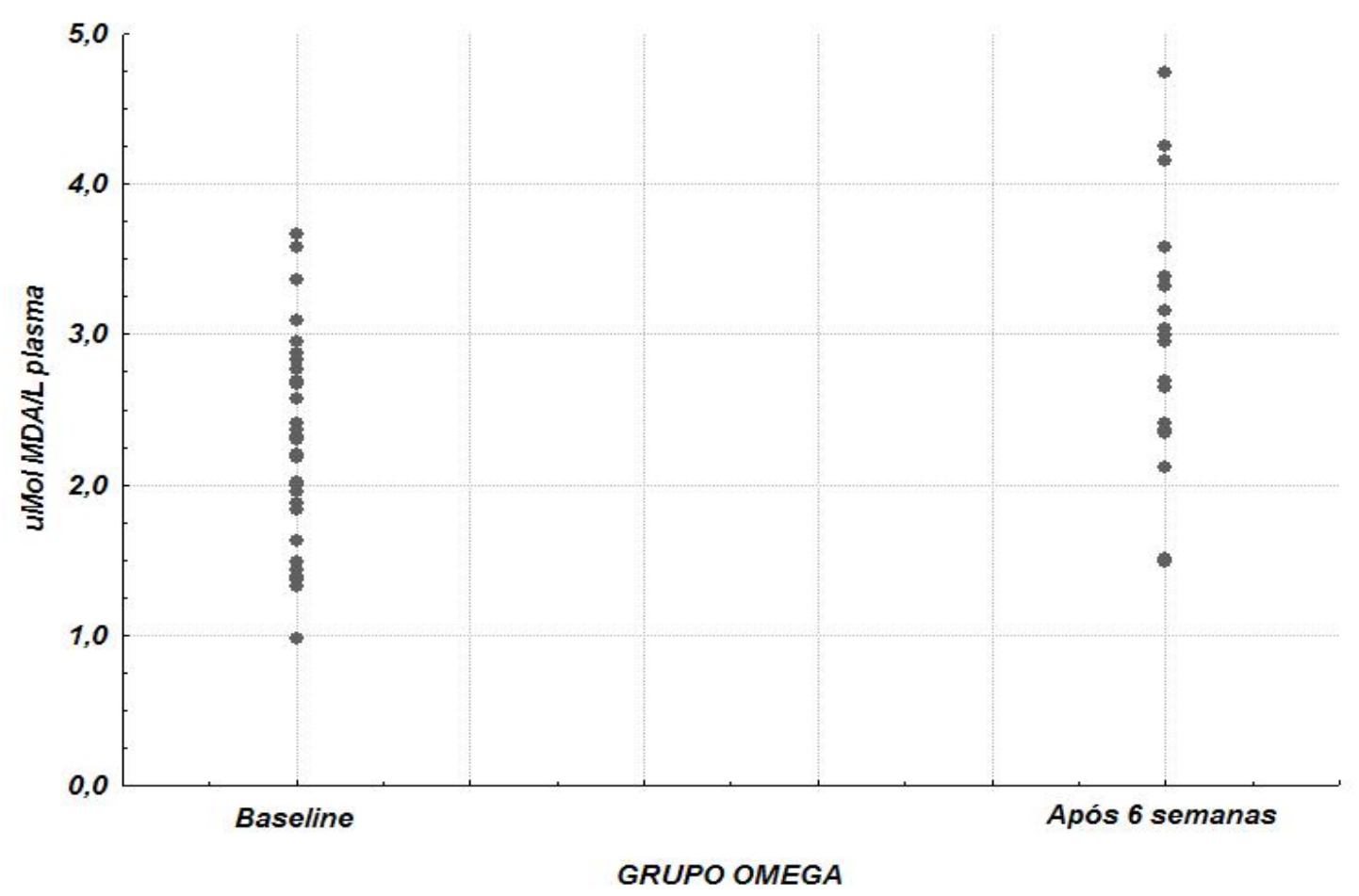

Figura 13. Dispersão apresentada pelos indivíduos pertencentes ao grupo OMEGA. 
A Figura 14 apresenta a dispersão dos indivíduos nas três dimensões geradas pela análise multivariada de correspondência múltipla.

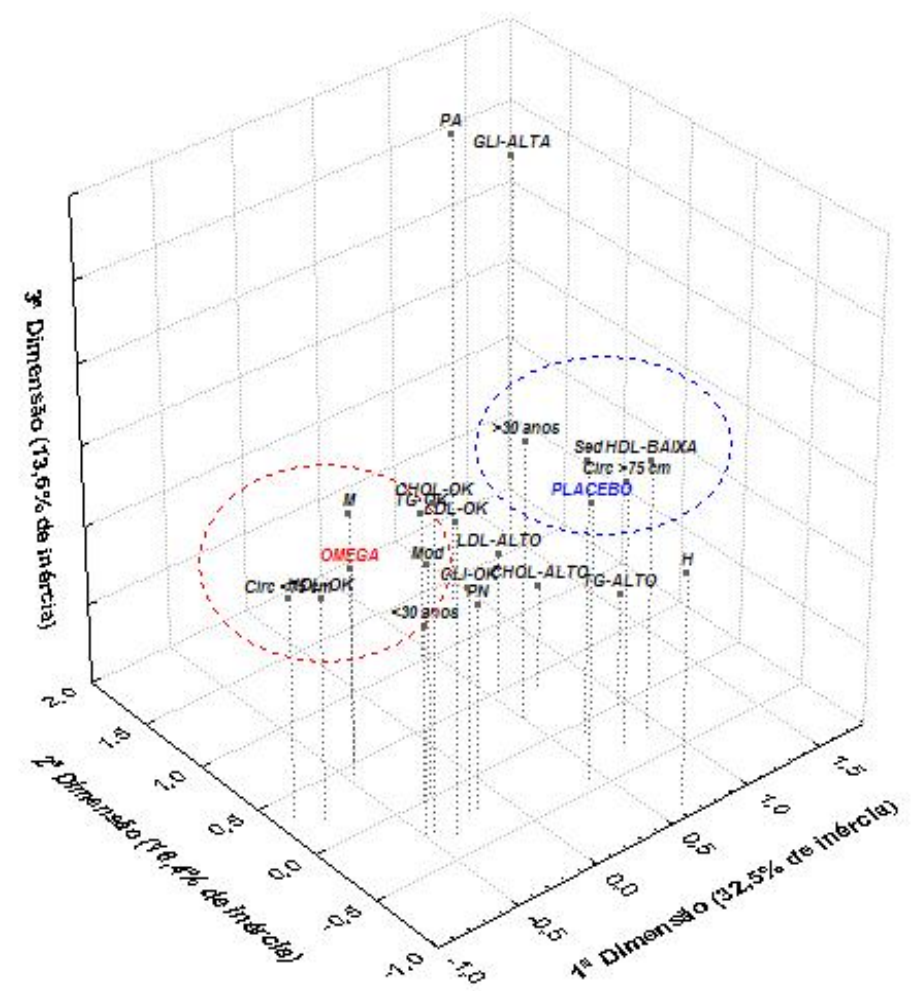

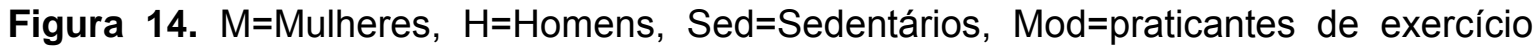

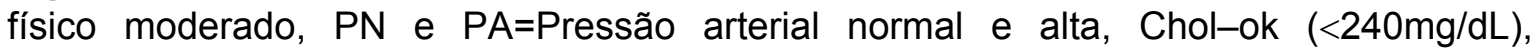
Chol-alto (>240mg/dL), TG-ok (<200 mg/dL), TG-alto (>200mg/dL), LDL-ok $(<160 \mathrm{mg} / \mathrm{dL})$, LDL-alto $(>160 \mathrm{mg} / \mathrm{dL}), \mathrm{HDL}-\mathrm{ok}(>40 \mathrm{mg} / \mathrm{dL}), \mathrm{HDL}-$ baixo $(<40 \mathrm{mg} / \mathrm{dL})$, Glicemia-ok (70 a 110mg/dL) e Glicemia-alta (>110 mg/dL). 


\subsubsection{Composição da dieta}

A Tabela 5 apresenta a composição química estimada da dieta dos indivíduos antes e depois da intervenção. Pode-se observar que a ingestão de nutrientes não se alterou entre os tratamentos durante o experimento.

Tabela 5. Composição da dieta (diária) dos indivíduos antes e depois da intervenção ${ }^{1}$.

\begin{tabular}{|c|c|c|c|c|c|}
\hline & \multicolumn{2}{|c|}{ PLACEBO } & \multicolumn{2}{|c|}{ OMEGA } & \multirow[t]{2}{*}{$p^{2}$} \\
\hline & Início & Após 6 semanas & Início & Após 6 semanas & \\
\hline Número de indivíduos & 15 & 17 & 15 & 17 & - \\
\hline Energia (kcal) & $1.679,0$ & $1.771,9$ & $1.591,6$ & $1.971,8$ & 0,61 \\
\hline Proteína (g) & $80,4 \pm 35,7$ & $94,0 \pm 22,5$ & $70,5 \pm 21,2$ & $95,9 \pm 34,0$ & 0,72 \\
\hline \% Energia da proteína & $18,9 \pm 4,5$ & $21,9 \pm 4,2$ & $18,1 \pm 4,3$ & $19,9 \pm 2,2$ & 0,54 \\
\hline Gordura $(\mathrm{g})$ & $52,8 \pm 22,4$ & $54,6 \pm 15,3$ & $54,5 \pm 18,0$ & $68,3 \pm 39,3$ & 0,53 \\
\hline$\%$ Energia da gordura & $27,7 \pm 6,9$ & $28,4 \pm 5,2$ & $31,1 \pm 8,1$ & $30,2 \pm 8,6$ & 0,85 \\
\hline Saturada (g) & $14,7 \pm 8,2$ & $14,6 \pm 6,3$ & $18,7 \pm 7,8$ & $19,7 \pm 16,3$ & 0,66 \\
\hline Monoinsaturada (g) & $15,6 \pm 8,9$ & $14,2 \pm 5,2$ & $16,5 \pm 6,7$ & $17,6 \pm 12,7$ & 0,74 \\
\hline Polinsaturada (g) & $5,6 \pm 3,0$ & $6,3 \pm 3,5$ & $5,0 \pm 2,2$ & $6,4 \pm 4,0$ & 0,92 \\
\hline Colesterol (mg) & $167,4 \pm 98,3$ & $203,7 \pm 93,3$ & $171,1 \pm 60,7$ & $168,4 \pm 96,3$ & 0,37 \\
\hline$\%$ Gordura saturada & $40,7 \pm 5,1$ & $41,3 \pm 7,1$ & $46,3 \pm 7,1$ & $44,0 \pm 10,7$ & 0,64 \\
\hline$\%$ Gord. Monoinsaturada & $42,6 \pm 5,8$ & $40,7 \pm 4,0$ & $40,9 \pm 5,0$ & $39,5 \pm 7,5$ & 0,94 \\
\hline$\%$ Gord. Polinsaturada & $16,6 \pm 4,8$ & $17,9 \pm 5,8$ & $12,8 \pm 3,2$ & $16,5 \pm 4,8$ & 0,59 \\
\hline Carboidrato (g) & $220,1 \pm 71,1$ & $226,2 \pm 60,8$ & $204,8 \pm 63,0$ & $243,5 \pm 61,4$ & 0,62 \\
\hline Cinzas (g) & $10,8 \pm 3,8$ & $9,9 \pm 3,8$ & $9,8 \pm 3,0$ & $11,3 \pm 4,3$ & 0,40 \\
\hline Fibras (g) & $16,6 \pm 7,0$ & $15,5 \pm 6,7$ & $15,1 \pm 7,8$ & $24,2 \pm 12,3$ & 0,17 \\
\hline
\end{tabular}

${ }^{1}$ Valores expressos como média \pm DP.

${ }^{2}$ Valor da probabilidade obtido por ANOVA. Diferenças significativas $(p<0,05)$. 


\subsubsection{Caracterização da fração lipídica}

As concentrações proporcionais dos diferentes ácidos graxos determinados no plasma dos indivíduos estão apresentadas na Tabela 6.

Tabela 6. Proporção dos ácidos graxos no plasma (\%) dos grupos experimentais antes e depois da intervenção ${ }^{1}$.

\section{PLACEBO OMEGA}

\begin{tabular}{|c|c|c|c|c|c|}
\hline Ácidos graxos (\%) & Baseline & Depois de 6s & Baseline & Depois de 6s & $p^{2}$ \\
\hline C12:0 & $0,4 \pm 0,2$ & $0,4 \pm 0,3$ & $0,5 \pm 0,2$ & $0,3 \pm 0,3$ & 0,20 \\
\hline C14:0 & $1,5 \pm 0,8$ & $1,5 \pm 0,5$ & $1,9 \pm 0,6$ & $1,7 \pm 0,5$ & 0,96 \\
\hline C16:0 & $20,5 \pm 2,2$ & $20,4 \pm 2,1$ & $21,5 \pm 1,5$ & $21,8 \pm 2,3$ & 0,65 \\
\hline C18:0 & $5,6 \pm 1,0$ & $5,6 \pm 1,0$ & $5,8 \pm 1,9$ & $5,0 \pm 1,3$ & 0,35 \\
\hline C22:0 & $0,5 \pm 0,2$ & 0,0 & $0,5 \pm 0,2$ & 0,0 & 0,74 \\
\hline$\Sigma$ SAFA & $28,6 \pm 3,5$ & $28,0 \pm 3,0$ & $29,7 \pm 1,9$ & $28,1 \pm 1,3$ & 0,68 \\
\hline C16:1 n-7 & $2,6 \pm 0,8$ & $2,5 \pm 0,7$ & $3,2 \pm 0,9$ & $3,0 \pm 0,8$ & 0,68 \\
\hline C18:1 n-9 & $17,7 \pm 3,1$ & $18,4 \pm 3,1$ & $19,1 \pm 3,3$ & $17,9 \pm 2,4$ & 0,37 \\
\hline$\Sigma$ MUFA & $20,0 \pm 3,7$ & $20,9 \pm 3,6$ & $22,3 \pm 3,9$ & $20,8 \pm 2,7$ & 0,48 \\
\hline C18:2 n-6 & $37,7 \pm 6,4$ & $37,8 \pm 5,9$ & $32,8 \pm 3,7$ & $35,5 \pm 4,2$ & 0,46 \\
\hline C18:3 n-3 & $1,3 \pm 0,3$ & $1,2 \pm 0,5$ & $1,2 \pm 0,4$ & $1,1 \pm 0,5$ & 0,80 \\
\hline$C 20: 3 n-6$ & $1,4 \pm 0,3$ & $1,4 \pm 0,3$ & $1,6 \pm 0,3$ & $1,4 \pm 0,3$ & 0,44 \\
\hline$C 20: 4 n-6$ & $8,6 \pm 1,4$ & $8,2 \pm 1,4$ & $9,0 \pm 2,0$ & $8,3 \pm 2,2$ & 0,88 \\
\hline C20:5 n-3 & $0,4 \pm 0,1^{a}$ & $0,5 \pm 0,2^{a}$ & $0,6 \pm 0,3^{a}$ & $1,1 \pm 0,7^{b}$ & 0,03 \\
\hline$C 22: 5 n-3$ & $0,4 \pm 0,1$ & $0,5 \pm 0,1$ & $0,4 \pm 0,2$ & $0,4 \pm 0,2$ & 0,87 \\
\hline$C 22: 6 n-3$ & $1,5 \pm 0,4^{a}$ & $1,2 \pm 0,3^{\mathrm{a}}$ & $1,7 \pm 0,5^{a}$ & $2,3 \pm 0,7^{b}$ & 0,02 \\
\hline$\Sigma$ PUFA & $51,0 \pm 7,0$ & $51,2 \pm 6,0$ & $48,5 \pm 5,0$ & $50,0 \pm 5,6$ & 0,59 \\
\hline Relação n6/n3 & $13,8 \pm 3,3^{a}$ & $14,1 \pm 2,9^{\mathrm{a}}$ & $11,2 \pm 1,5^{\mathrm{ab}}$ & $10,4 \pm 4,4^{b}$ & $<0,01$ \\
\hline $\mathbf{I S P}^{3}$ & $79,2 \pm 9,0$ & $78,2 \pm 7,6$ & $80,1 \pm 9,0$ & $82,7 \pm 12,1$ & 0,37 \\
\hline
\end{tabular}

${ }^{1}$ Valores expressos pela média \pm DP ( $n=18$ /grupo). Valores seguidos da mesma letra na linha não diferem significativamente $(p<0,05)$.

${ }^{2}$ Valor da probabilidade para a diferença avaliada por ANOVA.

${ }^{3}$ Índice de susceptibilidade a peroxidação. Calculado de acordo com HSU, LEE e CHEN (2001). 
Foi observada uma alteração significativa nas concentrações de EPA (C20:5 n-3) e DHA (C22:6 n-3) no plasma dos indivíduos do grupo OMEGA comparados tanto em relação aos valores no baseline como em relação ao grupo PLACEBO. EPA aumentou de $0,6 \%$ para $1,1 \%$ e DHA de $1,7 \%$ para $2,3 \%$ depois de seis semanas comparados aos valores obtidos no baseline, ou seja, a suplementação de $460 \mathrm{mg} / \mathrm{d}$ de ácidos graxos polinsaturados Omega-3 através de uma bebida láctea, elevou significativamente a presença desses ácidos graxos no plasma, confirmando a aderência dos indivíduos ao estudo.

\subsection{Modelo animal}

5.2.1 Composição centesimal aproximada e caracterização dos ácidos graxos das rações

A Tabela 7 apresenta a composição centesimal aproximada e a proporção dos ácidos graxos da ração CONTROLE e das duas rações experimentais (SO e $\mathrm{FO})$. 
Tabela 7. Composição química centesimal e proporção dos ácidos graxos presentes nas rações experimentais.

\begin{tabular}{|c|c|c|c|c|}
\hline NUTRIENTES $^{1}$ & CONTROLE & SO & FO & $P^{4}$ \\
\hline Umidade $(\mathrm{g} / 100 \mathrm{~g})$ & $6,9 \pm 0,1^{a}$ & $7,8 \pm 0,1^{b}$ & $6,9 \pm 0,0^{a}$ & $<0,01$ \\
\hline Proteína $(\mathrm{N} x \mathrm{6}, 25)(\mathrm{g} / 100 \mathrm{~g})$ & $12,3 \pm 0,9$ & $11,1 \pm 2,5$ & $12,8 \pm 2,1$ & 0,34 \\
\hline Carboidrato $^{2}(\mathrm{~g} / 100 \mathrm{~g})$ & $73,3 \pm 0,8$ & $70,6 \pm 1,4$ & $68,5 \pm 2,2$ & 0,07 \\
\hline Cinzas $(g / 100 g)$ & $3,1 \pm 0,1^{\mathrm{a}}$ & $2,8 \pm 0,1^{b}$ & $3,1 \pm 0,1^{\mathrm{a}}$ & 0,01 \\
\hline Energia (kcal) & $379,2 \pm 0,9^{a}$ & $395,1 \pm 3,0^{b}$ & $401,1 \pm 0,9^{c}$ & $<0,01$ \\
\hline Lipídio (g/100g) & $3,9 \pm 0,2^{a}$ & $7,5 \pm 0,6^{b}$ & $8,2 \pm 0,2^{b}$ & $<0,01$ \\
\hline C10:0 & - & $0,1 \pm 0,0$ & 0,0 & 0,03 \\
\hline C12:0 & - & $0,1 \pm 0,0$ & $0,2 \pm 0,0$ & 0,39 \\
\hline C14:0 & - & $0,3 \pm 0,1$ & $4,0 \pm 1,2$ & 0,05 \\
\hline C15:0 & - & 0,0 & $0,3 \pm 0,0$ & 0,42 \\
\hline C16:0 & - & $11,3 \pm 0,0$ & $14,0 \pm 1,4$ & 0,12 \\
\hline C17:0 & - & $0,1 \pm 0,0$ & $0,2 \pm 0,0$ & 0,76 \\
\hline C18:0 & - & $3,2 \pm 0,0$ & $3,2 \pm 0,2$ & 0,76 \\
\hline C 20:0 & - & $0,3 \pm 0,1$ & $0,3 \pm 0,0$ & 0,47 \\
\hline C 22:0 & - & $0,3 \pm 0,1$ & $0,2 \pm 0,0$ & 0,43 \\
\hline$\Sigma$ SAFA (\%) & - & $15,9 \pm 0,0$ & $21,8 \pm 3,8$ & 0,16 \\
\hline C16:1 n-7 & - & $0,1 \pm 0,0$ & $4,1 \pm 1,4$ & 0,06 \\
\hline C18:1 n-9 & - & $22,7 \pm 0,3$ & $18,4 \pm 0,7$ & 0,02 \\
\hline$C 20: 1 \mathrm{n}-9$ & - & $0,1 \pm 0,0$ & $0,7 \pm 0,3$ & 0,10 \\
\hline $\mathrm{C} 22: 1$ & - & $0,1 \pm 0,0$ & $0,8 \pm 0,0$ & 0,42 \\
\hline$\Sigma$ MUFA (\%) & - & $22,9 \pm 0,3$ & $23,6 \pm 1,5$ & 0,58 \\
\hline C16:2 n-6 & - & 0,0 & $0,5 \pm 0,0$ & 0,42 \\
\hline C16:4 n-6 & - & 0,0 & $1,3 \pm 0,0$ & 0,43 \\
\hline C18:2 n-6 & - & $55,2 \pm 0,3$ & $34,0 \pm 6,7$ & 0,05 \\
\hline C18:3 n-3 & - & $6,0 \pm 0,1$ & $4,3 \pm 1,1$ & 0,17 \\
\hline C18:4 n-6 & - & 0,0 & $1,5 \pm 0,0$ & 0,42 \\
\hline$C 20: 4 n-6$ & - & 0,0 & $0,3 \pm 0,0$ & 0,67 \\
\hline$C 20: 4 n-3$ & - & 0,0 & $0,4 \pm 0,2$ & 0,07 \\
\hline C20:5 n-3 & - & 0,0 & $8,7 \pm 2,9$ & 0,05 \\
\hline$C 22: 5 n-3$ & - & 0,0 & $0,7 \pm 0,3$ & 0,08 \\
\hline$C 22: 6 n-3$ & - & 0,0 & $4,6 \pm 1,8$ & 0,07 \\
\hline$\Sigma$ PUFA (\%) & - & $61,2 \pm 0,3$ & $54,6 \pm 5,3$ & 0,22 \\
\hline Relação n6/n3 & - & $9,2 \pm 0,1$ & $2,9 \pm 0,9$ & 0,01 \\
\hline $\mathbf{I S P}^{3}$ & - & $67,2 \pm 0,4$ & $114,2 \pm 6,4$ & 0,01 \\
\hline
\end{tabular}

${ }^{1}$ Valores expressos pela média \pm DP $(n=7$ ratos/grupo). Valores seguidos da mesma letra na linha não diferem significativamente $(p<0,05)$.

${ }^{2}$ Valores obtidos pela diferença.

3 Índice de susceptibilidade a peroxidação. Calculado de acordo com HSU, LEE e CHEN (2001).

${ }^{4}$ Valor da probabilidade obtido por ANOVA. 
Através da cromatografia gasosa pode-se confirmar a suplementação de EPA e DHA, na qual a dieta FO continha aproximadamente 9,0 \% dos lipídios na forma de C20:5 n-3 (EPA) e cerca de 5,0 \% na forma de C22:6 n-3 (DHA), enquanto que a dieta SO não apresentava nenhum destes dois ácidos graxos em sua composição. A relação n6/n3 reduziu de 9,2 na dieta SO para 2,9 na dieta FO e o índice de susceptibilidade a peroxidação, aumentou de 67,2 (SO) para 114,2 (FO).

\subsubsection{Composição de ácidos graxos no plasma dos animais}

Os ácidos graxos são incorporados em fluídos de tecidos humanos e de animais, tais como o cérebro e o plasma. As quantidades incorporadas geralmente refletem o perfil de ácidos graxos essências, linoléico (Omega-6) e linolênico (Omega-3) da dieta, uma vez que estes não são sintetizados pelo organismo humano e animal. A Tabela 8 demonstra a proporção de ácidos graxos determinada no plasma dos animais. 
Tabela 8. Proporção dos ácidos graxos (\%) determinada no plasma dos animais.

\begin{tabular}{|c|c|c|c|}
\hline$\overline{A ́ C I D O S ~ G R A X O S ~(\%) ~}^{1}$ & So & FO & $\overline{p^{2}}$ \\
\hline C12:0 & $1,8 \pm 0,3$ & $2,7 \pm 0,1$ & 0,03 \\
\hline C14:0 & $2,9 \pm 1,1$ & $3,6 \pm 1,0$ & 0,50 \\
\hline C16:0 & $22,2 \pm 0,9$ & $23,7 \pm 0,7$ & 0,10 \\
\hline C18:0 & $5,7 \pm 0,8$ & $5,9 \pm 0,4$ & 0,83 \\
\hline $\mathrm{C} 22: 0$ & 0,0 & $0,9 \pm 0,0$ & $<0,01$ \\
\hline$\Sigma$ SAFA (\%) & $32,6 \pm 2,7$ & $35,8 \pm 0,0$ & 0,20 \\
\hline C16:1 n-7 & $4,6 \pm 1,4$ & $4,9 \pm 0,2$ & 0,79 \\
\hline C18:1 n-9 & $12,7 \pm 2,2$ & $11,7 \pm 1,4$ & 0,58 \\
\hline$\Sigma$ MUFA (\%) & $17,3 \pm 3,6$ & $16,6 \pm 1,1$ & 0,80 \\
\hline C18:2 n-6 & $22,0 \pm 1,3$ & $16,9 \pm 1,8$ & 0,02 \\
\hline C18:3 n-3 & $1,3 \pm 0,1$ & 0,0 & $<0,01$ \\
\hline$C 20: 4$ n-6 & $24,1 \pm 1,4$ & $12,5 \pm 1,3$ & $<0,01$ \\
\hline C20:5 n-3 & $0,7 \pm 0,1$ & $10,9 \pm 1,5$ & $<0,01$ \\
\hline$C 22: 6 n-3$ & $2,0 \pm 0,4$ & $6,5 \pm 0,5$ & $<0,01$ \\
\hline$\Sigma$ PUFA (\%) & $50,0 \pm 2,5$ & $47,6 \pm 1,2$ & 0,28 \\
\hline Relação n6/n3 & $11,9 \pm 1,9$ & $1,8 \pm 0,4$ & $<0,01$ \\
\hline ISP $^{3}$ & $109,7 \pm 7,9$ & $130,5 \pm 14,2$ & $<0,01$ \\
\hline
\end{tabular}

${ }^{1}$ Valores expressos pela média \pm DP $(n=7)$.

${ }^{2}$ Valor da probabilidade avaliada através do test-t para amostras independentes.

${ }^{3}$ Índice de susceptibilidade a peroxidação. Calculado de acordo com HSU, LEE e CHEN (2001).

O aumento da proporção dos ácidos graxos polinsaturados Omega-3 observado no plasma dos animais, refletiu claramente o aumento desses ácidos graxos incorporados à dieta. Ambos os grupos apresentaram proporções similares de ácidos graxos polinsaturados (PUFAs), sendo que o aumento da proporção de EPA e DHA observado no plasma dos animais do grupo FO parece ter ocorrido às custas dos ácidos linoléico e araquidônico. 
5.2.3 Ganho de peso, ingestão dietética e concentração de MDA no plasma dos animais submetidos a diferentes dietas experimentais

A Tabela 9 apresenta o ganho de peso e o consumo de ração durante o período de intervenção de 21 dias, na qual os animais tiveram livre acesso a dieta. A concentração de MDA determinada no plasma dos animais pelo método de TBARS também está apresentada nesta mesma tabela. 
Tabela 9 - Ganho de peso, ingestão dietética e concentração de MDA plasmática em ratos alimentados por diferentes dietas experimentais.

\begin{tabular}{|c|c|c|c|c|c|c|c|c|c|c|}
\hline \multirow[b]{3}{*}{ Período experimental } & \multicolumn{9}{|c|}{ Grupos $^{1}$} & \multirow[b]{3}{*}{$p$} \\
\hline & \multicolumn{3}{|c|}{ CONTROLE } & \multicolumn{3}{|c|}{ so } & \multicolumn{3}{|c|}{ FO } & \\
\hline & $1^{\circ} \mathrm{dia}$ & $11^{\circ} \mathrm{dia}$ & $21^{\circ} \mathrm{dia}$ & $1^{\circ} \mathrm{dia}$ & $11^{\circ} \mathrm{dia}$ & $21^{\circ} \mathrm{dia}$ & $1^{\circ} \mathrm{dia}$ & $11^{\circ} \mathrm{dia}$ & $21^{\circ} \mathrm{dia}$ & \\
\hline Ganho de peso corporal (\%) & - & $23,9 \pm 3,0^{a}$ & $114,5 \pm 8,1^{b}$ & - & $15,3 \pm 9,2^{\mathrm{a}}$ & $106,5 \pm 16,1^{b}$ & - & $12,9 \pm 3,8^{a}$ & $99,7 \pm 20,6^{b}$ & $<0,01$ \\
\hline Ingestão dietética (g/dia) & - & $17,3 \pm 1,9$ & $18,2 \pm 2,3$ & - & $17,4 \pm 2,0$ & $17,2 \pm 1,1$ & - & $18,9 \pm 2,4$ & $16,3 \pm 1,5$ & 0,06 \\
\hline MDA plasmático ( $\mu \mathrm{Mol} / \mathrm{L})$ & $1,5 \pm 0,5$ & $2,3 \pm 0,8$ & $1,9 \pm 0,8$ & $1,5 \pm 0,5$ & $2,1 \pm 0,0$ & $2,4 \pm 0,6$ & $1,5 \pm 0,5$ & $2,2 \pm 0,0$ & $3,2 \pm 1,3$ & 0,30 \\
\hline
\end{tabular}

${ }^{1}$ Valores expressos pela média $\pm \mathrm{DP}(\mathrm{n}=7$ ratos/grupo). Valores seguidos da mesma letra na linha não são significativamente diferentes $(p<0,05)$. Peso corporal inicial $(\mathrm{g}) 132,8 \pm 1,7$. 
Pode ser observado que o consumo de ração não diferiu entre os três grupos bem como o ganho de peso. Baseado na ingestão alimentar e na composição de ácidos graxos, o grupo FO teve uma suplementação média diária de 116,3 mg de EPA, de 61,5 mg de DHA e de 14,7 mg de outros ácidos graxos polinsaturados Omega-3, correspondendo a uma suplementação de $2,9 \mathrm{mg} / \mathrm{kcal}$. A concentração de MDA determinada por TBARS no plasma dos animais não foi significativamente alterado durante o experimento.

\subsubsection{Perfil lipídico sérico dos grupos experimentais (CONTROLE, SO e FO) - modelo animal}

As Figuras 15, 16 e 17 apresentam as concentrações séricas de Colesterol total, HDL e TG respectivamente, nos animais dos grupos CONTROLE, SO e FO.

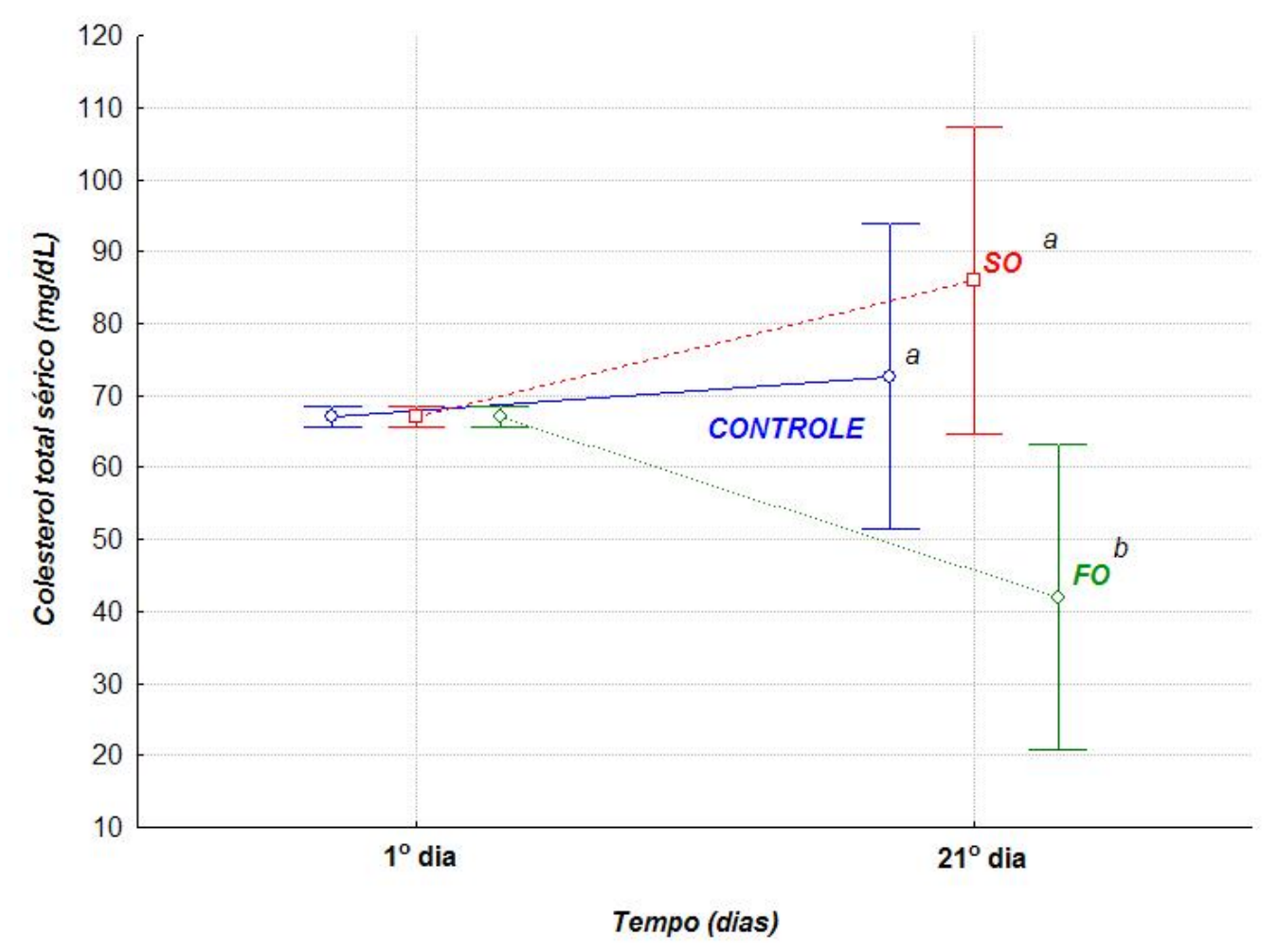

Figura 15. Concentraç̃os séricas de colesterol total nos animais pertencentes aos grupos CONTROLE, SO e FO. 


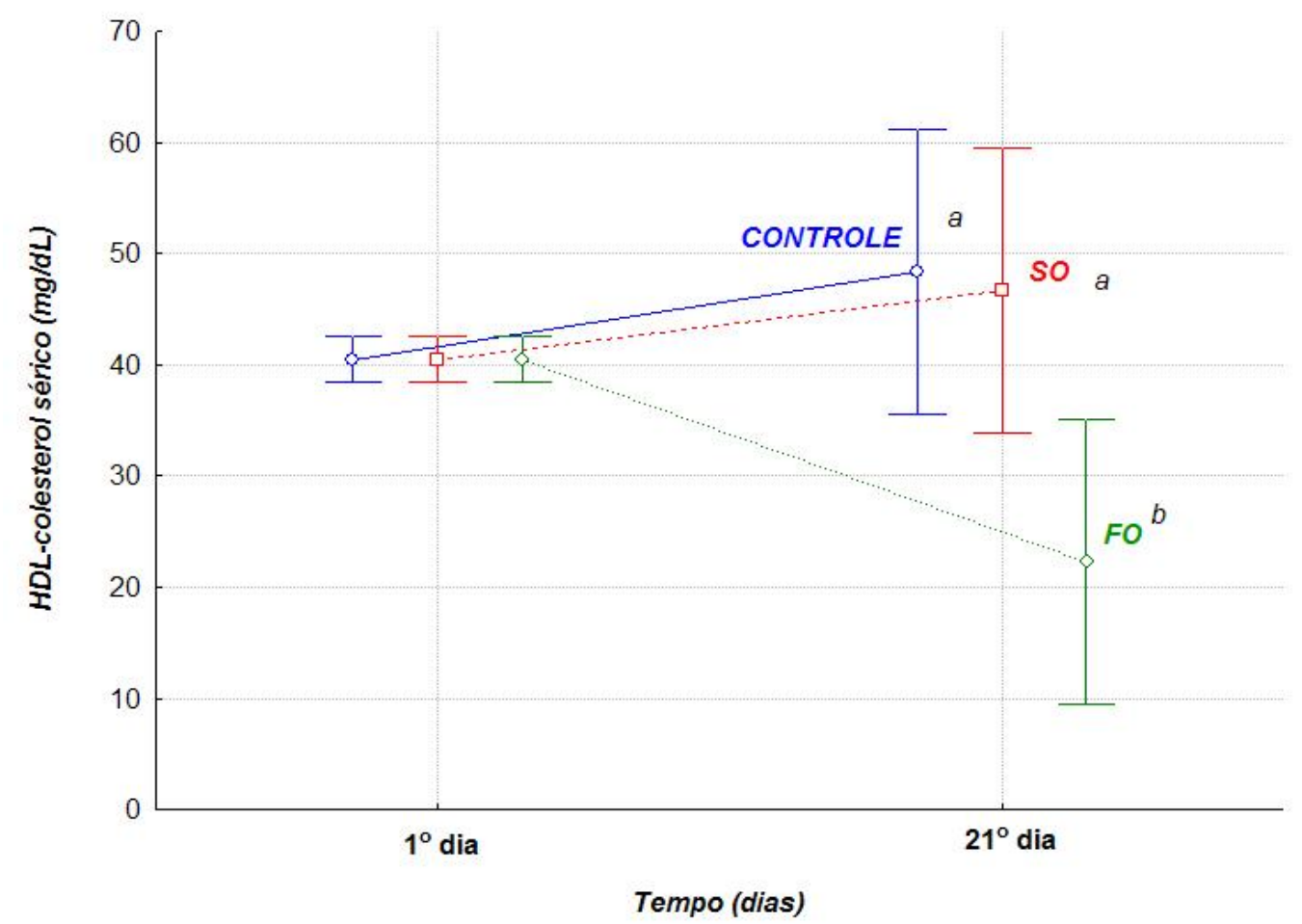

Figura 16. Concentrações séricas da HDL nos animais pertencentes aos grupos CONTROLE, SO e FO.

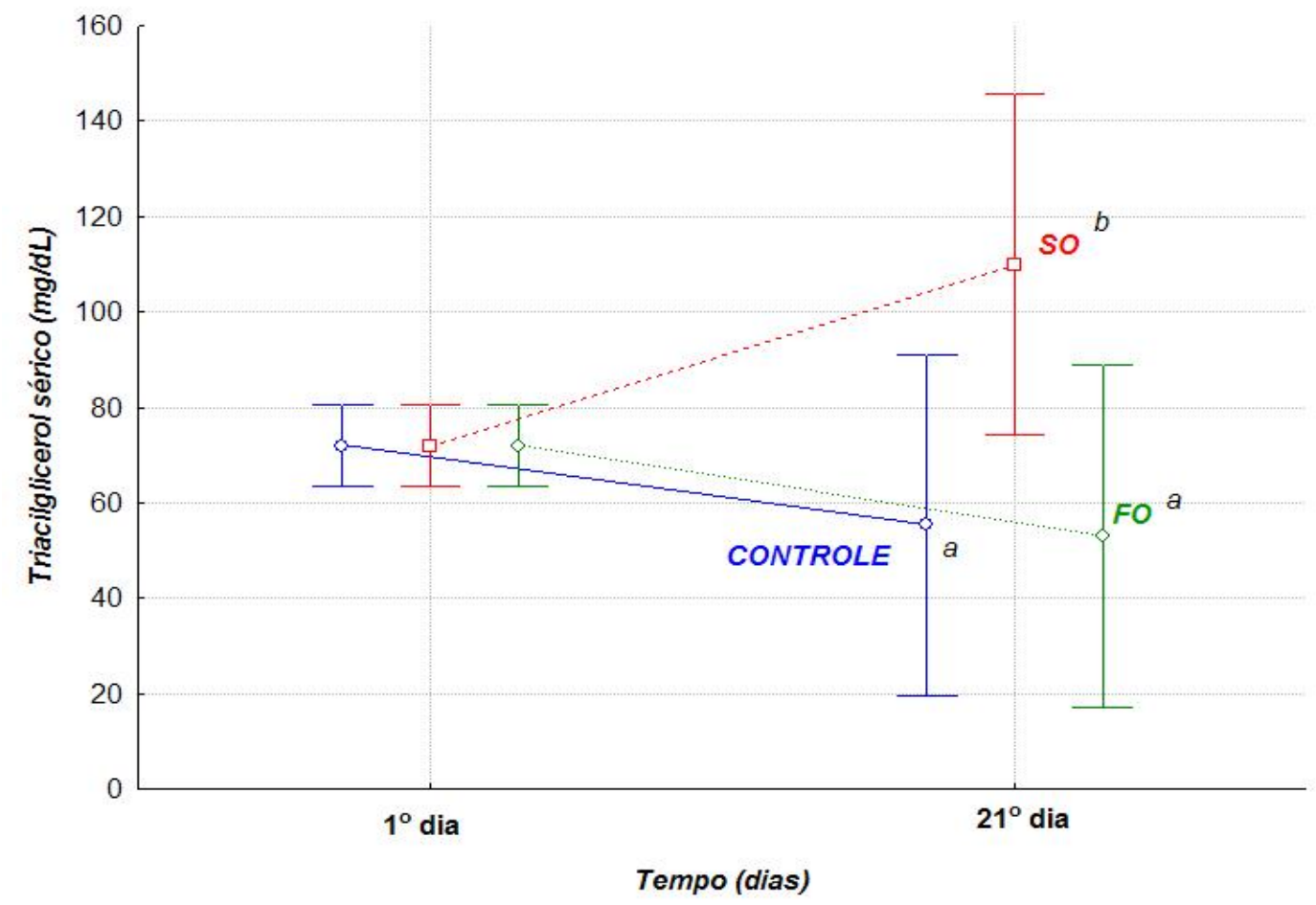

Figura 17. Concentrações séricas de TG nos animais pertencentes aos grupos CONTROLE, SO e FO. 
Com relação às concentrações séricas da LDL determinadas nos animais, não houve diferença significativa, sendo o valor médio observado nos grupos experimentais de $12,3 \pm 3,4(\mathrm{mg} / \mathrm{dL})$.

\subsubsection{Concentração de MDA em homogenato de cérebro}

A Figura 18 apresenta a concentração de MDA medida através de TBARS em homogenato de cérebro dos animais pertencentes aos grupos CONTROLE, SO e FO.

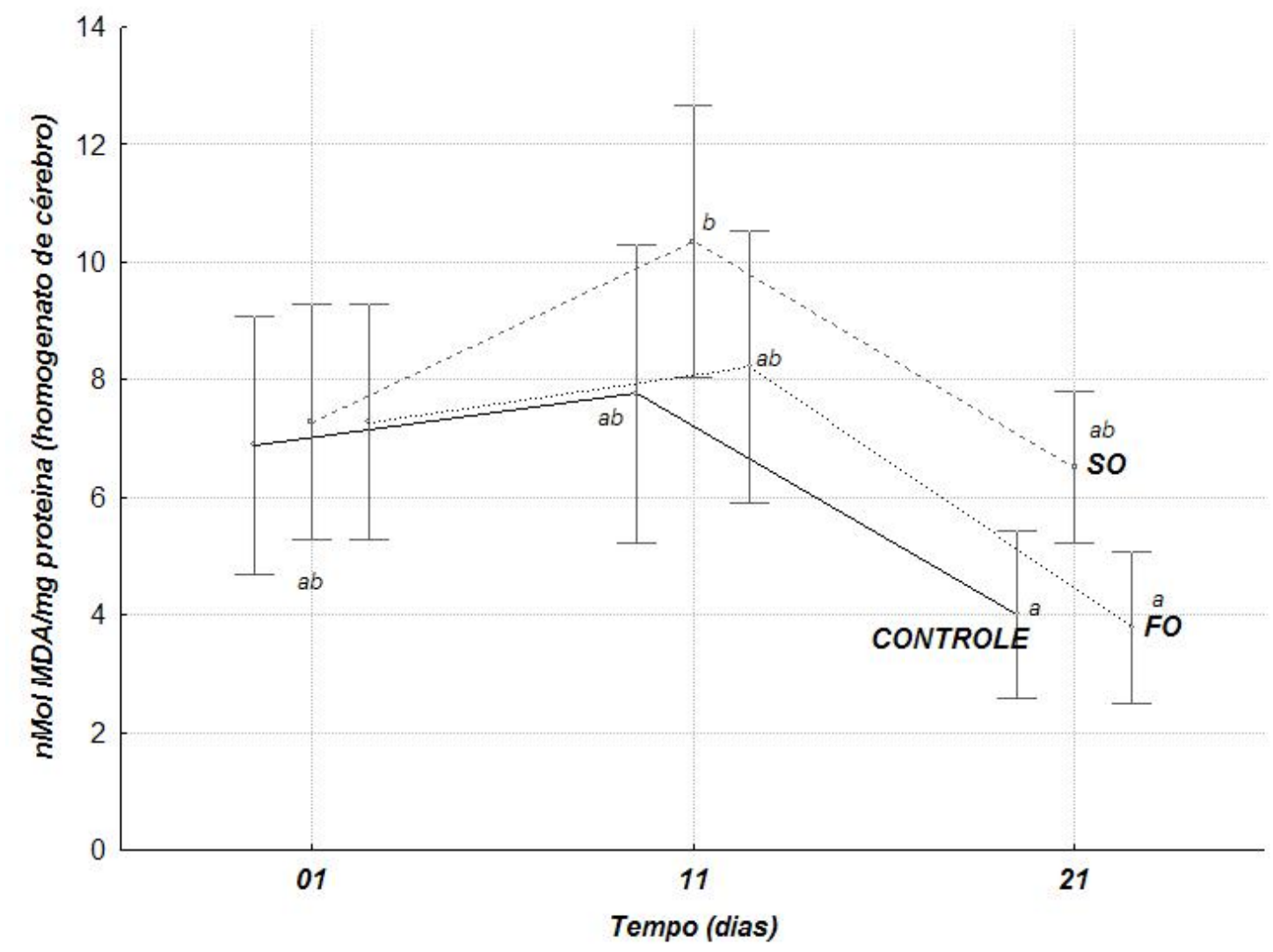

Figura 18. Formação de MDA estimada por TBARS no homogenato de cérebro utilizado como substrato nos animais dos grupos CONTROLE, SO e FO.

Nenhuma alteração na concentração de MDA analisada no homogenato de cérebro foi observada entre os três grupos durante o período experimental. 


\section{DISCUSSÃO}

Indivíduos pertencentes ao grupo PLACEBO apresentaram aumento das concentrações de TG e redução das concentrações de HDL após a intervenção.

Os indivíduos do grupo PLACEBO apresentaram uma redução nas concentrações séricas de HDL de 45,9 para $39,1 \mathrm{mg} / \mathrm{dL}$ e um aumento dos triacilgliceróis de 75,8 para $111,4 \mathrm{mg} / \mathrm{dL}$ durante as seis semanas de intervenção. Observou-se que grande parte dos indivíduos que participaram deste estudo havia perdido o hábito de ingerir um copo de leite/dia. A redução da concentração de HDL pode estar relacionada à maior ingestão de caseína, principal proteína do leite, que contribuiu com $8,8 \%$ das calorias consumidas diariamente. NILAUSEN e MEINERTZ (1999) constataram uma redução nas concentrações de HDL em indivíduos que ingeriram caseína através de uma formulação líquida quando comparados àqueles que não ingeriram esta proteína.

MADANI, PROST e BELLEVILLE (2000) suplementaram ratos com diferentes quantidades de caseína (deficiente, 10\%; normal, $20 \%$ e alta, 30\%) e verificaram que o grupo que recebeu $20 \%$ de caseína, apresentou redução de HDL quando comparado ao grupo com menor quantidade (10\%).

O aumento de triacilglicerol (TG) apresentado pelo grupo PLACEBO, pode estar associado as $150 \mathrm{kcal}$ fornecidas diariamente através da formulação láctea, sugerindo que os indivíduos não substituíram outro alimento pela formulação, mas a adicionaram à dieta. MADANI, PROST e BELLEVILLE (2000) no mesmo estudo citado anteriormente, também observaram que a dieta com $20 \%$ de caseína elevou a concentração de TG comparado ao grupo que recebeu menor quantidade de caseína (10\%). 


\section{Por que esse efeito não foi observado no grupo OMEGA?}

A associação entre o consumo de ácidos graxos polinsaturados Omega-3 e a redução do risco para doenças cardiovasculares é baseada na observação de que os indivíduos que ingerem uma dieta rica em peixes têm uma incidência menor de doenças cardiovasculares (CALDER, 2004a). Peixes são ricos em ácidos graxos polinsaturados Omega-3, sendo assim, deduziu-se que as propriedades protetoras de uma dieta rica em peixes fossem proporcionadas por esses ácidos graxos presentes.

Os ácidos graxos polinsaturados Omega-3 desempenham um potente efeito redutor dose-dependente nas concentrações de triacilgliceróis repetidamente demonstrado em estudos com humanos (LAIDLAW e HOLUB, 2003; BUCKLEY, et al., 2004; CASTRO, BARROSO e SINNECKER, 2005) e em animais (IKEDA et al., 2001; FANG, YANG e WU, 2002).

Os mecanismos pelos quais os ácidos graxos polinsaturados Omega-3 reduzem as concentrações de TG no plasma de indivíduos e animais envolvem o efeito combinado da inibição da lipogênese pela redução da expressão da SREBP-1 (Proteína ligante do elemento regulatório de esterol-1) com o maior estímulo a oxidação dos ácidos graxos pela ativação de fatores de transcrição como o PPAR- $\alpha$ (Receptor ativado por proliferador de peroxissomo- $\alpha$ ) (FERNANDEZ e WEST, 2005). Além disso, BOTHAM et al., (2003) sugeriram que o efeito hipotriglicêmico dos ácidos graxos polinsaturados Omega-3 pode também estar associado à inibição da secreção de VLDL pelo fígado resultante da regulação negativa da expressão de mRNA para ACAT2 (Acil coA: colesterol aciltransferase 2) enzima responsável pelo fornecimento de colesterol às VLDL.

Em relação às concentrações de colesterol total e frações, estudos realizados com humanos e animais têm apresentado efeitos diferentes nesses dois modelos.

Em geral, a suplementação de indivíduos com ácidos graxos polinsaturados Omega-3 promove redução das concentrações de TG no plasma, seguida de aumento das concentrações de colesterol, em particular da fração HDL (KRISETHERTON et al., 2003a; CASTRO, BARROSO e SINNECKER, 2005). Esse comportamento, entretanto não costuma ser observado em estudos realizados em animais onde tanto as concentrações de TG como de colesterol total e frações 
costumam ser reduzidas após suplementação com ácidos graxos polinsaturados Omega-3 (FRENOUX et al., 2001; GAÍVA et al., 2003).

Além dos prováveis efeitos dos ácidos graxos polinsaturados Omega-3 diretamente nas concentrações de HDL, o grupo OMEGA foi formado principalmente por indivíduos do sexo feminino que praticavam exercício físico moderado. Através da Figura 14 observou-se que a distribuição desses indivíduos entre os grupos PLACEBO e OMEGA não foi homogênea em relação a estas duas variáveis.

Estudos relatam que mulheres praticantes de atividade física apresentam concentrações séricas de HDL mais elevadas (ELOSUA et al., 2003; THOMPSON et al., 2003) quando comparadas às sedentárias e quando comparadas aos homens praticantes ou não de atividade física (SKOUMAS et al., 2003), embora os mecanismos associados a esse efeito ainda não estejam totalmente elucidados (OLCHAWA et al., 2004).

\section{Por que não foi observado um efeito mais expressivo na redução de TG nos indivíduos suplementados com ácidos graxos polinsaturados Omega-3?}

Em geral, estudos que conseguiram reduzir significativamente a concentração de TG foram conduzidos em indivíduos hipertriglicêmicos (TG > $200 \mathrm{mg} / \mathrm{dL}$ ) que receberam doses $\geq 1 \mathrm{~g} / \mathrm{dia}$ de ácidos graxos polinsaturados Omega-3 (SIRTORI et al., 1997; LEIGH-FIRBANK et al., 2002; BUCKLEY et al., 2004), sendo essa ingestão supra fisiológica dificilmente atingida por meios dietéticos (HARRIS, 2001).

CARRERO et al., (2004) suplementaram voluntários que apresentaram hiperlipidemia média com um produto lácteo contendo 330 mg/dia de EPA + DHA e observaram uma redução significativa de TG e colesterol total após 8 semanas. Entretanto, esse resultado pode ter sido influenciado pela presença de ácido oléico, também adicionado ao leite. FINNEGAN et al., (2003) sugeriram que aproximadamente $1,0 \mathrm{~g} / \mathrm{dia}$ de ingestão de EPA + DHA representariam o limite mínimo para detectar diferenças significativas na concentração de TG, a menos que o tamanho da amostra fosse significativamente elevado. Portanto, o efeito nutracêutico dos alimentos funcionais contendo ácidos graxos polinsaturados 
Omega-3 em doses diárias menores do que 1,0 g podem estar mais associadas com a reatividade vascular do que com alterações nos perfis lipídicos sanguíneos.

A ausência de um efeito hipotriglicêmico mais expressivo nos indivíduos suplementados com ácidos graxos polinsaturados observado neste estudo pode estar relacionada à dosagem de $460 \mathrm{mg} / \mathrm{d}$ considerada baixa em comparação com a maior parte dos estudos. No entanto, não foi possível adicionar valores mais elevados de ácidos graxos polinsaturados Omega-3 na formulação láctea sem alterar sua aceitabilidade.

Entretanto, uma suplementação de $460 \mathrm{mg}$ de ácidos graxos polinsaturados Omega-3/d equivale ao consumo de peixes ricos em EPA e DHA numa freqüência de duas vezes / semana, que pode ser considerada alta na dieta ocidental. Um fator importante na comparação de resultados entre os diferentes autores é a forma como a suplementação costuma ser expressa: óleo de peixe, ácidos graxos polinsaturados Omega-3 ou EPA + DHA, uma vez que vários estudos não descrevem a concentração de EPA e DHA presente no óleo de peixe utilizado, dificultando a comparação dos resultados. Portanto, o efeito combinado da "baixa dosagem" com o veículo (leite) utilizado na suplementação pode ter reduzido o potencial hipotriglicêmico dos ácidos graxos polinsaturados Omega-3 em nosso estudo.

Diferente do efeito em humanos, ácidos graxos polinsaturados Omega-3 reduzem as concentrações plasmáticas de colesterol em animais e esse efeito tem sido atribuído ao aumento da expressão gênica de receptores, principalmente hepáticos (DIETSCHY, 1998; FERNANDEZ e WEST 2005) e maior afinidade das LDL às membranas plasmáticas das células hepáticas em comparação com dietas saturadas (GAíVA et al., 2003). Esse fato pode ser parcialmente atribuído a diferenças no metabolismo lipídico observadas entre humanos e animais (HARRIS, 1996; BUCKLEY et al., 2004).

Em resumo, o efeito hipotriglicêmico e hipercolesterolêmico evidenciado após a suplementação de indivíduos com ácidos graxos polinsaturados Omega-3 talvez possa justificar porque apenas os indivíduos do grupo PLACEBO tenham apresentado aumento das concentrações de TG e redução das concentrações de HDL após seis semanas de intervenção. 


\section{Por que as concentrações de MDA aumentaram no plasma dos indivíduos suplementados com ácidos graxos polinsaturados Omega-3 e não aumentaram no plasma dos animais?}

Os ácidos graxos polinsaturados aumentam a insaturação dos ácidos graxos presentes nas membranas das células do organismo, tornando-as mais susceptíveis aos danos oxidativos. Segundo SONG e MIYAZAWA (2001), o plasma é um dos primeiros alvos para o estresse oxidativo induzido por óleo de peixe.

A suplementação com ácidos graxos polinsaturados Omega-3 proporcionou resultados diferentes entre os dois modelos utilizados neste estudo. No modelo humano a suplementação de 460 mg diários desses ácidos graxos promoveu um aumento da concentração de MDA no plasma de 2,2 $\mu \mathrm{Mol} / \mathrm{L}$ para 2,9 $\mu \mathrm{Mol} / \mathrm{L}$ após seis semanas. No entanto, a suplementação de $192,5 \mathrm{mg} / \mathrm{d}$ não causou alteração no modelo animal, embora os animais tenham recebido uma dosagem $(2,9 \mathrm{mg} / \mathrm{kcal})$ cerca de dez vezes maior que àquela oferecida aos indivíduos $(0,3 \mathrm{mg} / \mathrm{kcal})$.

A seguir iremos brevemente discutir algumas das hipóteses que poderiam justificar os resultados observados nos dois modelos:

$\left.1^{\circ}\right)$ Os ácidos graxos polinsaturados Omega-3 induziram a um aumento no estresse oxidativo que seria compensado pelo aumento de atividade do sistema antioxidante endógeno, sendo porém o tempo necessário a essa adaptação diferente entre humanos e roedores. HIGGINS et al., (2001) suplementaram indivíduos com diferentes doses de n3-PUFA $(0,3 ; 0,6$ ou 0,9 g/d) durante 16 semanas e não observaram aumento da susceptibilidade à oxidação da LDL sugerindo que um efeito adaptativo poderia modular o sistema antioxidante endógeno, justificando o aumento mais freqüente da oxidação em estudos que suplementaram por um curto período de tempo (3 a 6 semanas) que por um longo período. Os resultados do presente estudo, que teve a duração de 6 semanas, confirmam essa hipótese.

$2^{\circ}$ ) Ratos Wistar sintetizam ácido ascórbico nas células do fígado a partir da glicose, numa reação catalisada pela enzima L-Gulonolactona oxidase (NAIDU, 2003; VERGELY et al., 2004). Além de ser um dos mais efetivos antioxidantes presentes no plasma, o ácido ascórbico regenera $\alpha$-tocoferol. Pode ser que os 
animais tenham compensado o estresse oxidativo induzido pelo maior aporte de ácidos graxos polinsaturados Omega-3 através desse mecanismo.

$3^{\circ}$ ) No processo de refino e preparo do óleo de peixe, os antioxidantes naturalmente presentes são removidos. Usualmente, novos antioxidantes tais como $\alpha$-tocoferol, ascorbato, BHT e TBHQ são adicionados ao óleo final com o objetivo de manter a estabilidade do mesmo durante o shelf life. LUOSTARINEN et al., (2001) sugeriram que a susceptibilidade do plasma a oxidação após a ingestão de óleo de peixe poderia ser influenciada pela proporção de antioxidante adicionado ao óleo após seu refino.

$4^{\circ}$ ) Malondialdeído é um dos principais compostos que resultam da degradação dos hidroperóxidos formados pela oxidação do ácido linoléico, catalisado por enzimas oxidativas como lipoxigenases ou diretamente pela ação de compostos radicalares. O principal composto resultante da oxidação dos ácidos EPA e DHA é o propanal (FRANKEL et al., 2002). Uma vez que no modelo animal EPA e DHA elevaram-se no plasma às custas dos ácidos linoléico e araquidônico, é possível que a suplementação tenha proporcionalmente reduzido o substrato ideal para a formação de MDA. Ressalta-se ainda que o nível de suplementação no modelo humano não ocasionou essa substituição, mantendo-se praticamente as mesmas proporções de linoléico e araquidônico no início e no final da intervenção.

$\left.5^{\circ}\right)$ Alguns estudos recentes têm confirmado a ação antioxidante das HDL. Neste estudo observou-se que a proporção de HDL em relação ao colesterol total nos animais (36 mg/dL/64 mg/dL) foi maior que àquele observado nos indivíduos (43 mg/dL/193 mg/dL). Diferenças no metabolismo lipídico entre as duas espécies justificam esses resultados. HDL é um potente antioxidante e tanto suas apolipoproteínas Al e All como proteínas que são cotransportadas em sua estrutura como as paraxonases (PON) apresentam propriedades antioxidantes (BARTER et al., 2004). Além disso, a expressão das PON pode ser regulada pela dieta.

$6^{\circ}$ ) Em recente publicação, (QUINN, 2005) apresentou uma interessante comparação entre a idade de ratos e humanos em distintas fases da vida de ambos. Através desses cálculos, pode-se inferir que os animais utilizados neste estudo, assim como em vários outros estudos já publicados, teriam uma idade equivalente a 3,5 anos no modelo humano. 
Ainda em relação aos resultados observados no modelo humano, a Tabela 4 demonstrou que no início do estudo os indivíduos apresentaram perfil lipídico, idade, IMC e circunferência da cintura semelhantes, no entanto o estresse oxidativo medido através da concentração de MDA no plasma apresentou-se maior no grupo PLACEBO que no grupo OMEGA antes da intervenção. Essa diferença na concentração de MDA avaliada nos dois grupos antes da intervenção não foi causada por valores individuais discrepantes, uma vez que a dispersão desses valores mostrou-se normal como pode ser verificado na Figura 13.

Neste estudo, ressalta-se ainda que não foi observada alteração na atividade antioxidante total do plasma determinada pelo método DPPH. Nesse método, compostos antioxidantes presentes no plasma tais como ácido ascórbico, tocoferol, ácido úrico, glutationa e albumina (GHISELLI et al., 1995; POLIDORI et al., 2001) seriam capazes de reduzir a molécula de DPPH' proporcionando uma queda nos valores de absorbância medidas a 515 nm (BRAND-WILLIAMS, CUVELIER e BERSET, 1995). Portanto, caso os antioxidantes presentes no plasma estivessem sendo consumidos em razão do aumento do estresse oxidativo causado pela ingestão de ácidos graxos polinsaturados Omega-3, a redução nos valores de absorbância seria comparativamente menor. Nossos resultados mostraram não ter ocorrido alteração na capacidade antioxidante do plasma, sugerindo que a concentração dos compostos responsáveis por essa atividade não foi alterada pela ingestão de ácidos graxos polinsaturados Omega-3, como pode ser observado na concentração de tocoferol (Tabela 4). Apesar dos valores obtidos terem sido relativamente baixos, não houve alteração entre os grupos antes e depois da intervenção.

Atualmente, os estudos têm demonstrado resultados conflitantes em relação à capacidade antioxidante após a ingestão de ácidos graxos polinsaturados Omega-3 (THORLAKSDOTTIR et al., 2006). Além disso, vários métodos têm sido aplicados para estimar a capacidade antioxidante do plasma e os resultados obtidos na mesma amostra podem diferir significativamente (JANASZEWSKA e BARTOSZ, 2002).

Além disso, o estresse oxidativo no plasma pode não estar apenas associado às variáveis lipídicas, mas também com o sexo e a prática de exercício físico. De acordo com STREHLOW et al., (2003) a menor concentração de MDA teria uma relação direta com a ação do hormônio estrogênio estimulando a 
expressão da enzima antioxidante superóxido dismutase (SOD). Portanto, as diferenças entre os indivíduos apresentada na Figura 14 também podem ter influenciado os resultados observados neste estudo.

\section{A relação n6/n3 e o índice de peroxidação nos dois modelos.}

A suplementação diária de $460 \mathrm{mg}$ de ácidos graxos polinsaturados Omega-3 pode ser considerada elevada para a população brasileira que consome poucos alimentos fonte desse nutriente. $O$ consumo de peixes no mundo tem crescido a uma taxa de $3,6 \%$ ao ano desde 1961, enquanto que a população aumenta em 1,8 \% ao ano. A ingestão per capita média aumentou de aproximadamente $9,0 \mathrm{~kg}$ por ano em 1960 para 16,0 kg em 1997. Nos países industrializados, onde as dietas geralmente são mais diversificadas em relação às proteínas animais, há uma ascensão per capita de 19,7 kg para $27,7 \mathrm{~kg}$, representando uma taxa de crescimento de $1,0 \%$ ao ano (WHO/FAO, 2003).

No Brasil, a média de consumo de peixes é de $6,4 \mathrm{~kg} / \mathrm{per}$ capita ao ano (BRASIL, 2002), que corresponde a um consumo de 17,5 g per capita diários. Considerando-se um teor médio de gordura de $10 \%$, sendo destes $20 \%$ na forma de ácidos graxos polinsaturados Omega-3, tem-se uma estimativa média de consumo per capita diário da ordem de $350 \mathrm{mg}$ em ácidos graxos polinsaturados Omega-3. Portanto, a suplementação oferecida neste estudo correspondeu a um aumento de $130 \%$ na dieta. Apesar desse valor ter se mostrado elevado o suficiente para alterar a relação n6/n3 de 11,2 para 10,4, não foi suficiente para alterar o ISP entre os dois grupos experimentais, PLACEBO e OMEGA de 78,2 para 82,7 respectivamente. O índice de peroxidação é usado para expressar à susceptibilidade dos lipídios à oxidação, e neste estudo, esses valores não se alteraram entre os grupos PLACEBO e OMEGA, indicando que ambos os grupos apresentaram o mesmo potencial oxidativo.

Os animais apresentaram uma redução na relação n6/n3 de 11,9 para 1,8 e um aumento no ISP de 109,7 para 130,5 após a suplementação, aumentando a susceptibilidade à oxidação. No entanto este modelo não apresentou aumento na concentração de MDA no plasma, pelos mecanismos citados anteriormente. 


\section{Os animais pertencentes aos três grupos experimentais não apresentaram} diferenças significativas nas concentrações de MDA determinadas no homogenato de cérebro.

O tecido cerebral contém níveis elevados de ferro e desenvolve um mecanismo de defesa antioxidante relativamente pobre (GARCIA et al., 2000). SPITELLER (2005) relatou que não há um excesso da decomposição de proteínas contendo ferro no material biológico, permitindo que íons de metais bivalentes tornem-se disponíveis à peroxidação exceto pela destruição maciça do tecido, que ocorre por exemplo, durante a homogeneização. Portanto, resultados obtidos em modelos ex vivo devem ser discutidos com cautela.

CHAUTAN et al., (1990) relataram que membranas enriquecidas com ácidos graxos polinsaturados Omega-3 são eficientemente protegidas contra a peroxidação através do aumento da concentração de $\alpha$-tocoferol. ERDOGAN et al., (2004) relataram que o Omega-3 aumenta o nível da catalase dentro dos peroxissomos e no citoplasma, resultando em uma maior defesa ao ataque das espécies reativas de oxigênio. Outra hipótese apresentada por SPITELLER (2005), é que um composto antioxidante, conhecido como ácido graxo furano, seria responsável pela capacidade antioxidante associada à ingestão de EPA e DHA. BARBOSA et al., (2003) sugeriram que ácidos graxos polinsaturados Omega-3 poderiam agir como scavengers de radicais protegendo as células do estresse oxidativo.

Algumas das hipóteses citadas anteriormente referente às diferenças na concentração plasmática de MDA entre os dois modelos também podem ser consideradas na justificativa destes resultados. 


\section{CONCLUSÕES}

A discussão dos resultados obtidos neste estudo permite sugerir que:

- O modelo animal com ratos Wistar não parece ser adequado para avaliação do estresse oxidativo após ingestão de ácidos graxos polinsaturados Omega-3.

- Variáveis categóricas podem influenciar a medida de biomarcadores de estresse oxidativo e devem ser controladas através de delineamento "cross-over" ou aplicação de técnicas multivariadas de correspondência antes da divisão dos indivíduos nos grupos experimentais.

- A determinação da concentração de MDA, apesar de ser amplamente utilizada, talvez não seja um biomarcador adequado para avaliar o estresse oxidativo após ingestão de ácidos graxos polinsaturados Omega-3, nas condições aplicadas neste estudo.

- O leite utilizado neste estudo para a adição de ácidos graxos polinsaturados Omega-3 pode não ser o veículo mais adequado para esse tipo de suplementação em adultos. 


\section{REFERÊNCIAS BIBLIOGRÁFICAS}

ABDALLA, D.S.P. Estresse oxidativo e alimentação. In: TIRAPEGUI, J. Nutrição: Fundamentos e aspectos atuais. São Paulo: Atheneu, 2000. p.179-200.

AMERICAN HEART ASSOCIATION. Heart Disease and Stroke Statistics - 2006 Update. Dallas, Texas: American Heart Association, 2006.

ANDERSON, J.W.; DAVIDSON, M.H.; BLONDE, L.; BROWN, W.V.; HOWARD, W.J.; GINSBERG, H.; ALLGOOD, L.D.; WEINGAND, K.W. Long-term cholesterollowering effects of psyllium as an adjunct to diet therapy in the treatment of hypercholesterolemia. American Journal of Clinical Nutrition, v.71, p.14331438, 2000.

ASSOCIATION OF OFFICIAL ANALYTICAL CHEMISTS. Official methods of analysis of AOAC International. 15.ed. Arlinton, 1990.

ASSOCIATION OF OFFICIAL ANALYTICAL CHEMISTS. Official methods of analysis of AOAC International. 16.ed. Washington DC, 1995. v.2.

BAGCHI, K.; PURI, S. Free radicals and antioxidants in health and disease. Eastern Mediterranean Health Journal, v.4, p.350-360, 1998.

BANG, H.O.; DYERBERG, J. Plasma lipids and lipoproteins in Greenlandic west coast Eskimos. Acta Medica Scandinavica, v.192, n.1-2, p.85-94, 1972.

BARTE, P.J.; NICHOLLS, S.; RYE, K.A.; ANANTHARAMAIAH, G.M.; NAVAB, M.; FOGELMAN, A.M.; BERLINER, J.A.; HEINECKE, J.W. The role of oxidized lipoproteins in atherogenesis. Radicals in Biology and Medicine, v.20, n.5, p.707-727, 1996.

BARBOSA, D.S.; CECCHINI, R.; EL KADRI, M.Z.; RODRÍGUEZ, M.A.M.; BURINI, R.C.; DICHI, I. Decreased oxidative stress in patients with ulcerative colitis supplemented with fish oil $\omega-3$ fatty acids. Nutrition, v.19, p.837-842, 2003. 
BERLINER, J.A.; HEINECKE, J.W. The role of oxidized lipoproteins in atherogenesis. Free Radical Biology \& Medicine, v.20, n.5, p.707-27, 1996.

BLIGH, E.G.; DYER, W.J. A rapid method of total lipid extraction and purification. Canadian Journal of Biochemistry and Physiology, v.37, p.911-917, 1959.

BOTHAM, K.M.; ZHENG, X.; NAPOLITANO, M.; AVELLA, M.; CAVALLARI, C.; RIVABENE, R.; BRAVO, E. The effects of dietary n-3 polyunsaturated fatty acids delivered in chylomicron remnants on the transcription of genes regulating synthesis and secretion of very-low-density lipoprotein by the liver: modulation by cellular oxidative state. Experimental Biology and Medicine, v.228, n.2, p.143$151,2003$.

BRAND-WILLIAMS, W.; CUVELIER, M.E.; BERSET, C. Use of a free radical method to evaluate antioxidant activity. Food Science and Technology, v.28, n.1, p.25-30, 1995.

BRASIL. Ministério da Agricultura, Pecuária e Abastecimento. Relatório Anual de Avaliação - PPA 2000-2003. Exercício 2002. Disponível em: http://www.camara.gov.br/internet/comissao/index/mista/orca/ppa/ppa\%2020002003/ppa_rel_aval/003_Agricultura.PDF. Acesso em: 20 fev. 2007.

BRASIL. Ministério da Saúde. Secretaria de Vigilância em Saúde. Secretaria de Atenção à Saúde. Instituto Nacional de Câncer. Coordenação de Prevenção e Vigilância. Inquérito domiciliar sobre comportamentos de risco e morbidade referida de doenças e agravos não transmissíveis: Brasil, 15 capitais e Distrito Federal, 2002-2003. Rio de Janeiro: INCA, 2004. p.151-157.

BRAY, T.M. Dietary antioxidants and assessment of oxidative stress. Nutrition, v.16, n.7-8, p.578-581, 2000.

BRITISH NUTRITION FOUNDATION. Recommendations for intakes of unsaturated fatty acids. Unsaturated fatty acids: nutritional and physiological significance. The Report of the British Nutrition Foundation's Task Force, p.152-163, 1992. apud ROCHE, H.M. Unsaturated fatty acids. Proceedings of the Nutrition Society, v.58, p.397-401, 1999. 
BUCHER, H.C.; HENGSTLER, P.; SCHINDLER, C.; MEIER, G. N-3 polyunsaturated fatty acids in coronary heart disease: a meta-analysis of randomized controlled trials. American Journal of Medicine, v.112, n.4, p.298$304,2002$.

BUCKLEY, R.; SHEWRING, B.; TURNER, R.; YAQOOB, P.; MINIHANE, A.M. Circulating triacylglycerol and apoE levels in response to EPA and docosahexaenoic acid supplementation in adult human subjects. British Journal of Nutrition, v.92, n.3, p.477-483, 2004.

CALDER, P.C. Fatty acids and gene expression related to inflammation. Nestlé Nutrition Workshop Series: Clinical \& Performance Program, v.7, p.19-40, 2002.

CALDER, P.C. Immunoregulatory and anti-inflammatory effects of n-3 polyunsaturated fatty acids. Brazilian Journal of Medical and Biological Research, v.31, n.4, p.467-490, 1998.

CALDER, P.C. Long-chain n-3 fatty acids and cardiovascular disease: further evidence and insights. Nutrition Research, v.24, p.761-772, 2004a.

CALDER, P.C. n-3 fatty acids and cardiovascular disease: evidence explained and mechanisms explored. Clinical Science, v.107, n.1, p.1-11, 2004b.

CALVANI, M.; BENATTI, P. Polyunsaturated fatty acids (PUFA). S.I.: Sigma-tau S.p.A. - Scientific Department, 2003. p.5. Disponível em: http://www.sths.it/TMA_Forum/PUFA\%20-\%20Calvani\%20Benatti\%20-20Feb\%202K3.pdf Acesso em: 06 fev. 2006.

CAO, G.; PRIOR, R.L. Comparison of different analytical methods for assessing total antioxidant capacity of human serum. Clinical Chemistry, v.44, n.6, p.13091315, 1998.

CARRERO, J.J.; BARÓ, L.; FONOLLÁ, J.; GONZALEZ-SANTIAGO, M.; MARTINEZ-FEREZ, A.; CASTILLO, R.; JIMENEZ, J.; BOZA, J.J.; LOPEZHUERTAS, E. Cardiovascular effects of milk enriched with Omega-3 
polyunsaturated fatty acids, oleic acid, folic acid, and vitamins $E$ and B6 in volunteers with mild hyperlipidemia. Nutrition, v.20, n.6, p.521-527, 2004.

CASTRO, I.A.; BARROSO, L.P.; SINNECKER, P. Functional foods for coronary heart disease risk reduction: a meta-analysis using a multivariate approach. American Journal of Clinical Nutrition, v.82, p.32-40, 2005.

CHAUTAN, M.; CALAF, R.; LEONARDI, J.; CHARBONNIER, M.; ANDRE, M.; PORTUGAL, H.; PAULI, A.M.; LAFONT, H.; NALBONE, G. Inverse modifications of heart and liver alpha-tocopherol status by various dietary $n-6 / n-3$ polyunsaturated fatty acid ratios. Journal of Lipid Research, v.31, p.2201-2208, 1990.

DEL MAESTRO, R.F. An approach to free radicals in medicine and biology. Acta Physiologica Scandinavica, v.492, p.153-168, 1980.

DEVLIN, T.M., ed. Textbook of biochemistry with clinical correlations. 5.ed. New York: Wiley-Liss, 2002. 728p.

DIETSCHY JM. Dietary fatty acids and the regulation of plasma low density lipoprotein cholesterol concentrations. Journal of Nutrition, v.128 (2 Suppl), p.444S-448S, 1998.

DIN, N.J.; NEWBY, D.E.; FLAPAN, A.D. Omega 3 fatty acids and cardiovascular disease-fishing for a natural treatment. British Medical Journal, v.328, p.30-35, 2005.

DRIs. Dietary reference intakes for vitamin C, vitamin E, selenium, and carotenoids. Washington (DC): National Academy Press; 2000. p.195, 225-226.

EATON, J.W. Catalases and peroxidases and glutathione and hydrogen peroxide: mysteries of the bestiary. Journal of Laboratory and Clinical Medicine, v.118, n.1, p.3-4, 1991.

ELOSUA, R.; MOLINA, L.; FITO, M.; ARQUER, A.; SANCHEZ-QUESADA, J.L.; COVAS, M.I.; ORDONEZ-LLANOS, J.; MARRUGAT, J. Response of oxidative stress biomarkers to a 16-week aerobic physical activity program, and to 
acute physical activity, in healthy young men and women. Atherosclerosis, v.167, n.2, p. 327-334, 2003.

ENGLER, M.M.; ENGLER, M.B.; ARTERBURN, L.M.; BAILEY, E.; CHIU, E.Y.; MALLOY, M.J.; MIETUS-SNYDER, M.L. Docosahexaenoic acid supplementation alters plasma phospholipid fatty acid composition in hyperlipidemic children: results from the endothelial assessment of risk from lipids in youth (EARLY) study. Nutrition Research, v.24, p.721-729, 2004.

ERDOGAN, H.; FADILLIOGLU, E.; OZGOCMEN, S.; SOGUT, S.; OZYURT, B.; AKYOL, O.; ARDICOGLU, O. Effect of fish oil supplementation on plasma oxidant/antioxidant status in rats. Prostaglandins, Leukotrienes and Essential Fatty Acids, v.71, n.3, p.149-152, 2004.

ERKKILÄ, A.T.; LEHTO, S.; PYÖRÄLÄ, K.; USITUPA, M.I.J. n-3 Fatty acids and $5-y$ risks of death and cardiovascular disease events in patients with coronary artery disease. American Journal of Clinical Nutrition, v.78, p.65-71, 2003.

ERKKILÄ, A.T.; LICHTENSTEIN, A.H.; MOZAFFARIAN, D.; HERRINGTON, D.M. Fish intake is associated with a reduced progression of coronary artery atherosclerosis in postmenopausal women with coronary artery disease. American Journal of Clinical Nutrition, v.80, p.626-632, 2004.

FANG, Y.; YANG, S.; WU, G. Free radicals, antioxidants, and nutrition. Nutrition, 18, 872-879, 2002.

FERNANDEZ, M.L.; WEST, K.L. Mechanisms by which dietary fatty acids modulate plasma lipids. Journal of Nutrition, v.135, n.9, p.2075-2078, 2005.

FERREIRA, A.L.A.; MATSUBARA, L.S. Radicais livres: conceitos, doenças relacionadas, sistema de defesa e estresse oxidativo. Revista da Associação Médica Brasileira, v.43, n.1, p.61-68, 1997.

FINNEGAN, Y.E.; MINIHANE, A.M.; LEIGH-FIRBANK, E.C.; KEW, S.; MEIJER, G.W.; MUGGLI, R.; CALDER, P.C.; WILLIAMS, C.M. Plant- and marine-derived n-3 polyunsaturated fatty acids have differential effects on fasting and postprandial blood lipid concentrations and on the susceptibility of LDL to oxidative modification 
in moderately hyperlipidemic subjects. American Journal of Clinical Nutrition, v.77, p.783-795, 2003.

FOLCH, J.; LEES, M.; SLOANE STANLEY, G.H. A simple method for the isolation and purification of total lipids. Journal of Biological Chemistry, v.226, p.497-509, 1957.

FOOD AND AGRICULTURE ORGANIZATION; WORLD HEALTH ORGANIZATION. General conclusions and recommendations of the consultation. In: Expert Consultation on Fats and Oils in Human Nutrition. 1998. p.3-9. apud ROCHE, H.M. Unsaturated fatty acids. Proceedings of the Nutrition Society, v.58, p.397-401, 1999.

FOOD AND DRUG ADMINISTRATION (FDA). Omega-3 Fatty Acids \& Coronary Heart Disease. Docket No. 2003Q-0401, 2004. Disponível em: http://www.cfsan.fda.gov/ dms/qhc-sum.html\#omega3. Acesso em: 15 abr. 2006.

FRANKEL, E.N. Lipid oxidation. 2.ed. Bridgwater: Oily Press, 2005. 7p. (Oily Press lipid library, v.18).

FRANKEL, .E.; SATUE-GRACIA, T.; MEYER, A.S.; GERMAN, J.B. Oxidative stability of fish and algae oils containing long-chain polyunsaturated fatty acids in bulk and in oil-in-water emulsions. Journal Agricultural and Food Chemistry, v.50, n.7, p.2094-2099, 2002.

FRENOUX, J.M.; PROST, E.D.; BELLEVILLE, J.L.; PROST, J.L. A polyunsaturated fatty acid diet lowers blood pressure and improves antioxidant status in spontaneously hypertensive rats. Journal of Nutrition, v.131, p.39-45, 2001.

FRIEDEWALD, W.T.; LEVY, R.I.; FREDRICKSON, D.S. Estimation of concentration of low-density lipoprotein cholesterol in plasma, without use of the preparative ultracentrifuge. Clinical Chemist, v.18, p.499-502, 1972.

GAÍVA, M.H.; COUTO, R.C.; OYAMA, L.M.; COUTO, G.E.C.; SILVEIRA, V.L.F.; RIBEIRO, E.B.; NASCIMENTO, C.M.O. Diets rich in polyunsaturated fatty acids: Effect on hepatic metabolism in rats. Nutrition, v.19, n.2, p.144-149, 2003. 
GARCIA, J.J.; MARTINEZ-BALLARÍN, E.; ROBINSON, M.; ALLUÉ, J.L.; REITER, R.J.; OSUNA, C.; ACUÑA-CASTROVIEJO, D. Protective effect of $\beta$-carbolines and other antioxidants on lipid peroxidation due to hydrogen peroxide in rat brain homogenates. Neuroscience Letters, v.294, p.1-4, 2000.

GARDĖS-ALBERT, M.; JORE, D.; FERRADINI, C. Membrane lipid peroxidation: pulse and g-radiolysis in oxyradical research. In: VIGO-PELFREY, C., ed. Membrane lipid oxidation. Boca Raton: CRC Press, 1991. p.2-30.

GIBBONS, G.F.; ISLAM, K.; PEASE, R.J. Mobilisation of triacylglycerol stores. Biochimica et Biophysica Acta, v.1483, n.1, p.37-57, 2000.

GIL, A. Polyunsaturated fatty acids and inflammatory disease. Biomedicine \& Pharmacotherapy, v.56, n.8, p.388-396, 2002.

GRIENDLING, K.K.; FITZGERALD, G.A. Oxidative stress and cardiovascular injury: Part II: animal and human studies. Circulation. v.108, n.17, p.2034-2040, 2003.

GHISELLI, A.; SERAFINI, M.; MAIANI, G.; AZZINI, E.; FERRO-LUZZI, A. A fluorecence method for measure total plasma antioxidant capability. Free Radicals in Biology and Medicine, 18, 29-36, 1995.

GHISELLI, A.; SERAFINI, M.; NATELLA, F.; SCACCINI, C. Total antioxidant capacity as a tool to assess redox status: critical view and experimental data. Free Radical Biology \& Medicine, v.29 n.11, p.1106-14, 2000.

HALLIWELL, B.; GUTTERIDGE, J.M.C. Oxygen toxicity, oxygen radicals, transitions metals and disease. Biochemical Journal, v.219, n.1, p.1-14, 1984.

HALLIWELL, B.; GUTTERIDGE, J.M.C. Free radicals in biology and medicine. 3.ed. New York: Clarendon Press; Oxford: Oxford University Press, 1999. p.285, 293, 625. (Oxford Science Publications).

HALSTED, C.H. Dietary supplements and functional foods: 2 sides of a coin? American Journal of Clinical Nutrition, v.77, n.4, p.1001S-1007S, 2003. 
HARRIS, W.S. Fish oil supplementation: evidence for health benefits. Cleveland Clinic Journal of Medicine, v.71, n.3, p.208-210, 212, 215-218, 2004.

HARRIS, W.S. n-3 fatty acids and lipoproteins: comparison of results from human and animal studies. Lipids. v.31, n.3, p.243-52, 1996.

HARRIS, W.S. n-3 fatty acids and serum lipoproteins: animal studies. American Journal of Clinical Nutrition, v.65, p.1611S-1616S, 1997.

HARRIS, W.S. n-3 fatty acids and serum lipoproteins: human studies. American Journal of Clinical Nutrition, v.65, p.1645S-1654S, 1997.

HARRIS, W.S. Omega-3 long-chain PUFA and triglyceride lowering: minimum effective intakes. European Heart Journal, v.3, p.D59-D61, 2001.

HARRIS, W.S.; SCHACKY, C. The Omega-3 index: a new risk factor for death from coronary heart disease? Preventive Medicine, v.39, p.212-220, 2004.

HARTMAN, L.; LAGO, R.C.A. Rapid preparation of fatty acid methyl esters from lipids. Laboratory Practice, v.22, p.475-477, 1973.

HAU, M.F.; SMELT, A.H.M.; BINDELS, A.J.G.H.; SIJBRANDS, E.J.G.; VAN DER LAARSE, A.; ONKENHOUT, W.; VAN DUYVENVOORDE, W.; PRINCEN, H.M.G. Effects of Fish Oil on Oxidation Resistance of VLDL in Hypertriglyceridemic Patients. Arteriosclerosis, Thrombosis, and Vascular Biology, v.16, n.9, p.1197-1202, 1996.

HERBERT, J.R.; EBBELING, C.B.; OCKENE, I.S.; MA, Y.; RIDER, L.; MERRIM, P.A.; OCKENE, J.K.; SAPERIA, G.M. A dietitian-delivered group nutrition program leads to reductions in dietary fat, serum cholesterol, and body weight: the worcester area trial for counseling in hyperlipidmia (WATCH). Journal of the American Dietetic Association, v.99, n.5, p.544-552, 1999.

HIGGINS, S.; CARROLL Y.L.; MCCARTHY S.N.; CORRIDAN, B.M.; ROCHE, H.M.; WALLACE, J.M.; O'BRIEN, N.M.; MORRISSEY, P.A. Susceptibility of LDL to oxidative modification in healthy volunteers supplemented with low doses of $n-3$ polyunsaturated fatty acids. British Journal of Nutrition, v.85, n.1, p.23-31, 2001. 
HIGDON, J.V.; DU, S.H.; LEE, Y.S.; WU, T.; WANDER, R.C. Supplementation of postmenopausal women with fish oil does not increase overall oxidation of LDL ex vivo compared to dietary oils rich in oleate and linoleate. Journal of Lipid Research, v.42, n.3, p.407-418, 2001.

HIGUCHI, M.L.; SANTOS, M.H.H.; PIERRI, H.; PALOMINO, S.; SAMBIASE, N.V.; RAMIRES, J.A.F.; WAJNGARTEN, M. Mycoplasma pneumoniae and Chlamydia pneumoniae in calcified nodules of aortic stenotic valves. Revista do Instituto de Medicina Tropical de São Paulo, v.44, n.4, p.209-212, 2002.

HINO, A.; ADACHI, H.; TOYOMASU, K.; YOSHIDA, N.; ENOMOTO, M.; HIRATSUKA, A.; HIRAI, Y.; SATOH, A.; IMAIZUMI, T. Very long chain n-3 fatty acids intake and carotid atherosclerosis: an epidemiological study evaluated by ultrasonography. Atherosclerosis, v.176, p.145-149, 2004.

HOLM, F. New functional food ingredients: cardiovascular health. Paris: FoodGroup Denmark, Institut National de la Recherche Agronomique, 2003. p.1920. (SMEs, n.5). Disponível em: http://www.nutrition.org.uk/upload/SME\%20functionalfood.pdf\#search=\%22HOLM $\% 20 \mathrm{New} \% 20$ functional\%20food\%20ingredients\%3A\%20cardiovascular\%20health \%22. Acesso em: 30 nov. 2005.

HOLUB, D.J.; HOLUB, B.J. Omega-3 fatty acids from fish oils and cardiovascular disease. Molecular and Cellular Biochemistry, v.263, p.217-225, 2004.

HSU, H.C.; LEE, Y.T.; CHEN, M.F. Effects of fish oil and vitamin E on the antioxidant defense system in diet-induced hypercholesterolemic rabbits. Prostaglandins \& Other Lipid Mediators, v.66, p.99-108, 2001.

HUANG, D.; OU, B.; PRIOR, R.L. The chemistry behind antioxidant capacity assays. Journal of Agricultural and Food Chemistry, v.53, n.6, p.1841-1856, 2005.

HUDERT, C.A.; WEYLANDT, K.H.; LU, Y.; WANG, J.; HONG. S.; DIGNASS, A.; SERHAN, N.; KANG, J.X. Transgenic mice rich in endogenous omega-3 fatty acids are protected from colitis. Proceedings of the National Academy of Sciences of the United States of America v.103, n30, p.11276-1181, 2006. 
IKEDA, I.; KUMAMARU, J.; NAKATANI, N.; SAKONO, M.; MUROTA, I.; IMAIZUMI, K. Reduced hepatic triglyceride secretion in rats fed docosahexaenoic acid-rich fish oil suppresses postprandial hypertriglyceridemia. Journal of Nutrition, v.131, n. 4, p.1159-1164, 2001.

INTERNATIONAL FOOD INFORMATION COUNCIL FOUNDATION. Background on functional foods, 2004 . Disponível em: http://ific.org/nutrition/functional/upload/FuncFdsBackgrounder.pdf. Acesso em: 30 mar. 2006.

IUPAC. INTERNATIONAL UNION OF PURE AND APPLIED CHEMISTRY. Standard Methods for the Analysis of Oils, Fats and Derivatives, 7ed. PAQUOT, C. and HAUTFENNE, A. Blackwell Science Publications, Oxford, 1987.

JACKSON, M.J. An overview of methods for assessment of free radical activity in biology. Proceedings of the Nutrition Society, n.58, n.4, p.1001-1006, 1999.

JANASZEWSKA, A.; BARTOSZ, G. Assay of total antioxidant capacity: comparison of four methods as applied to human blood plasma. Scandinavian Journal of Clinical and Laboratory Investigation, v.62, p.231-236, 2002.

JONES, P.J. Clinical nutrition. 7. Functional foods: more than just nutrition. Canadian Medical Association Journal, v.166, n.12, p.1555-1563, 2002.

JORDÃO Jr., A.A.; CHIARELLO, P.G.; BERNARDES, M.S.M.; VANNUCCHI, H. Peroxidação lipídica e etanol: papel da glutationa reduzida e da vitamina E. Medicina, v.31, p.434-449, 1998.

KACIMI, R.; KARLINER, J.S.; KOUDSSI, F.; LONG, C.S. Expression and regulation of adhesion molecules in cardiac cells by cytokines: response to acute hypoxia. Circulation Research, v.82, n.5, p.576-586, 1998.

KARTEN, B.; BEISIEGEL, U.; GERCKEN, G.; KONTUSH, A. Mechanisms of lipid peroxidation in human blood plasma: a kinetic approach. Chemistry and Physics of Lipids, v.88, n.2, p.83-96, 1997. 
KRIS-ETHERTON, P.M.; HARRIS, S.W.; APPEL, J.L. Fish consumption, fish oil, omega-3 fatty acids, and cardiovascular disease. Arteriosclerosis, Thrombosis, and Vascular Biology, v.23, p.20-30, 2003a.

KRIS-ETHERTON, P.M.; HARRIS, S.W.; APPEL, J.L. Omega-3 fatty acids and cardiovascular disease: new recommendations from the American Heart Association. Arteriosclerosis, Thrombosis, and Vascular Biology, v.23, p.151$152,2003 b$.

LAIDLAW, M.; HOLUB, B.J. Effects of supplementation with fish oil-derived n-3 fatty acids and gamma-linolenic acid on circulating plasma lipids and fatty acid profiles in women. American Journal of Clinical Nutrition, v.77, n.1, p.37-42, 2003.

LEE, J.; KOO, N.; MIN, D.B. Reactive oxygen species, aging, and antioxidative nutraceuticals. Comprehensive Reviews in Food Science and Food Safety, v.3, p.21-33, 2004.

LEE, K.W.; LIP, G.Y. The role of omega-3 fatty acids in the secondary prevention of cardiovascular disease. Quarterly Journal of Medicine, v.96, n.7, p.465-480, 2003.

LEHNINGER, A.L.; NELSON, D.L.; COX, M.M. Lehninger principles of biochemistry. 3.ed. New York: Savier, 2002. p.376.

LEIGH-FIRBANK, E.C.; MINIHANE, A.M.; LEAKE, D.S.; WRIGHT, J.W.; MURPHY, M.C.; GRIFFIN, B.A.; WILLIAMS, C.M. Eicosapentaenoic acid and docosahexaenoic acid from fish oils: differential associations with lipid responses. British Journal of Nutrition, v.87, p.435-445, 2002.

LOPEZ, A.D. Assessing the burden of mortality from cardiovascular diseases. World Health Statistics Quarterly, v.46, n.2, p.91-96, 1993.

LUOSTARINEN, R. L.; LAASONEN, K.; CALDER, P. C. $\alpha$-tocopherol concentrations, lipid peroxidation and superoxide dismutase and glutathione peroxidase activities in rat heart and liver after feeding stabilized and unstabilized fish oil. Nutrition Research, v.21, p.1529-1544, 2001. 
LOWRY, O.H.; ROSEBROUGH, N.J.; FARR, A.L.; RANDALL, R.J. Protein measurement with the Folin protein reagent. Journal of Biological Chemistry, v.193, p.265-275, 1951.

LUCESOLI, F.; FRAGA, C. Evaluación del estres oxidativo. Antioxid Calid Vida, v.1, n.4, p.8-13,1995.

MADANI, S.; PROST, J.; BELLEVILLE, J. Dietary protein level and origin (casein and highly purified soybean protein) affect hepatic storage, plasma lipid transport, and antioxidative defense status in the rat. Nutrition, v.16, n.5, p.368-375, 2000.

MCLAUGHLIN, J.; MIDDAUGH, J.; BOUDREAU, D.; MALCOM, G.; PARRY, S.; TRACY, R.; NEWMAN, W. Adipose tissue triglyceride fatty acids and atherosclerosis in Alaska Natives and non-Natives. Atherosclerosis, v.181, n.2, p.353-362, 2005.

MORENO, J.J.; MITJAVILA, M.T. The degree of unsaturation of dietary fatty acids and the development of atherosclerosis (Review). Journal of Nutritional Biochemistry, v.14, n.4, p.182-195, 2003.

MURALIDHAR, B.; CARPENTER, K.L.H.; MÜLLER, K.; SKEPPER, J.N.; ARENDS, M.J. Potency of arachidonic acid in polyunsaturated fatty acid-induced death of human monocyte-macrophages: implications for atherosclerosis. Prostaglandins, Leukotrienes and Essential Fatty Acids, v.71, p.251-262, 2004.

MURRAY, R.K.; GRANNER, D.K.; MAYES, P.A.; RODWELL, V.W. Harper's biochemistry. 25.ed. New York: McGraw-Hill, 2000. p.160-163. (A Lange medical book).

NAEEMI, E.D.; AHMD, N.; AL SHARRAH, T.K.; BEHBAHANI, M. Rapid and simple method for determination of cholesterol in processed food. Journal of AOAC International, v.78, p.1522-1525, 1995.

NAIDU, K,A. Vitamin $C$ in human health and disease is still a mystery? An overview. Nutrition Journal, v.21, n.2:7, 2003. 
NELSON, S.K.; BOSE, S.; RIZEQ, M.; MCCORD, J.M. Oxidative stress in organ preservation: a multifaceted approach to cardioplegia. Biomedicine \& Pharmacotherapy, v.59, p.149-157, 2005.

NESTEL, P.; SHIGE, H.; POMEROY, S.; CEHUM, M.; ABBEY, M.; RAEDERSTORFF, D. The n-3 fatty acids eicosapentaenoic acid and docosahexaenoic acid increase systemic arterial compliance in humans. American Journal of Clinical Nutrition, v.76, n.2, p.326-330, 2002.

NILAUSEN, K.; MEINERTZ, H. Lipoprotein(a) and dietary proteins: casein lowers lipoprotein(a) concentrations as compared with soy protein. American Journal of Clinical Nutrition, v.69, n.3, p.419-25, 1999.

NORBERG, J.; ARNÉR, E.S.J. Reactive oxygen species, antioxidants and the mammalian thioredoxin system. Free Radical Biology \& Medicine, v.31, n.11, p.1287-1312, 2001.

OLCHAWA, B.; KINGWELL, B.A.; HOANG, A.; SCHNEIDER, L.; MIYAZAKI, O.; NESTEL, P.; SVIRIDOV, D. Physical fitness and reverse cholesterol transport. Arteriosclerosis, Thrombosis, and Vascular Biology, v.24, n.6, p.10871091, 2004.

PALSDOTTIR, H.; HUNTE, C. Lipids in membrane protein structures. Biochimica et Biophysica Acta, v.1666, n.1/2, p.2-18, 2004.

PASTERnAK, T.; POTTERS, G.; CAUBERGS, R.; JANSEN, M. Complementary interactions between oxidative stress and auxins control plant growth responses at plant, organ, and cellular level. Journal of Experimental Botany, v.56, n.418, p.1991-2001, 2005.

PENNATHUR, S.; BERGT, C.; SHAO, B.; BYUN, J.; KASSIM, S.Y.; SINGH, P.; GREEN, P.S.; MCDONALD, T.O.; BRUNZELL, J.; CHAIT, A.; ORAM, J.F.; O'BRIEN, K.; GEARY, R.L.; HEINECKE, J.W. Human atherosclerotic intima and blood of patients with established coronary artery disease contain high density lipoprotein damaged by reactive nitrogen species. Journal of Biological Chemistry, v.279, n.41, p.42977-42983, 2004. 
POLIDORI, M.C.; STAHL, W.; EICHLER, O.; NIESTROJ, I.; SIES, H. Profiles of antioxidants in human plasma. Free Radical Biology \& Medicine, v.30, n.5, p.456-462, 2001.

PRESOTO, A.E.F.; RIOS, M.D.G.; ALMEIDA-MURADIAN, L.B. HPLC determination of alpha-tocopherol, beta-carotene and proximate analysis of Brazilian parsley leaves. Bolletino dei Chimici Igienisti, Milão, v.51, n.7, p.127$130,2000$.

PROSKY, L.; ASP, N.G.; FURDA, I.; DEVRIES, J.W.; SCHWEIZER, T.F.; HARLAND, B.F. Determination of total dietary fiber in foods and food products: collaborative study. Journal - Association of Official Analytical Chemists v.68, n.4, p.677-679, 1985.

PUIGGRÓS, C.; CHACÓN, P.; ARMADANS, L.I.; CLAPÉS, J.; PLANAS, M. Effects of oleic-rich and omega-3-rich diets on serum lipid pattern and lipid oxidation in mildly hypercholesterolemic patients. Clinical Nutrition, v.21, n.1, p.79-87, 2002.

QUINN, R. Comparing rat's to human's age: How old is my rat in people years? Nutrition, v.21, p.775-777, 2005.

REAVEN, P.D.; WITZTUM, J.L. Oxidation low density lipoproteins in atherogenesis: role of dietary modification. Annual Review of Nutrition, v.16, p.51-71, 1996.

REDDY, K.S. Cardiovascular diseases in the developing countries: dimensions, determinants, dynamics and directions for public health action. Public Health Nutrition, v.5, n.1A, p.231-237, 2002.

REDDY, K.S.; YUSUF, S. Emerging epidemic of cardiovascular diseases in developing countries. Circulation, v.97, p.596-601, 1998.

REEVES, P.G.; NIELSEN, F.H.; FAHEY Jr., G.C. AIN-93 purified diets for laboratory rodents: final report of the American Institute of Nutrition ad hoc writing committee on the reformulation of the AIN-76A rodent diet. Journal of Nutrition, v.123, n.11, p.1939-1951, 1993. 
ROCHE, H.M. Unsaturated fatty acids. Proceedings of the Nutrition Society, v.58, p.397-401, 1999.

ROSS, R. Atherosclerosis: an inflamatory disease. New England Journal of Medicine, v.340, n.2, p.115-126, 1999.

SALEM Jr., N. Introduction to polyunsaturated fatty acids. Backgrounder, v.3, n.1, p.1-8, 1999.

SALGADO FILHO, W.; MARTINEZ FILHO, E.E.; HORTA, P.; LEMOS, P.A.; MIGUELETTO B.C.; SERRANO Jr., C.V.; RAMIRES, J.A.F.; MARTINEZ, T.L.R. Marcadores inflamatórios intracoronarianos após intervenções coronarianas percutâneas. Arquivos Brasileiros de Cardiologia, v.85, n.3, p.180-185, 2005.

SANTOS, R.D.; GIANNINI, S.D.; FONSECA, F.A.H. III Diretrizes brasileiras sobre dislipidemias e diretriz de prevenção da aterosclerose do departamento de aterosclerose da sociedade brasileira de cardiologia. Arquivos Brasileiros de Cardiologia, v.77, n.3, p.1-48, 2001.

SARWAR, G.; RATNAYAKE, W.M.N. Effects of Amino Acid Supplementation of Dietary Proteins on Serum Cholesterol and Fatty Acids in Rats, Nutrition Research, v.20, n.5, p. 665-674, 2000.

SCHACKY, C.; HARRIS, W.S. Cardiovascular benefits of omega-3 fatty acids. Cardiovascular Research, v.73, p.310-315, 2007.

SCHMIDT, E.B.; ARNESEN, H.; CATERINA, R.; RASMUSSEN, L.H.; KRISTENSEN, S.D. Marine n-3 polyunsaturated fatty acids and coronary heart disease. Part I. Background, epidemiology, animal data, effects on risk factors and safety. Thrombosis Research, v.115, n.3, p.163-170, 2005.

SCIENTIFIC COMMITTEE FOR FOOD. Essential fatty acids: reports of the Scientific Committee for Food. Nutrient and Energy Intakes for the European Community, Luxembourg: Commission of the European Communities, v.31, p.5259, 1993. apud ROCHE, H.M. Unsaturated fatty acids. Proceedings of the Nutrition Society, v.58, p.397-401, 1999. 
SIES H. Oxidative stress: from basic research to clinical application. American Journal of Medicine, v.91, n.3C, p.31S-38S, 1991.

SIES, H.; STAHL, W.; SEVANIAN, A. Nutritional, dietary and postprandial oxidative stress. Journal of Nutrition, v.135, n.5, p.969-972, 2005.

SIMOPOULOS, A.P. Evolutionary aspects of diet, essential fatty acids and cardiovascular disease. European Heart Journal, v.3, suppl.D, p.D8-D21, 2001.

SIMOPOULOS, A.P. Omega-3 fatty acids in inflammation and autoimmune diseases. Journal of the American College Nutrition, v.6, p 495-505, 2002.

SIRTORI, C.R.; PAOLETTI, R.; MANCINI, M.; CREPALDI, G.; MANZATO, E.; RIVELLESE, A.; PAMPARANA, F.; STRAGLIOTTO, E. N-3 fatty acids do not lead to an increased diabetic risk in patients with hyperlipidemia and abnormal glucose tolerance. American Journal of Clinical Nutrition, v.65, n.6, p.1874-1881, 1997.

SKOUMAS, J.; PITSAVOS, C.; PANAGIOTAKOS, D.B.; CHRYSOHOOU, C.; ZEIMBEKIS, A.; PAPAIOANNOU, I.; TOUTOUZA, M.; TOUTOUZAS, P.; STEFANADIS, C. Physical activity, high density lipoprotein cholesterol and other lipids levels, in men and women from the ATTICA study. Lipids in Health and Disease, v.2, p.1-7, 2003.

SMITH, W.G.; WANG, J.; DANG, A.; REEVES, C.; BIBBS, D.; FAAS, F.H. Lipoprotein susceptibility to oxidation in the macromolecular fraction of plasma: relation to plasma lipids and oleate/linoleate ratio in comparison with whole plasma in hypertriglyceridemia. Clinica Chimica Acta, v.316, n.1/2, p.11-17, 2002.

SONG, J.H.; FUJIMOTO, K.; MIYAZAWA, T. Polyunsaturated (n-3) fatty acids susceptible to peroxidation are increased in plasma and tissue lipids of rats fed docosahexaenoic acid-containing oils. Journal of Nutrition, v.130, n.12, p.30283033, 2000.

SONG, J.H.; MIYAZAWA, T. Enhanced level of $n-3$ fatty acid in membrane phospholipids induces lipid peroxidation in rats fed dietary docosahexaenoic acid oil. Atherosclerosis, v.155, p.9-18, 2001. 
SPITELLER, G. The relation of lipid peroxidation processes with atherogenesis: a new theory on atherogenesis. Molecular Nutrition \& Food Research, v.49, p.999-1013, 2005.

STOCKS, J.; GUTTERIDGE, J. M. C.; SHARP, R. J.; DORMANDY, T. L. Assay using brain homogenate for measuring the antioxidant activity of biological fluids. Clinical Science and Molecular Medicine, v.47, p.215-222, 1974.

STREHLOW, K.; ROTTER, S.; WASSMANN, S.; ADAM, O.; GROHE, C.; LAUFS, K.; BOHM, M.; NICKENIG, G. Modulation of antioxidant enzyme expression and function by estrogen. Circulation Reseach. v.93, n.2, p.170-177, 2003.

TAPIERO, H.; BA, G.N.; COUVREUR, P.; TEW, K.D. Polyunsaturated fatty acids (PUFA) and eicosanoids in human health and pathologies. Biomedicine \& Pharmacotherapy, v.56, n.5, p.215-222, 2002.

TAYLOR, D.C.; KUNST, L.; MACKENZIE, S.L. Bioassembly of storage lipids in oilseed crops; Target: Trierucin. In: JANICK, J.; SIMON, J.E., eds. NEW CROPS: Exploration, research, and Commercialization New York, Chichester: Wiley, 1993. p.181-191. (Proceedings of the $2^{\text {nd }}$ National Symposium NEW CROPS: exploration, research, and commercialization, Indianapolis, 1991).

THOLSTRUP T, HELLGREN LI, PETERSEN M, BASU S, STRAARUP EM, SCHNOHR P, SANDSTROM B. A solid dietary fat containing fish oil redistributes lipoprotein subclasses without increasing oxidative stress in men. Journal of Nutrition, v.134, n.5, p.1051-1057, 2004.

THOMAS, J.A. Estresse oxidativo e defesa contra oxidantes. In: SHILS, M.E.; OLSON, J.A.; SHIKE, M.; ROOS, A.C. Tratado de nutrição moderna na saúde e na doença. 9.ed. São Paulo: Manole, 2003. cap.46, p.801-811.

THOMPSON, P.D.; BUCHNER, D.; PINA, I.L.; BALADY, G.J.; WILLIAMS, M.A.; MARCUS, B.H.; BERRA, K.; BLAIR, S.N.; COSTA, F.; FRANKLIN, B.; FLETCHER, G.; GORDON, N.F.; PATE, R.R.; RODRIGUEZ, B.L.; YANCEY, A.K.; WENGER, N.K. Exercise and physical activity in the prevention and treatment of atherosclerotic cardiovascular disease: a statement from the Council on Clinical Cardiology (Subcommittee on Exercise, Rehabilitation, and Prevention) and the 
Council on Nutrition, Physical Activity, and Metabolism (Subcommittee on Physical Activity). Circulation, v.107, n.24, p.3109-3116, 2003.

THORLAKSDOTTIR, A.Y.; SKULADOTTIR, G.V.; PETURSDOTTIR, A.L.; TRYGGVADOTTIR, L.; OGMUNDSDOTTIR, H.M.; EYFJORD, J.E.; JONSSON, J.J.; HARDARDOTTIR, I. Positive association between plasma antioxidant capacity and n-3 PUFA in red blood cells from women. Lipids, v.41, p.119-125, 2006.

TINKER, L.F.; PARKS, E.J.; BEHR, S.R.; SCHNEEMAN, B.O.; DAVIS, P.A. $(n-3)$ fatty acid supplementation in moderately hypertriglyceridemic adults changes postprandial lipid and apolipoprotein B responses to a standardized test meal. Journal of Nutrition, v.129, n.6, p.1126-1134, 1999.

USDA. National Nutrient Database for Standard Reference. Disponível em: http://www.nal.usda.gov/fnic/foodcomp. Acesso em: 20 jul. 2005.

VERGELY, C.; GOIRAND, F.; ECARNOT-LAUBRIET, A.; RENARD, C.; MOREAU, D.; GUILLAND, J.; DUMAS, M.; ROCHETTE, L. Vitamin C deficiency exerts paradoxical effects in osteogenic disorder shionogi (ODS) rats. Journal of Nutrition, 134, 729-735, 2004.

VIOLI, F.; MICHELETTA, F.; IULIANO, L. Antioxidants and atherosclerosis. European Heart Journal, v.4, suppl.B, p.B17-B21, 2002.

VOET, D.; VOET, J.G.; PRATT, C.W. Fundamentals of biochemistry. 2.ed. New York: Wiley, 2002. p.220-231.

WANG, C.; HARRIS, W.S.; CHUNG, M.; LICHTENSTEIN, A.H.; BALK, E.M.; KUPELNICK, B.; JORDAN, H.S.; LAU, J. n-3 Fatty acids from fish or fish-oil supplements, but not alpha-linolenic acid, benefit cardiovascular disease outcomes in primary- and secondary-prevention studies: a systematic review. American Journal of Clinical Nutrition, v.84, n.1, p.5-17, 2006.

WANG, L.H.; HUANG, S.H. Determination of vitamins A, D, E, and $\mathrm{K}$ in human and bovine serum, and $\beta$-carotene and vitamin $A$ palmitate in cosmetic and pharmaceutical products, by isocratic. Chromatographia, v.55, p.289-296, 2002. 
WILHELM, J.; VANKOVA, M.; MAXOVA, H.; SISKOVA, A. Hydrogen peroxide production by alveolar macrophages is increased and its concentration is elevated in the breath of rats exposed to hypoxia: relationship to lung lipid peroxidation. Physiological Research, v.52, n.3, p.327-332, 2003.

WINTERBOURN, C.C.; GUTTERIDGE, J.M.; HALLIWELL, B. Doxorubicindependent lipid peroxidation at low partial pressures of $\mathrm{O}_{2}$. Journal of Free Radicals in Biology \& Medicine, v.1, p.43-49, 1985.

WORLD HEALTH ORGANIZATION. WHO Sites. Media Centre. News. All News Reelases. 2004. 23 September 2004. WHO Publishes definitive atlas on global heart disease and stroke epidemic. Disponível em: http://www.who.int/mediacentre/news/releases/2004/pr68/en/index.html. Acesso em: 05 abr. 2006.

WORLD HEALTH ORGANIZATION/ FOOD AND AGRICULTURAL ORGANIZATION (WHO/FAO). WHO Sites. Global and regional food consumption patterns and trends, 2003. Disponível em: http://www.who.int/nutrition/topics/3_foodconsumption/en/print.html. Acesso em: 18 fev. 2007.

YOSHIDA, Y.; ITO, N.; SHIMAKAWA, S.; NIKI, E. Susceptibility of plasma lipids to peroxidation. Biochemical and Biophysical Research Communications, v.305, n.3, p.747-753, 2003.

YU, B.P. Cellular defenses against damage from reactive oxygen species. Physiological Reviews, v.74, n.1, p.139-162, 1994.

ZWART, L.L.; MEERMAN, J.H.; COMMANDEUR, J.N.; VERMEULEN, N.P. Biomarkers of free radical damage applications in experimental animals and in humans. Free Radical Biology \& Medicine, v.26, n.1-2, p.202-226, 1999. 


\section{ANEXOS}

Aprovação do Comitê de Ética 1 - Humanos (Anexo 1)

Questionário Clínico e dados pessoais (Anexo 2)

Inquérito Alimentar (Anexo 3)

Aprovação do Comitê de Ética 2 - Ratos (Anexo 4) 


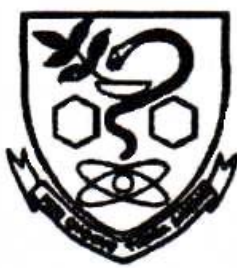

Oricio CEP n० 94
UNIVERSIDADE DE SĀO PAULO

Faculdads do Cisncias Farmaceluticas Comin do Élica en Pupqua - CEP

Săo Paulo, 30 de outubro de 2002.

Prezada Senhora

O Comitê de Ética em Pesquisa da FCF/USP, em reunião realizada em 28 do corrente, APROVOU o projeto intitulado "Efeito da suplementação dietética com ácidos graxos pollinsaturados ômega 3 e fibras solúveis no perfil lipidico sérico em humanos" e, ainda, resolveu solicitar de Vossa Senhoria o que segue:

a) Excluir, no Termo de Consentimento Livre e Esclarecido, o termo "remunerados", pois os individuos da pesquisa não deverão ser remunerados, mas sim "ressarcidos".

b) Esclarecer sobre o ressarcimento mencionado.

Lembramos que após a execução de $\mathbf{5 0 \%}$ do cronograma do projeto, deverá ser apresentado um relatório parcial, de acordo com o Artigo 18 - item C, da Portaria FCF-111/97.

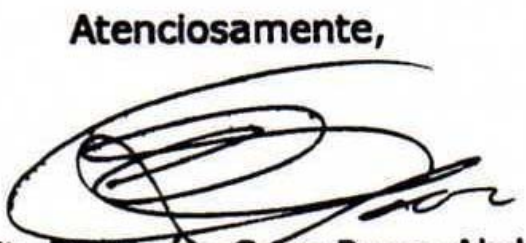

Prof. Tit. Duicinêa-Saes Parra Abdalla Coordenadora do Comitê de Ética em Pesquisa da FCF/USP

IIma. Sra.

Inar Alves de Castro

FBA 


\section{Questionário: Clínico e Dados Pessoais}

Nome:

Favor responder às seguintes questões

Idade:

\section{Sexo}
( ) Feminino
( ) Masculino

\section{Escolaridade}

( ) Até primeiro grau completo

( ) Até segundo grau completo

( ) Superior completo

( ) Pós-graduado

Peso: kg

Altura: m

\section{Fumante?}
( ) Não
( ) Sim
( ) Menos de $1 / 2$ maço de cigarro/dia
( ) De $1 / 2$ maço a 2 maços de cigarro/dia
( ) Mais de 2 maços de cigarro/dia

\section{Pratica exercícios físicos?}

( ) Não

( ) Sim ( ) Suave, de 1 a 2 vezes / semana

( ) Moderado, de 3 a 5 vezes / semana

( ) Intenso, acima de 5 vezes / semana

\section{Apresenta no momento, ou já sofreu algum desses problemas?}

( ) derrame ou isquemia cerebral

( ) infarto do miocárdio, cirurgia ou angioplastia

( ) doença da circulação periférica

( ) angina do peito

( ) insuficiência cardíaca

( ) Outro. Especifique:

( ) Nenhum
Algum familiar apresenta no momento ou já sofreu alguma doença cardiovascular descrita acima?

( ) Sim. Qual?

( ) Não.

\section{Ingere bebida alcoólica?}

( ) Nunca

( ) Sim ( ) Eventualmente

( ) Diariamente

Tem hipertensão arterial (acima de 140/90 mmHg)?

$\mathrm{Sim} \rightarrow($ ) e estou em tratamento

$\mathrm{Sim} \rightarrow(\quad)$ mas não estou em tratamento

Tem diabetes (glicemia em jejum acima de $126 \mathrm{mg} / \mathrm{dl}$ )?

( ) Sim

( ) Não

( ) Não sei

Questão só para as mulheres: Já alcançou a menopausa?

$\mathrm{Sim} \rightarrow($ ) e faço reposição hormonal

$\mathrm{Sim} \rightarrow($ ) e não faço reposição hormonal

Tem algum outro distúrbio de saúde?

( ) Sim. Qual?

( ) Não

Se preocupa com a sua dieta?

( ) Não

( ) Sim, procuro controlar o consumo de calorias

( ) Sim, procuro controlar o consumo de açúcares

( ) Sim, procuro controlar o consumo de gorduras e colesterol

( ) Sim, procuro controlar o consumo de sal

Muito obrigada pela atenção! 
Registro Alimentar de 24 horas

(três dias, 2 durante a semana e um no final de semana)

Data: 1

Dia da semana:

Nome:

\begin{tabular}{|c|c|c|c|}
\hline Refeição & Alimentos & Quantidade & Observações \\
\hline \multicolumn{4}{|c|}{ Café da manhã } \\
\hline \multicolumn{4}{|l|}{ Hora: } \\
\hline \multirow{2}{*}{\multicolumn{4}{|c|}{ Local: }} \\
\hline & & & \\
\hline & & & \\
\hline \multicolumn{4}{|l|}{ Lanche } \\
\hline \multicolumn{4}{|l|}{ Hora: } \\
\hline \multirow{2}{*}{\multicolumn{4}{|c|}{ Local: }} \\
\hline & & & \\
\hline \multicolumn{4}{|l|}{ Almoço } \\
\hline \multicolumn{4}{|l|}{ Hora: } \\
\hline \multicolumn{4}{|l|}{ Local: } \\
\hline & & & \\
\hline & & & \\
\hline & & & \\
\hline & & & \\
\hline & & & \\
\hline \multicolumn{4}{|l|}{ Lanhe } \\
\hline \multicolumn{4}{|l|}{ Hora: } \\
\hline \multirow{2}{*}{\multicolumn{4}{|c|}{ Local: }} \\
\hline & & & \\
\hline \multicolumn{4}{|l|}{ Jantar } \\
\hline \multicolumn{4}{|l|}{ Hora: } \\
\hline \multicolumn{4}{|l|}{ Local: } \\
\hline & & & \\
\hline & & & \\
\hline \multicolumn{4}{|l|}{ Ceia } \\
\hline \multicolumn{4}{|l|}{ Hora: } \\
\hline Local: & & & \\
\hline & & & \\
\hline
\end{tabular}




\section{UNIVERSIDADE DE SÃO PAULO \\ Feculdado do Cinncias Farmaceluticas \\ Comiselo do Elice em Expinenteclo Animal}

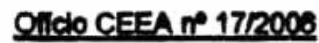

Såo Paulo, 16 de março de 2006.

IImo(a). Sr(a).

Vania Claudia Barros Montelro

Orlentador: Profa. Inar Alvee do Castro

FBA

Prezado(a) Senhor(a),

Informamos que o projeto "Avaliaģa do estresse axidativo em humanos e em animais suplementados com ácidos graxos poliinsaturados ómega-3" (Protocolo CEEA no 100), foi APROVADO "ad referendum" de Comissăo de Ética om Experimentaçăo Animal da FCF/USP.

Sendo o que nos cumpre, reiteramos protestos de estima e consideraçăo.

Atenciosamente,

Profa. Dra. Lidja Ferreira Gomes

Presidente da Comissắo de Ética em Experimentaçăo Animal 